NBSIR 86-3353 (NASA)

\title{
A Comparative Study of the Structure and Mechanical Properties of Polyethylene Films Used in Heavy Lift Balloons
}

\section{F. Khoury}

J.M. Crissman

J.D. Bárnes

B.M. Fanconi

H.L. Wagner

C.M. Guttman

J.R. Maurey

C.A. Harding

L.H. Boiz

Report for the Poriod

November 1984 - July 1985

NASA Crder 8216070

July 1986

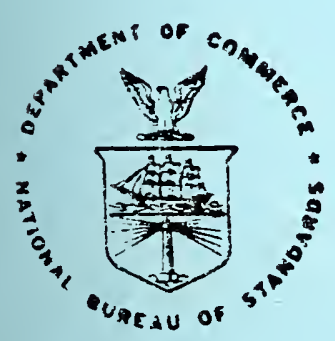

U.S. DEPARTMENT OF COMMERCE NATICNAL QUREAU OF STANDARDS
FILE COPY

DO NOT REMOUE 

NBSIR 86-3353 (NASA)

A COMPARATIVE STUDY OF THE STRUCTURE AND MECHANICAL PROPERTIES OF POLYETHYLENE FILMS USED IN HEAVY LIFT BALLOONS

\author{
F. Khoury \\ J.M. Crissman \\ J.D. Barnes \\ B.M. Fanconi \\ H.L. Wagner \\ C.M. Guttman \\ J.R. Maurey \\ C.A. Harding \\ L.H. Bolz
}

Report for the Period

November 1984 - July 1985

NASA Order 8216070

July 1986

U.S. DEPARTMENT OF COMMERCE, Maicolm Baldrige, Secretary NATIONAL BUREAU OF STANDARDS, Ernest Ambler, Director 



\section{Abstract}

Aspects of the mechanical properties and structure of three types of polyethylene film (I, III and BI) useci by NASA in helium filled heavy lift balloons have been investigated and compared. An additional film (FI) which has as yet not been used in heavy lift balloons was also studied. The following are among the features which have been investigated:- Biaxial deformation behavior under inflation at $23^{\circ} \mathrm{C}$ and $-73^{\circ} \mathrm{C}$, biaxial creep under inflation at $23^{\circ} \mathrm{C}$ and $-73^{\circ} \mathrm{C}$, tensile properties at $23^{\circ} \mathrm{C}$ of unoriented specimens prepared by compression molding multilayers of the films, film shrinkage upon melting. The preferred orientation characteristics of the crystalline regions in the films were determined from pole figures coupled with small angle $x$-ray diffraction data. The possible morphological origins of the various orientation characteristics exhibited by the films are discussed with reference to three 'model' orientations and combinations thereof. Numerical simulations of the experimental pole figures were attempted in an effort to compare differences in orientation among the films quantitatively. Finally, the following features which had been determined for films I, III and $B I$ in a previous study have been determined for the 'newer' film Fl: Chain branching, molecular weight and molecular weight distribution, intrinsic viscosity, melting/crystallization, density/crystallinity, birefringence, and tersile properties at $23^{\circ} \mathrm{C}$ (uniaxial extension in the machine and transverse directions). 


\section{Table of Contents}

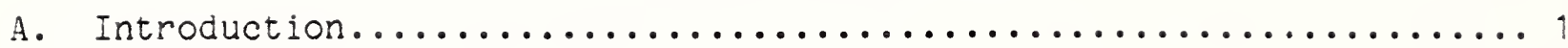

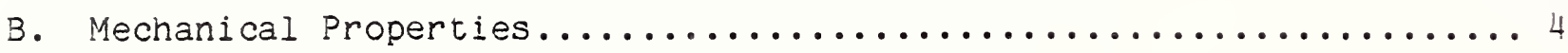

(1) Biaxial Deformation Under Inflation at $23^{\circ} \mathrm{C}$ and $-73^{\circ} \mathrm{C}$ : Deformation to Near Failure.

(2) Biaxial Creep Under Inflation at $23^{\circ} \mathrm{C}$

(3) Biaxial Creep Under Inflation at $-73^{\circ} \mathrm{C}$

(4) Tensile Properties at $23^{\circ} \mathrm{C}$ of Unoriented Specimens Prepared by the Compression Molding of Multilayers of Films

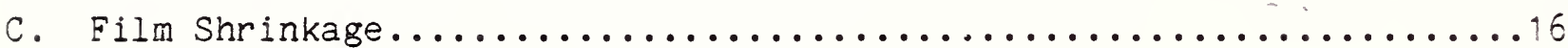

D. Orientation Characteristics in Films I, III, $B I$ and FI..........18

(i) Experimental Details and Descriptions of Pole Figure Projections

(ii) Results and Discussion

(iii) Numerical Simulation of Pole Figures

E. Summary/Discussion/Conclusions............................ 37

Appendix A: Morphological Background and Models of Preferred Orientations.......................... 45

Appendix B: Film Fl, Branching, Molecular Weight Distribution, Intrinsic Viscosity, Melting/Crystallization, Density/Crystallinity, Birefringence, Tensile Properties at $23^{\circ} \mathrm{C}$ (Uniaxial extension in the $M$ and $T$ Directions.....50

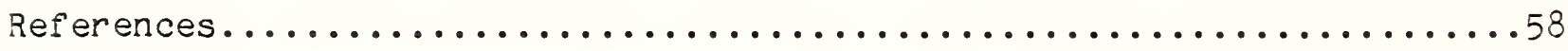
Tables $1-15$

Figures $1-39$ 
A. Introduction

The work described in this report is a continuation of an earlier exploratory study [1] sponsored by the National Aeronautics and Space Agency (NASA). It is part of an ongoing investigation undertaken by NASA to determine the causes of the catastrophic failure of helium filled 'heavy-lift' balloons in which the helium is contained by low density polyethylene film. The thickness of the polyethylene film is usually in the range $13 \mu \mathrm{m}-25 \mu \mathrm{m}$. The balioons are used to raise instrument payloads of up to about $2500 \mathrm{Kg}$ to elevations of over $35 \mathrm{~km}$ for various research projects. The capacity of the balloons at float attitude can be as large as $1.16 \times 10^{6}$ cu. meters.

Since 1980 there has been an increased incidence of catastrophic balloon failures during ascent at elevations between $12 \mathrm{Km}$ and $18 \mathrm{Km}$ where the ambient temperature is about $-70^{\circ} \mathrm{C}$. The causes of the increased failures of this type from 1980 to the present as compared to the performance of balloons prior to 1980 have been elusive. Limitations inherent in the design characteristics of the balloon coupled with trends to higher payloads, inadvertent flaws which may occur in the process of balioon assembly (construction), and changes in the raw polymer and/or the processing conditions used in the production of the polyethylene films prior to and since 1980 are among the possible causes investigated by NASA.

The overall purpose of our earlier study [1] and the present investigation was to examine and compare various aspects of the structure and mechanical properties of proprietary films representative of those used in heavy lift balloons prior to and since 1980. The goal was to determine whether there are significant differences among the films which are not covered by present acceptance criteria and which might have a bearing on film 
performance in balloons. Eive films (denoted I, II, III, V and $3 I$ ) were investigated in our earlier study [1]. Film III was the only one representative of films used prior to 1980. Similarities as well as differences between various features of the films were identified.

Among the close similarities between the films were the following: methyl group content $\left(2 \mathrm{CH}_{3} / 100\right.$ carbon atcms, crystallinity $(46.2 \%-48.2 \%)$, and peak melting temperature $\left(105.5^{\circ} \mathrm{C}-107.1^{\circ} \mathrm{C}\right)$. All the films were negatively birefringent, i.e., $n_{M}-n_{T}<0$ where $n_{M}$ and $n_{T}$ are the refractive indices parallel to the machine $(M)$ and transverse ( $T$ ) directions respectively. The birefringence was low in all the films and $\vec{i}$ ell in the range -0.0009 to -0.0019. Wide angle $x$-ray diffraction patterns obtained with the $x$-ray beam parallel to $M, T$ and $N$ (normal to the film) respectively indicated that there were qualitative similarities between the preferred orientations of the microcrystalline regions in the various films. The indications were (I) that the a-axis tended to be oriented preferentially parallel to the MT plane and preferentially parallel to $M$ in that plane, and (2) that the b-axis tended to be preferentially oriented parallel to the NT plane and preferentialiy paraliel to $\mathrm{N}$ in that plane. A possible working model consistent with these features was suggested.

Differences among the films were revealed in two main features, namely in the molecular weights of the polymer, and in the balance of the strain to break behavior in the machine direction relative to that in the transverse direction. Thus, films II and III (the latter being the only one representative of films used prior to 1980) had relatively higher molecular weights than the other films, whereas Bl film had the lowest. Concerning mechanical properties, films II, III and IV exhibited in uniaxial deformation experiments higher average extensions to break parallel to I than 
to $M$ at both $23^{\circ} \mathrm{C}$ and $-70^{\circ} \mathrm{C}$. In contrast, the average strains to break in both directions for film I were essentially the same at $23^{\circ} \mathrm{C}$, furthermore at $-70^{\circ} \mathrm{C}$ the extension to break was higher in the M direction. The extension to break behavior of the $B I \mathrm{film}$ in the M relative to the $\mathrm{I}$ direction was similar to that of the film I at $23^{\circ} \mathrm{C}$ and to that of films II, III and IV at $-70^{\circ} \mathrm{C}$. In addition, although the average strain to break in the $M$ and $T$ directions in each of the five films met the NSBE specification that the strain should not be less than $250 \%$ in both the $M$ and $T$ directions at $-70^{\circ} \mathrm{C}$, film III was the only one for which none of the measurements fell below $250 \%$.

The present study has been limited to three of the films investigated previously, namely films I, III, and BI, to which an additional film (denoted Fl) of interest to NASA has been added. Films I and BI are currently used in heavy lift balloons. Film III is, as pointed out earlier, representative of films used prior to 1980. Film $F 1$ has not been used by NASA in heavy lift balloons. Various characteristics which had been previously [1] determined for films $I$, III and $B I$ were also determined for the FI film during the period covered by the present report. The results which include measurements of molecular weight distribution, intrinsic viscosity, density (crystallinity), peak melting temperature, birefringence, and uniaxial (tensile) deformation behavior at $23^{\circ} \mathrm{C}$ are presented collectively in Appendix 3. The main part of the report is concerned with a description and discussion of the results of a study of the following aspects of the films:-

- Deformation behavior of the four films under inflation (bubble geometry) at $23^{\circ} \mathrm{C}$ and $-73^{\circ} \mathrm{C}$.

- Uniaxial deformation behavior at $23^{\circ} \mathrm{C}$ of unoriented specimens made by melting and remolding films I, III and 31 .

- Shrinkage upon melting. 
- A more detailed study and comparison of the preferred orientation characteristics of films I, III and BI. Our earlier probings [1] have been supplemented with the determination of $(200),(020)$ and \{110\} pole figures. In addition, small angle xaray diffraction (SAXD) patterns have been obtained with the $x$-ray beam parallel to the $N, M$ and $T$ directions respectively. Similar pole figure and SAXD data were obtained for the additional Fl film.

The results (covered in the present and in our earlier investigation [1]) on films I, III, BI and EI are examined collectively at the end of this report.

\section{B. Mechanical Properties}

(1) Biaxial Deformation Behavior Under Inflation at $23^{\circ} \mathrm{C}$ and $-73^{\circ} \mathrm{C}$ : Deformation to Near Failure (Films I, III, BI and FI)

The first experiments described below are the inflation behavior of the four films at room temperature $\left(23^{\circ} \mathrm{C}\right)$. It is instructive however before describing the results to dwell in more detail on some of the characteristics of the inflation experiment which we mentioned in our previous report [I]. For this purpose we have chosen as an example the inflation of a thin sheet of dentaldam rubber which remains stable (under inflation) up to quite large deformations. Prior to inflation, two sets of twelve ink marks, six on either side of the pole spaced $0.50 \mathrm{~cm}$ apart, were placed at $90^{\circ}$ to one another on the flat sheet. The sheet was then inflated until its shape was approximately that of a hemisphere. While the sheet was held at constant internal pressure, the strain was determined between each set of adjacent marks. The results are presented in Fig. I where the numbers shown represent the percent strain between each set of marks. Over that portion of the sheet where marks were placed the strain, in a radial direction, varies by a factor of about two. Close to the pole the deformation is equalbiaxial, whereas it 
approaches pure shear near the clamping ring. The average strain over the portion of the surface examined was 67 percent. In anticipation of procedures to be described below in section $B 2$ it should be noted that the deformation is fairly uniform over the central region out to about the third mark away from the pole (radius of $1.5 \mathrm{~cm}$ ).

Eollowing the same procedures used for the rubber, a series of experiments was carried out at $23^{\circ} \mathrm{C}$ on samples from each of the four films under investigation. In each case the film was inflated slowly to a condition just short of failure, at which point the pressure was reduced slightly to prevent rupture. The strain was then determined between each adjacent set of marks. The results are summarized in Figs. 2-5. For film I (Fig. 2) one can see that in the region between the first set of marks on either side of the pole, where the deformation is greatest, both the machine and transverse directions have deformed an equal amount (145\%). A similar result was observed for film BI shown in Fig. 3 where in the region nearest the pole it can be seen that this film has also deformed almost an equal amount in both the machine (170\%) and transverse (180\%) directions. No evidence of necking was observed in either of these two films. Based upon the inflation experiments both films $I$ and $B I$ appear to be rather well balanced.

In comparison, film III showed a different behavior, as can be seen in Fig. 4. As the inflation progressed a necked region appeared (Eig. 4a), which upon further inflation widened in the transverse direction and eventualiy several other necks appeared in the region of the pole. Upon reaching the condition shown in Fig. $4 \mathrm{~b}$ just prior to rupture, it can be seen that in the region of the pole the film has elongated significantly more in 
the transverse direction (200\%) than in the machine direction ( $135 \%$ ). Eilm Fl also exhibited necking as can be seen in Fig. 5a. In this case however, the neck formed well away from the pole between the second and third marks. The necked region lies along the same direction as that found for film III. Upon further inflation the condition shown in Fig. 5b was reached. For this film it was observed that once the neck developed almost all of the subsequent deformation occurred within the small region between the first and second marks on the right hand branch.

A comparison of the results obtained from the bubble inflation experiment with those obtained from the elongation at break measurements in uniaxial extension (Table 10, reference [1], and Appendix B in this report for film FI) is presented in Table 1. The values shown represent the ratio of the deformation in the transverse direction to that in the machine direction. For films I, III, and BI the values shown from the inflation experiment represent the average value of the strain between the first set of marks on either side of the pole at a condition just prior to rupture. In the case of the film Fl the neck did not occur in the region nearest the pole. Therefore the value shown was obtained by taking the average deformation over all twelve marks in both the machine and transverse directions. For the most part there is a rather good correlation between the two sets of results which indicate that films I and $B I$ are well balanced with regard to deformation in the machine relative to the transverse directions, whereas films III and FI are unbalanced.

Inflation experiments were also done at $-73^{\circ} \mathrm{C}$ using a low temperature chamber which will be described in Section $B(3)$. In this case no determination of the strain was made over localized areas of the film since such measurements were found difficult to perform inasmuch as opening the 
chamber even for a short period of time resulted in rapid heating and failure of the film specimen. Films from each category were visually monitored as the pressure was gradually increased up to the point of failure. As was the case at room temperature, films I and BI deformed uniformly and did not exnibit necking, whereas multiple necks appeared in film III, and a single neck occurred in film Fl. The occurrence, both at $23^{\circ} \mathrm{C}$ and $-73^{\circ} \mathrm{C}$, of multiple necks in film III and of a single neck in the film Fl would appear to be a characteristic feature which distinguishes these two films from one another.

(2) Biaxial Creep Under Inflation at $23^{\circ} \mathrm{C}$ (Films I, III, BI)

The creep behavior under inflation of films I, BI, and III was examined at $23^{\circ} \mathrm{C}$. In the previous subsection it was observed that in the case of the dentaldam rubber under inflation the deformation was fairly uniform in the region near the pole out to about the third mark away from the pole. This condition was also true for the polyethylene films provided necking did not occur and the strain did not exceed about 20 percent. In the present set of experiments ink marks were placed $1.5 \mathrm{~cm}$ on either side of the pole, one set parallel to the machine direction, and one set parallel to the transverse direction. The measured strain, then, represents an average strain over the $3.0 \mathrm{~cm}$ diameter portion of the bubble surrounding the pole. Three sets of experiments were done in which the applied pressure was set at one of three values $(5000,7000$, and $9000 \mathrm{~Pa})$. The thickness of each specimen was determined from the thickness profile data provided by NASA. Since the film thickness varied from $.0017 \mathrm{~cm}$ to $.0021 \mathrm{~cm}$ the pressure was adjusted in such a manner than each film specimen was normalized to a thickness of .0018 $\mathrm{cm}(0.7 \mathrm{mil})$. [i.e., the pressure was adjusted such that $P(\mathrm{~h} / .0018)$ was set equal to one of the three values noted above, $h$ being the actual profile thickness.] The results are shown in Fig. 6. It can be seen that, with one 
exception, the behavior of all three films at each level of applied pressure is nearly indistinguishable. The one specimen of the BI film tested at 9000 $\mathrm{Pa}$ extended to a strain of nearly 0.70 before failure. No great significance should be assigned to the relatively higher deformation exhibited by this specimen. Its different behavior may be associated with the large variations in thickness in the specimen. At pressures higher than $9000 \mathrm{~Pa}$ all of the films, immediately upon application of the pressure, extended to a strain of more than 0.25 and the bubble quickly became unstable losing its spherical symmetry. In these instances, the films either ruptured or took the shape of a tube at which point the experiment was stopped.

In Table 2 are shown values of the true stress (in the region of the pole) as determined using the following equation:

$$
\sigma_{T}=\frac{P}{2} \frac{r}{h} \lambda^{2}
$$

where $P$ is the inrlation pressure, $r$ is the radius of curvature, $h$ is the initial film thickness, and $\lambda$ is the stretch ratio given by $\lambda=1+\varepsilon$, $\varepsilon$ being the strain. Equation (I) is applicable only in the region near the pole, and when the material remains stable and the strain does not exceed $0.40-0.50$. The left hand numbers in the columns in Table 2 represent the minimum value and the right hand number the maximum value of stress measured during each creep experiment. It can be seen that at the lower levels of pressure the experiment is one in which the true stress remains essentially constant, a consequence of the fact that very little creep is occurring with time. At a given pressure there is very little difference in the values of true stress from film to film. From these measurements it would appear that all of the films remain stable under inflation at $23^{\circ} \mathrm{C}$ for values of true stress up to about $16 \mathrm{MPa}$. 
(3) Biaxial Creep Under Inflation at $-73^{\circ} \mathrm{C}$ (Films I, III, B1)

A low temperature chamber was assembled to examine the low temperature creep behavior of the films using the same bubble gecmetry described in the previous two sections. The low temperature chamber was equipped with a window to allow visual access to the film with a cathetometer. The window was constructed from two sheets of PMMA separated by a narrow air gap. In order to prevent frosting of the window, a steady flow of dry air was maintained across the outer surface of the window. The chamber was cooled by maintaining a pool of liquid $\mathrm{N}_{2}$ in a foil pan covering the bottom of the chamber. A proportional controller and heating element was used to supply sufficient heat to hold the temperature constant at the desired temperature in the vicinity of the film. The air inside the chamber was circulated by means of a blower which had a capacity of 1.53 cubic meters per minute ( 54 cubic feet per minute). As a matter of convenience, all the low temperature measurements were carried out at $-73^{\circ} \mathrm{C}$. At $-73^{\circ} \mathrm{C}$, it was found that in the vicinity of the inflation apparatus the temperature could be held constant to within $\pm 1{ }^{\circ} \mathrm{C}$ over a period of from one to two hours.

Since no suitable extensometer was available and the chamber could not be opened at low temperature once the experiment was started, the strain had to be estimated by indirect means. This was accomplished by first carrying out a set of experiments at $23^{\circ} \mathrm{C}$ in which both the radius of curvature of the bubble and the strain were determined directly. The radius of curvature was determined by measuring the height of the bubble with a cathetometer. The strain was monitored by placing two sets of marks on the film, one set along the machine direction and one along the transverse direction. Each set of marks was separated by $3 \mathrm{~cm}(1.5 \mathrm{~cm}$ on either side of the pole). The film was then inflated by increasing the pressure in small 
steps. Between each step increase in pressure the radius of curvature and the strain in both directions were measured. The two measures of strain were then averaged and the resulting strain was plotted versus the radius of curvature. Such a plot is shown in Fig. 7 where the filled circles correspond to the experimentally determined values. The crosses shown in Fig. 7 are the values of the strain which would be predicted using the known values of the radius of curvature and by assuming that the deformation is uniform over the surface of the bubble. It can be seen that, for this special case where the marks have been placed approximately 40 percent of the distance from the pole to the clamping ring, the predicted values of strain determined using only the radius of curvature agree rather well with the actual data determined using the marks.

A set of creep experiments was then carried out at $-73^{\circ} \mathrm{C}$ in which the strain was determined from the radius of curvature measurement. An additional assumption being made is that the inflation characteristics of the bubble at $-73^{\circ} \mathrm{C}$ do not differ significantly from those at $23^{\circ} \mathrm{C}$. The results for films I, III, and BI are presented in Fig. 8. It can be seen that all three films show a quite similar behavior. At a pressure of $34 \mathrm{kPa}$ all three films failed in three minutes or less. On the other hand, at $33 \mathrm{kPa}$ none of the films failed after one hour. Table 3 indicates the range of values of the true stress at each level of applied pressure at $-73^{\circ} \mathrm{C}$. These data indicate that all three films remain stable over a period of time of one hour or more for values of true stress at least as high as $50 \mathrm{MPa}$.

We have also examined the situation in which the film is subjected to a deformation history under inflation at $23^{\circ} \mathrm{C}$ and then is cooled slowly to $-73^{\circ} \mathrm{C}$ at constant pressure. One piece of film from each of the three film categories was inflated gradually at $23^{\circ} \mathrm{C}$ until it reached an average strain 
of $20 \%$. While holding the pressure constant the bubble was then cooled slowly to $-73^{\circ} \mathrm{C}$ and the radius of curvature, $r$, monitored as a function of decreasing temperature. For all three film categories it was found that the radius of curvature did not change appreciably during cooling, and, within experimental error, remained constant throughout the experiment. Upon reaching $-73^{\circ} \mathrm{C}$ the internal pressure was quickiy doubled and, again, no change was observed in $r$ for any of the three films. The maximum value of the true stress observed in all three experiments was about $49 \mathrm{MPa}$, which from Table 3 can be seen to be still below the levels required for failure to occur after one hour.

(4) Tensile Properties at $23^{\circ} \mathrm{C}$ of Unoriented Specimens Prepared by the Compression Molding of Multi-Layers of Films I, III and $B I$

In work summarized in reference [1], it was shown that clear differences exist between the various films in their molecular weight and molecular weight distribution. Comparison of the normalized chromatograms revealed that film III contained a larger proportion of high molecular weight species than did the other films and, on a relative basis, had the highest $M_{W}$, followed in decreasing order of molecular weight by film I and film 31 . The question remains open as to whether specific information can be derived concerning the contribution of differences in molecular weight and molecular weight distribution between the films to differences in their mechanical performance. The influence which differences in molecular weight can have on the tensile creep behavior of initially unoriented high density linear poiyethylenes was illustrated in our earlier report [1]. Ideally, determination of the effect of molecular weight differences per se on the mechanical properties of the oriented films would require the availability of films made from resins of different molecular weights but processed under 
identical conditions (i.e., same blow ratio, draw ratio, cooling history, etc.). In the absence of such films, we have, as background information, examined the possible effect of differences in the molecular weight of the polymer in films I, III, and $B I$ by studying the mechanical properties of specimens of the unoriented material. The specimens were prepared by remolding material taken from each of the three categories of film.

Specimens of the unoriented polymer were prepared as follows: sheets of film were folded repeatedly into stacks approximately four centimeters on a side, each containing 128 layers of film. The stacks were then placed in a press and subjected to a pressure of $100 \mathrm{MPa}$ (14500 psi) in order to remove as much air as possible and to fuse the layers together. The stacks were next placed in a mold which consisted of an aluminum frame and two one centimeter thick aluminum plates coated with teflon*. The frame had an opening $15 \mathrm{~cm}$ long and $5 \mathrm{~cm}$ wide. The press was preheated to $130^{\circ} \mathrm{C}$ and the mold placed in the press under light contact pressure for a period of ten minutes. The pressure was then increased to $15 \mathrm{MPa}$ ( $\equiv 2200 \mathrm{psi}$ ) and the heat turned off. The mold was cooled in the press at a rate of about $1^{\circ} \mathrm{C}$ per minute to a temperature below $75^{\circ} \mathrm{C}$ before removal from the press. Sheets prepared in this manner were nominally about one milimeter thick. Specimens were cul from each sheet using one of two different dies depending upon the experiment to be done.

In the first set of experiments the tensile behavior was investigated under conditions of constant rate of clamp separation at $23^{\circ} \mathrm{C}$. For this purpose, the same specimen geometry chosen earlier to study the film

\footnotetext{
${ }^{*}$ Certain commercial materials and equipment are identified in this paper in order to specify adequately the experimental procedure or materials. In no case does such identification imply recommendation or endorsement by the National Bureau of Standards, nor does it imply necessarily the best available for the purpose.
} 
specimens was used [1]. As before, the gage length was set at $0.60 \mathrm{~cm}$. The specimen width was $0.30 \mathrm{~cm}$. One of two different test machines was used depending upon the properties to be measured. Determination of the yield stress and strain at yield were accomplished using the same servo controlled hydraulic test equipment described in our previous report [1]. However since this machine has only $15 \mathrm{~cm}$ of actuator travel, it was found necessary to determine the strain at break and tensile strength using a screw driven machine having a much greater crosshead travel. In all cases the rate of clamp separation was the same as that used in our previous study of the film specimens ( $991 \%$ per minute).

Table 4 presents the test results for 23 specimens taken from the three categories of film. A minimum of three specimens was used to determine each property. Table 5 summarizes the average values for each property. It.is apparent from Table 5 that, on average, there is no great difference in properties from film to films. Film III does exhibit the greatest average value for tensile strength while the film 31 exhibits the smallest value, although the observed differences cannot be considered large. The vaiues for the elongation at break require special attention. The values quoted represent the elongation at break as determined from the clamp separation, and do not represent the actual elongation within the original gage section, as is discussed in the following paragraph.

For two specimens, marks were placed $0.5 \mathrm{~cm}$ apart on the initial exposed portion of the specimen. During the course of the experiment the stretching process was interrupted periodically long enough to measure both the clamp separation and the distance between marks. This process was continued until fracture occurred. Fig. 9 shows a plot of the strain, as determined from the clamp separation, versus the strain, as determined using the marks. It can 
be seen that at strains up to $\varepsilon=4 \quad(\lambda=5)$ essentially all of the deformation occurs within the gage section. However, at yet greater eiongations, a significant amount of material is being drawn out from inside the clamps. By the time the clamp separation has reached a stretch ratio, $\lambda$, of 15 it is estimated that up to $60 \%$ of the total amount of material exposed has been drawn out of the clamps. Therefore the values shown should be scaled down by a factor of two, or more. In spite of the fact that a considerable amount of material is drawn out of the clamps during this type of experiment, it appears that, on average, all three categories of film behave in a very similar manner. The stress-strain curves for all three categories of film were identical in character and it is unlikely that, among them, any significant differences in behavior occurred in the original gage section alone.

Comparison of the results for the remolded material (Tables 4 and 5) with similar tests done on specimens of the balloon films at $23^{\circ} \mathrm{C}$ ( Tables $10 \mathrm{a}$ and 12 in reference [1]) shows the following similarities and differences. The yield stress is slightly higher for the initially unoriented remolded materials than for the films. On the other hand, the tensile strength for the three categories of balloon film is about $65 \%$ higher than for the corresponding unoriented sampies.

In addition to the experiments described above the creep behavior of the remolded material at $23^{\circ} \mathrm{C}$ was examined. Of particular interest in this regard is the region of deformation beyond the yield point where cold drawing and ultimate fracture occur. Under these conditions, any contributions to the cold-drawing and failure behavior due to differences in molecular weight may become more apparent than in tests carried out a constant rate of clamp separation. For this phase of the work a different specimen geometry was 
used from that used for the constant rate of clamp separation experiments. In the present case dumbbell shaped specimens having a straight section 3.0 $\mathrm{cm}$ long and a width of approximately $0.30 \mathrm{~cm}$ were cut with a die from the compression molded sheets. Marks were placed on the specimen approximately $2.5 \mathrm{~cm}$ apart, and during the creep experiment the length wi thin the gage section was monitored with a cathetometer. For each type of film creep experiments were done at each of three levels of applied stress, 10, 12.5, and $15 \mathrm{MPa}$.

The results are presented in Eig. 10. All three specimens tested at 10 MPa did not fail after $10^{4}$ minutes at which point the experiment was stopped. For the other six specimens the times to failure are given in Table 6 . At the higher levels of applied stress ( 12.5 and $15.0 \mathrm{MPa}$ ) it was found necessary to apply the load rather slowly initially in order to prevent rapid heating of the specimen and premature failure. It can be seen fron Fig. 10 that all six specimens tested at these stresses attained nearly all of their Ultimate elongation in a time less than ore minute. For the three specimens tested at $10 \mathrm{MPa}$ there are some differences in the eariy time creep behavior $\left(<10^{2}\right.$ minutes). However, no great significance should be placed on these differences, since factors such as how rapidly the specimen was loaded or local variations in thickness may well influence the early time behavior. As it relates to differences in molecular weight or molecular weight distribution, the most significant differences in behavior among the unoriented specimens remolded from the three types of films would appear to be in the maximum strain attained prior to failure or termination of the experiment. In Table 7 a comparison of the maximum strain attained prior to failure is shown for the three materials at $23^{\circ} \mathrm{C}$. Since the three specimens tested at $10 \mathrm{MPa}$ did not fail within 104 minutes, the values shown are those 
corresponding to a creep time of $10^{4}$ minutes. At all three lavels of applied stress it can be seen that film III material exhibits the least amount of creep, while the film BI exhibits the greatest amount prior to failure. We have previously reported [1] that the film III had the highest molecular weight and film BI the lowest. It appears, then, that the differences in molecular weight observed between the various categories of film are reflected in the creep behavior of the unoriented remolded materials, the order being the higher the molecular weight the lesser the amount of creep prior to failure, as might have been expected. The small differences observed in the tensile strength may also be a manifestation of the differences in molecular weight.

(C) Eilm Shrinkage

Ey vintue of affecting the orientation characteristics and fine texture in films, differences in draw ratio and blow ratio used in film production are reflected in differences in the shrinkage behavior which the films exhibit in the transverse relative to the machine direction upon melting. Examination of shrinkage behavior is thus a useful, if qualitative, method for probing the existence and possible origins of intrinsic differences between films due to processing, even though interpretation of the results in the present case is complicated by differences among the proprietary films in the molecular characteristics (molecular weight distribution, branching) of their constituent polymers.

Film shrinkage is a highly temperature-sensitive and time-dependent phenomenon and care must be taken to ensure that each piece of $\mathrm{fiIm}$ is exposed to the same melting conditions. In the present case pieces of film were cut into the shape of a square $6 \mathrm{~cm}$ on a side with adjacent sides parallel to the machine and transverse directions respectively. Each piece 
of film was floated on hot silicon oil $\left(140^{\circ} \mathrm{C}\right)$ for a period of ten minutes. After ten minutes each piece of film was removed from the oil, allowed to cool, and was then wiped dry. The new dimensions were recorded and the ratio of the initial to final dimensions calculated $\left(R_{M}\right.$ or $\left.R_{T}\right)$. At least two pieces of film from each roll or sheet were examined. The four films of primary interest in the present phase of this investigation are the films $I$, III, BI, and FI. However, for completeness we have included shrinkage data obtained on films II and IV which were investigated in the earlier phase of our work [I]. Films I - IV and BI all exhibit peak melting points near $107^{\circ} \mathrm{C}$, whereas the Fl melting peak is in the $122-123^{\circ} \mathrm{C}$ range (see Appendix $B(d))$.

Shrinkage data for 58 pieces of film from the six different categories of film are presented in Table 8. The results for films I - IV are presented in chronological order of manufacture. Since four of the specimens of film III were taken from rolls of a thicker $1.0 \mathrm{~cm}$ cap material, their shrinkage results will be excluded from further consideration in this discussion. The average values of the shrinkage ratios for each film category are given in Table 9. Excluding for the moment the film Fl, it can be seen that overall the films IV and II show the greatest shrinkage in the machine direction, I and $\mathrm{BI}$ the least, and film III falls intermediate. In the transverse direction films I and $\mathrm{BI}$ show the greatest shrinkage, IV and II the least, and film III again is intermediate. In both the machine and transverse directions the shrinkage of film III represents very closely the average value of the shrinkage ratio for all five film categories. All five films show significantly greater shrinkage in the machine direction than in the transverse direction. 
Film Fl shows quite different shrinkage characteristics from any of the other five films (see Table 9). On average, the Fl film shrinks by a factor of nearly 12 in the machine direction, whereas in the transverse direction it has actually expanded. These results would suggest that of the four films of primary concern in this phase of the wor'k (I, III, BI, and FI) the FI film is the most highly oriented in the machine direction (see later section D). (D) Orientation Characteristics in Films I, III, 31 and FI

Supplementing our earlier limited probing of the orientation characteristics of the crystalline regions in films I, III, BI and other films, we present and compare in this section the results of the determination of the (200) (020) and $\{110\}$ pole figures exhibited by these three films as well as film El, coupled with a consideration of the small angle $x$-ray diffraction patterns obtained from these films with the $x$-ray beam parallel to the M, T and N film directions. This section of the report is divided into three subsections. Some experimental details, as well as a brief description of the method of displaying the pole intensicy distributions relative to the $\mathrm{M}, \mathrm{T}$ and $\mathrm{N}$ directions in the pole figures, are given in subsection $D(i)$. The pole figure and small angle x-ray diffraction results are described, compared and discussed in section $D(i i)$ with reference to "working models" the elements of which are described in detail in

Appendix A. Surface replicas of film Fl were briefly examined. Scme Iimited observations derived from this examination are included at the end of section $D(i i)$. Finally, the results of an initial attempt to simulate numerically the (200) and (020) pole intensities of the four films are presented in subsection $D(i i i)$. 
(i) Experimental Details and Description of Pole Eigure Projections

The specimens prepared for the pole figure determinations consisted of about 70-90 parallel strips of film stacked on top of one another (total thickness $-1.5 \mathrm{~mm}$ ). The sides of the strips which coincided with the $M$ and $T$ directions, were $-8 \mathrm{~mm}$ and $1.5 \mathrm{~mm}$ long respectively. A special procedure using templates was used to facilitate the stacking of the strips as closely parallel to one another [i.e. with as small deviations in the $M$, $T$ and $N$ (normal) directions as possible throughout the stack].

An automated wide angle $x$-ray diffractometer, equipped with a four circle goniometer sample holder, and operated in the transmission mode was used to determine the (200), (020) and $\{110\}$ pole figures of the polyethylene films. A pole figure is a planar projection of the dispositions of the points of intersection (poles) of the normal to a given type of crystallographic plane [e.g. (200)] in the variously oriented microcrystalline regions of the specimen with the surface of a reference hemisphere which is concentric with the center of mass of the specimen. An example of the azimuthal equidistant projection of the reference hemisphere in relation to the $M, T$ and $N$ directions of a film specimen is shown in Fig. 11 in which $M$ is normal to the plane of the projection. The radial lines and concentric circles in Fig. 11 are, respectively, the projections of the longitudes $\phi$ and the latitudes $x$ of the hemisphere. The spherical coordinates $(\phi, x)$ specify the disposition of a pole on the surface of the hemisphere and hence the spacial orientation of the corresponding plane normal relative to the $\mathrm{M}, \mathrm{T}$, and $\mathrm{N}$ axes in the specimen. The coordinates of plane normals which are parallel to $M, T$ and $N$ are as follows: Parallel to M: $\quad\left(\chi=90^{\circ}\right)$; parallel to $\mathrm{T}:\left(\phi=0^{\circ}, \chi=0^{\circ}\right)$ or $\left(\phi= \pm 180^{\circ}, \chi=0^{\circ}\right)$; parallel to $\mathrm{N}$ : $\left(\phi=90^{\circ}, \quad \chi=0\right)$ or $\left(\phi=-90^{\circ}, \quad \chi=0\right)$. 
Briefly, the experiments consist of systematically varying the orientation of the specimen relative to the incident monochronatic xaray beam (Cu Ka radiation) and recording the relative intensities of the $\mathrm{x}$-rays diffracted by a chosen type of crystallographic plane [e.g (200)] at each orientation. The corresponding variations in intensity of the (200) poles as a function of $(\phi, \chi)$ are displayed in projection in the corresponding pole figure as contour lines which serve to delineate the spatial distribtuion in the orientation of the (200) plane normals relative to $M, T$ and $N$ in the specimen.

Small angle $x$-ray diffraction (SAXD) patterns were recorded photographically using a pinmhole collimated small angle camera. Ni filtered CuKa radiation from a rotating anode source was used. The same specimens as those used in the pole figure experiments were used to obtain the SAXD patterns with the xuray beam parallel to either $N$ or $T$. For obtaining SAXD patterns with the beam parallel to $M$ the template system mentioned above was used to prepare stacks of parallel film strips which were $-1.5 \mathrm{~mm}$ thick in the $M$ direction. Details concerning some experiments involving optical and electron microscopy are given later in the text.

\section{(ii) Results and Discussion}

The $(200),(020)$ and $\{110\}$ pole figures exhibited by films I, III, $3 I$ and $E I$ are shown in Figs. $12-15$ respectively. To facilitate comparisons between the films their respective (200) pole figures are shown together in Fig. 16; their (020) and $\{110\}$ pole figures are shown in Fig. 1? and Fig. 18. The plotting of the relative pole intensity variations which are delineated by eight contour lines (\#s I-8) in each pole figure is based on a scale consisting of nine intensity levels. The intensity increment between each successive level is equal to $\Delta I / 9=(\operatorname{Imax}-I \min ) / 9$, where $I \max$ 
and Imin are respectively the highest and lowest intensities among all the data recorded for each pole figure. Intensities in the lowest level range i.e. Imin to (Imin+ $\Delta I / 9)$ are circumscribed by contour line 非. Intensities in the highest level $i . e$. in the range Imin+8 I/9 to Imax are circumscribed by contour line 非. The intensities in regions bounded by contour lines 非 4 and \#5 fall in the range $(\operatorname{Imin}+4 \Delta I / 9)$ to $(\operatorname{Imin}+5 \Delta I / 9)$, and so on. The values of the ratio (Imax/Imin) for each pole figure are listed in Table 10. For ease in identifying the regions of highest pole intensity (circumscribed by contour line $\# 8$ ), these have been shaded in Figs. 12-15, and Figs. 16-18. The SAXD patterns taken with the $\mathrm{x}$-ray beam parallel to each of the $M, T$ and $N$ reference directions in the films are shown in Figs. 19-23.

Many considerations which guided the examination and interpretation of the pole figures and SAXD patterns listed above and discussed below stem from, or were prompted by, several previous studies on polyethylene films [2-11]. The papers of Lustig and Lindenmeyer [6] and Keller and Machin [7] were particularly relevant in this connection. Various limitations and/or ambiguities in interpretation which arise in the determination of preferred orientations (in low density polyethylene films having broad orientation distributions) from pole figures, are discussed in both papers [12]. In addition, the discussion by Keller and Machin [7] on the origins of the manifestation of preferred a-axis orientation parallel to the machine direction $(M)$ in polyethylene films, and the row structure models they proposed in this connection, were particularly pertinent as will become evident later.

It is evident from even a cursory examination of the pole figures in Figs. 16-18 that the (200), (020), and $\{110\}$ pole intensity distributions in film Fl differ significantly from those in Films I, III and Bl. In what 
ensues we shall first examine and compare the results on Films I, III and BI collectively, and speculate (with reference to the "Transcrystalline" and "Row" type model orientations described in Appendix A) on the possible morphologyarelated origins of both the preferred orientation characteristics these three films exhibit in common (see later), and the differences which distinguish film $B I$ from films $I$ and III. We shall then discuss film Fl.

Confining ourselves at this stage to a consideration of only the (200) and (020) pole figures exhibited by films I, III and BI (Eigs. 16-17), the following similarities between these films may be noted: - First, the (200) pole intensity in each film is higher in and close to the MT plane $\left(\phi=0^{\circ}, \chi=0^{\circ}\right.$ to $90^{\circ} ; \phi= \pm 180^{\circ}, \chi=0$ to $90^{\circ}$ ) than elsewhere, and is highest in and close to the $M$ direction $\left(\chi=90^{\circ}\right)$. Second, the (020) pole intensity is higher in and close to the NT plane $\left(\phi=0^{\circ}\right.$ to $\left.\pm 180^{\circ}, x=0^{\circ}\right)$ than elsewhere and is highest in

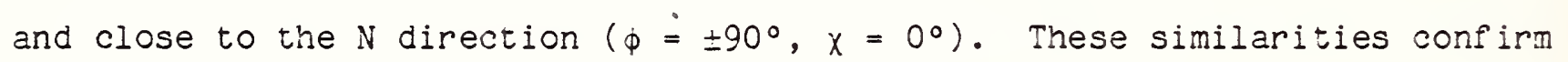
the qualitative deductions we reported previously [1] concerning the preferred a-axis and b-axis orientations in the films. However, the pole figures reveal the additional information that the distribution of the a-axis orientation [i.e. the (200) poles] in the NT plane in the BI film differs from those in Eilms I and III, the latter two films being closely similar to one another.

Thus, as can be seen from Fig. 16 the decrease in the (200) pole intensity in the MT plane from the maximum at and around $M$ to its lowest level (in that plane), which is at and around $T$ in all three films, is relatively less pronounced in film BI than in films I and III. The ratios of the (200) pole intensity at and around $M$ to the intensity at and around $T$ are as follows: Film BI $\left(1.36^{-1.54}\right)$, film I (2.3-3), and film III $(2 \cdot 2-2 \cdot 7)$. 
Note in this connection (Fig. 16) that the (200) pole intensity at $T$ is in the range $(\operatorname{Imin}+5 \Delta I / 9)$ to $(\operatorname{Imin}+6 \Delta I / 9)$ in $\mathrm{film} B I$, whereas it is in the range $(\operatorname{Imin}+2 \Delta I / 9)$ to $(\operatorname{Imin}+3 \Delta I / 9)$ in films I and III.

As for the distributions of the (020) the pole intensities in the NT plane (see Fig. 17), the decrease in pole intensity from the maximum at and around $N$ to its lowest level (in that plane), which is at and around $T$, is relatively more pronounced in the BI film than in films I and III. The ratios of the (020) pole intensity around $N$ to the intensity around $I$ for the three films are as follows: - Film BI (3.2-4.4), films I and III (2-2.4).

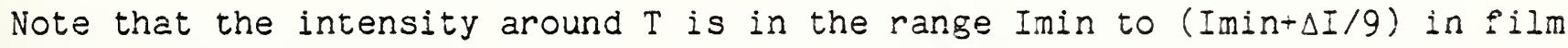

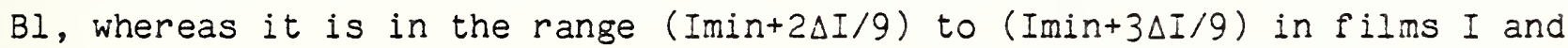
III.

We turn at this juncture to a preliminary consideration of the possible origins of the above mentioned preferred a-axis and b-axis orientation characteristics which films I, III, and BI display in common reiative to $M$, $T$, and N. Referring to the idealized (200) and (020) pole figures corresponding to the three morphologically-based "preferred-orientation-models" described in Appendix A (Figs. 26, 28, 29), and shown collectively in Fig. 30, the following may be noted:-

First, superposing the (200) pole figure of the lamellar Transcrystalline orientation upon that of either the Row(ac), the Row(a), or the combined Row(ac) and Row(a) orientations, yields in each case a composite pole figure in which the overall (200) pole intensity distribution is qualitatively consistent with those exhibited by the three films (I, III, BI, Fig. 16): i.e. the (200) pole intensity in the composite pole figure is higher in the MT plane than elsewhere, and is highest parallel to M. As can be seen from Fig. 30, the later feature is due specifically to any one, or a 
combination of both, Row orientations. The ratio of the (200) pole intensity at $M$ relative to that at $T$, would be expected to be relatively smaller the lower the content of Row oriented as compared to Transcrystalline oriented material in a film. Accordingly, the appreciably smaller value of this ratio of intensities in film BI as compared to films I and III, considered in terms of the composite working model(s) envisaged above, would indicate that BI contains relatively less Row oriented material.

Second, returning to $\mathrm{Fig} .30$, it can be seen that superposing the (020) pole figure of the lamellar Transcrystalline orientation upon that of either (or a combination of both) Row orientations yields a composite pole figure in which the overall (020) pole intensity distribution is qualitatively consistent with those exhibited by the three filns (Fig. 17): i.e. the (020) pole intensity in the composite pole figure is higher in the NT plane than elsewhere, and is highest parallel to $\mathrm{N}$, the latter feature being due specifically to the Transcrystalline orientation. The fact that the ratio of the intensity at $\mathrm{N}$ to that at $\mathrm{T}$ in the (020) pole figure of film 31 is appreciably larger than in films I and III indicates that there is relatively less Row oriented than Transcrystalline material in BI than in films I and III.

In summary, comparisons of both the (200) and the (020) pole figures exhibited by films, I, III and $B I$ in terms of a working model based on the Transcrystalline and Row orientations described in Appendix $A$, lead to the same conclusion, namely that film BI contains relatively less Row orienced relative to material with Transcrystalline orientation as compared to Films I and III. With this apparent difference among the three films as background, we proceed below to a discussion of their $\{110\}$ pole figures (Fig. I8) and 
the small angle x-ray diffraction patterns (Figs. 19-21, 23). Both sets of results have a bearing on the question of whether the Row oriented material in the composite model is predominantly Row(ac) or Row(a).

We start with a consideration of a composite orientation model consisting of the Transcrystalline and Row(a) orientations. As pointed out in Appendix A these two types of orientation correspond respectively to the 'populations' in the hypothetical model envisaged in our previous report [1] (Figs. 25a, b, reference [1]). It can be readily surmised from Fig. 30 that superposing the idealized $\{110\}$ pole figures corresponding to these two preferred orientations yields a composite $\{110\}$ pole figure exhibiting maximum pole intensity where the arcs due to the Transcrystalline orientation overlap the circle (latitude $\left.x=34^{\circ}\right)$ due to Row(a) material, i.e. at $\left(\phi=+90^{\circ}\right.$, $\left.x=34^{\circ}\right)$ and $\left(\phi=-90^{\circ}, x=34^{\circ}\right)$. This is in close agreement with the dispositions of the regions of highest pole intensity (circumscribed by contour line $k^{3} 8$ ) in the $\{110\}$ pole figures of the three films (I, III, and BI) shown in Fig. 13. However, referring again to Appendix A and Fig. 30, the combination of the Transcrystalline, Row(a), and Row(ac) $\{110\}$ pole figures also yields maximum pole intensity at $\left(\phi=+90^{\circ}, x=34^{\circ}\right)$ and $\left(\phi=-90^{\circ}, x=34^{\circ}\right)$ where all three pole distributions overlap. Indeed, it is not possible to distinguish with any certainty from the maxima in the experimental $\{110\}$ pole figures or from the character of the overall spread of pole intensities in these figures whether the films contain, in addition to the Transcrystalline component, only Row (a) or both Row(a) and Row (ac) oriented material. A distinction between these alternatives can however be made from a consideration of the small angle x-ray diffraction patterns exhibited by the films. This is discussed below. 
As pointed out in Appendix A the fine textures associated with the Transcrystalline, Row (ac) and Row(a) models are lamellar in character as is the case in the spherulitic structures from which they derive. At the local level crystalline lamellae and disordered layers are packed in an alternating fashion (see Fig. 25c) with the c-axis in the lamellar crystals oriented normal to the plane of the lamellar crystals as well as to the intervening disordered layers. It is the essentially regular (periodic) variation in electron density associated with this layer-like disposition of crystalline and disordered regions at the local level which gives rise to discrete $x$-ray diffraction maxima at small angles. As additional background we point out that the conditions for diffraction to occur are governed to a good approximation [16] by Bragg's law, $\lambda=2 \mathrm{ds}$ in $\phi$ where $\lambda=0.15418 \mathrm{~nm}$ is the

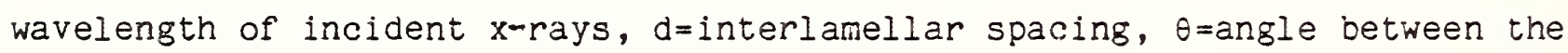
incident $x$-ray beam and the plane parallel to the alternating crystalline and disordered layers.

For an interlameliar spacing which is usually of the order of $10 \mathrm{~nm}$ $\theta \leqq 0.44^{\circ}$, i.e. Only those regions in the films in which the crystalline and intervening disordered layers are almost parallel to the $\mathrm{x}$-ray beam will given rise to discrete diffraction. Since the $\underline{c}^{-a x i s}$ in the crystalline lamellar layers is oriented preferrentially at right angles to these layers as well as to the intervening disordered layers, it follows that only the locally layered regions in the films in which the craxis is oriented at close to $90^{\circ}$ to the incident beam will be appropriately oriented to diffract. This criterion will be used below for comparing the observed SAXD patterns with those which would be expected based on the respective preferred $\underline{c}$-axis orientation characteristics (relative to $M, T$ and $N$ ) in the Transcrystalline, Row (ac) and Row (a) models and combinations thereof. 
The small angle x-ray diffraction patterns (Figs. 19-2l) obtained from the three films exhibit the following features. The patterns obtained with the x-ray beam parallel to $N$, Figs. (19-2l)a, exhibit a diffuse but nonetheless distinguishable diffraction ring which is more intense in the $M$ direction than in the $T$ direction. This latter feature is however perceptively less pronounced in the BI film than in films I and III as can be seen in Fig. 23 where the patterns from these three films are shown side by side. The periodicity in the fine texture (interlamellar spacing) calculated from the angular displacement of the diffraction ring from the center of the patterns, and assuming Bragg's law, is about $15.5 \mathrm{~nm}\left(\theta=0.28^{\circ}\right)$ in the three films. The patterns obtained with the x-ray beam parallel to M, Figs. (19-21)b, all exhibit a pair of diffuse diffraction spots which lie along an axis parallel to the $T$ direction in the films. The patterns obtained with the $x$-ray beam parallel to T, Figs. $(19-21)$, exhibit a pair of diffuse diffraction spots which lie along an axis parallel to the $M$ direction. The periodicity in fine texture corresponding to the diffraction spots in Figs. (19-21)b, and Figs. $(19-21) c$ is also approximately $15.5 \mathrm{~nm}$. (The intense streaks which extend from the beam stop along an axis parallel to the $\mathrm{N}$ direction in Figs. (19-21)b,c may be attributed to interstrip scattering from the stacked strips of films which constituted the specimens used to obtain the diffraction patterns.)

Using the interrelated diffraction criteria pointed earlier concerning the orientation of the crystalline and disordered layers, and hence the c-axis in the crystalline lamellae relative to the incident $x$-ray beam, we proceed to an examination of the characteristics of the experimental SAXD patterns in terms of the three model orientations. 
We start with a consideration of the SAXD patterns which would de expected from the three models with the incident x-ray beam parallel to $N$. In the case of the Transcrystalline model, the craxis in the lamellae is oriented preferentially parallel to the MT plane and is randomly oriented in that plane (Table 11). Accordingly, the corresponding SAXD pattern would be expected to exhibit a diffraction ring of uniform circumferential intensity. In the case of the Row(ac) model, there is a preferential orientation of the craxis parallel to $M(T a b l e ~ 11)$. The corresponding SAXD pattern would be expected to exhibit discrete intensity maxima along an axis parallel to $\mathrm{M}$. As for the Row(a) model, the c-axis is oriented preferentially in the NT plane and is randomly oriented in that plane (Table 11). In this case only those portions of the lamellar fine texture having the c-axis oriented nearly parallel to $\mathrm{T}$ will diffract giving rise to intensity maxima (spots) which lie along an axis parallel to $T$.

It follows from the considerations outlined in the previous paragraph that, with the incident $x-r a y$ beam parallel to $N$, the Transcrystalline and Row(a) orientations combined would yield a composite SAXD pattern exhibiting a diffraction ring (due to the Transcrystalline component) in which the intensity is greater in the $T$ than in the $M$ direction [due to the Row(a) component]. In contrast, the composite SAXD pattern of the Transcrystalline and Row(ac) orientations combined would exhibit a diffraction ring in which the intensity is higher in the $M$ chan in the $T$ direction, which is what is observed experimentally in the patterns from films I, III, and BI (see Fig. 23). In short, viewed in terms of the model orientations depicted in Appendix A, the experimental SAXD patterns taken with the $x-r a y$ beam parallel to $\mathrm{N}$ indicate that the predominant orientations in Films I, III and $B I$ are the Transcrystalline and Row(ac) orientations. Although the presence of some 
Row(a) oriented material is indicated by the $\{110\}$ pole figures it may be reasonably concluded from the nature of the intensity distributions in the SAXD patterns shown in Fig. 23 that such material is a relatively minor component in the films.

Finally, insofar as the SAXD patterns of films I, III and $3 I$ taken with the incident $\mathrm{X} \sim \mathrm{ray}$ beam parallel to $\mathrm{N}$ are concerned, it should be noted that these patterns and the pole figure data are consistent with one another in the following respect. In describing the SAXD patterns ( $F i g .23$ ) earlier, it was pointed out that although the intensity of the diffraction ring obtained in all three cases was higher in the $M$ than in the $T$ direction, this feature is perceptively less pronounced in the BI film than in films I and III. On the basis of the foregoing considerations this difference can be reasonabiy interpreted as indicating that there is relatively less of the Row(ac) as compared to Transcrystalline orientation in the BI film. As indicated previously (see page 24) comparison of the (200) and (020) pole figures exhibited by the three films leads to a similar conclusion although in the latter case the alternatives among the Row oriented species were not readily distinguishable.

An examination of the SAXD patterns obtained with the incident $x$-ray beam parallel to $M$ and to $T$ in terms of the criteria discussed above shows that the dispositions of the diffraction spots along the direction parallel to $\mathrm{T}$ in the patterns taken with the $\mathrm{x}$-ray beam parallel to $M$ [Figs. (19-2l)bJ, and along the direction parallel to $M$ in the patterns obtained with the x-ray beam parallel to I [Figs. (19-21)c], are consistent with the conclusion that the dominant preferred orientations in films I, III and 31 are the Transcrystaline and Row(ac) orientations. 
A summary of the various deductions discussed above concerning the preferred orientation characteristics of films I, III and 31 will be given at the end of this section, where they will be compared with the orientation characteristics of film Fl to which we turn to at this juncture.

An initial indication that the orientation characteristics of film Fl might differ substantially from those of the other three films was that it is positively birefringent [Appendix $B(f)$ ] whereas films I, III and $B I$ are negatively birefringent (Appendix $B(P)$ and reference [l]). As indicated oriefly earlier in this section ( $p .21$ ) and as we shall examine in more detail in what ensues, this is borne out by the pole figure as well as the SAXD resuits.

The (200), (020) and $\{110\}$ pole intensity distributions exhibited by film FI (Fig. 15) and the SAXD pattern taken with the xaray beam parallel to N (Fig. 22a, Fig. 23) exhibit none of the various interrelated characteristics associated with the Transcrystalline type of preferred orientation. While, as will be pointed out in more detail below, it may be readily concluded from the pole figures, coupled with the SAXD data, that Row(ac) is the dominant preferred orientation, with Row(a) an apparent minor component, the (020) and $\{110\}$ pole intensity distributions (Figs. 15b,c) exhibit deviations from the rotational symmetry about $M$ expected of the Row(ac) and Row(a) preferred orientations. These deviations will be pointed out in due course.

As can be seen in Fig. 15a, the (200) pole intensity in film Fl is highest in and close to the $M$ direction and the pole intensity distribution is close to being rotationally symmetric about the $M$ direction. Both of these features are consistent with the Row(ac) and Row(a) preferred orientations. Referring in this connection to the SAXD patterns in Fig. 22, it can be seen 
that the pattern obtained with the x-ray beam parallel to $N$ ( $I$ ig. 22a) exhibits diffuse diffraction spots which lie in the M direction. This latter feature indicates that the dominant preferred orientation is Row(ac). The spacing corresponding to the spots is approximately $18 \mathrm{~nm}$. The SAXD pattern taken with the x-ray beam parallel to T (Fig. 22b), which exhibits spots which also lie along $M$, is consistent with Row(ac) being the dominant preferred orientation.

The (020) and $\{110\}$ pole intensity distributions in film El (Figs. 15b, c) are consistent, in their broad outlines, with Row(ac) being the dominant preferred orientation and Row(a) a minor constituent. However, the observed distributions differ from the expected rotationally symmetric ones (about the M direction) characteristic of both the Row(ac) and Row(a) orientations. In the case of the (020) pole intensity - which is hignest in the NT plane than elsewhere as would be expected of both types of orientation o the observed intensity, instead of being uniform in all directions in that plane, is actually slightly higher in and around the $T$ direction (intensity $\geqq \operatorname{Imin}+7 \Delta I / 9$ )

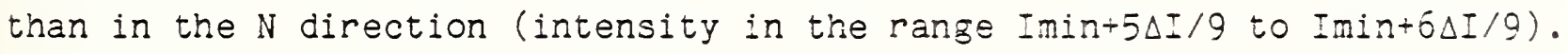
The trace of contour line $k^{7}$ may be noted in this connection, as well as the dispositions relative to the $\mathrm{N}$ and $\mathrm{T}$ directions of the three regions of nighest intensity which are circumscribed by contour Iine 非8. An apparentiy related deviation from the expected rotationally symmetric intensity distribution about $M$ is manifested in the $\{110\}$ pole figure shown in $F i g .15$, as evidenced by the disposition of the broad arced regions of higher intensity circumscribed by contour lines $\# 7$ and $k^{2} 8$ which straddle the $x=30^{\circ}$ latitude. 
It may be reasonably concluded from a consideration of the 'deviational' features of the (020) and $\{110\}$ pole figures pointed out in the previous paragraph, coupled with the (200) pole figure and the small angle $x-r a y$ diffraction characteristics described earlier, that while the dominant orientation in film $F I$ is of the Row(ac) type (with some Row(a) orientation), there exists in the film a slight surfeit of lamellae which are oriented with their a-axis preferentially paraliel to $M$, and with their b-axis preferentially in the NT plane but at angles of up to about $50^{\circ}$ to $\mathrm{T}$. It would follow that the craxis in these lamellae lies in the NT plane.

In summary, the orientation characteristics exhibited by the (200), (020) and $\{110\}$ pole figures and SAXD patterns of films I, III and 31 can be interpreted in terms of an idealized composite model in which it is envisaged that the films consist mainly of two "populations" of twisted lamellar crystals: namely a Transcrystalline population, and a "rowastructured" population of the Keller-Machin type [7] which we refer to as Row(ac).

The Transcrystalline lamellae are oriented with their b-axis preferentially parallel to $N$, with the $\underline{a}$ and $\subseteq$ axes preferentially parallel to the MT plane and randomly oriented in that plane (See Appendix A). An important feature of the Transcrystaline type of preferred orientation which should be borne in mind, and which will be discussed in connection with the mechanical properties of the films (in Section $E$ ), is the fact that the distributions of both the a and $\underline{c}$ axis orientations in the MT plane are isotropic.

In the case of the kow(ac) population in which, averaged over all the constituent lamellae, the b-axis is oriented preferentially parallel to the NT plane and is randomized in that plane, the a and $\underline{c}-a x e s$ are, on average, preferentially oriented parallel to the $M$ direction (see Appendix A). The 
orientation distribution of the latter axes is cylindrically symmetrical about the $M$ direction, and is clearly anisotropic in the MT plane in contrast with the Transcrystalline population.

Comparison of the pole figures and SAXD patterns exhibited by films I, III and $\mathrm{Bl}$ in terms of the Transcrystalline/Row(ac) composite orientation model described above indicates that, on a relative scale, film $B l$ contains appreciably less Row(ac) material than films I and III, i.e. it is structurally less anisotropic with respect to the $M$ as compared to the $T$ directions than the latter two films in which the pole intensity distributions are closely similar to one another.

Film Fl is structurally the most anisotropic of the four films studied. The pole figure data and small angle diffraction patterns indicate that it consists predominantly of Row(ac) material. Various orientation features which are typical of the Transcrystalline orientation and which were exhibited in the pole figures of films I, III and BI, were not manifested in the pole figures of film Fl.

The results of an attempt to simulate numerically the observed (200) and (020) pole intensity distributions exhibited by the four films are described in the next section ( $($ (iii)).

We close this section with some observations derived from a brief examination of surface replicas of film Fl which confirm the row-structured nature of its fine structure. A light micrograph (phase contrast transmission optics) of the actual film is shown in Fig. 33. Micrographs of nitrocellulose replicas of opposite surfaces of the film taken under similar optical conditions but at a higher magnification are shown in Fig. 34. A carbon replica of one of these nitrocellulose replicas was prepared by shadowing the latter with Pt/Pd, followed by evaporation of a film of carbon 
onto the shadowed surface. The nitrocelzulose was then dissolved away. Transmission electron micrographs of portions of the resulting carbon replica of the film surface are shown in Figs. 35,36 .

As can be seen in Fig. 33 the film Fl exhibits an overall mottled appearance as was the case for films I, III and BI [1]. However, in contrast with the later films fine striations running parallel to the machine direction (M) colid be faintly discerned. Both of these features can be seen more clearly in the higher magnification micrographs of the nitrocellulose replicas shown in Fig. 34 in which the arrows point to regions in the fields of view where finely separated (of the order of 1 um) striations running parallel to the $M$ direction can be seen most clearly. Examination of the carbon replicas in an electron microscope (Fig. 35) reveals ridges of varying sharpness running parallel to the $M$ direction. They correspond to the striations seen in the light microscope. These ridges are crossed and/or bridged by lamellae whose edges are oriented at right angles to $M$, as is typical of row structures (e.8. see reference [7]). The lanellar morphology of the surface texture and the orientation of the lameliae with their edges transverse to the machine direction can be seen more clearly in the higher magnification electron micrograph shown in Fig. 36. Similar exploratory experiments on $\mathrm{film}$ III indicate that etching techniques may be required to reveal the nature of the surface rexture of this film. Such experiments, and a detailed electron microscopical study of the fine structure of the four films would complement the findings reported in this section. They fall however beyond the scope of the present investigation. 


\section{(iii) Numerical Simulation of Pole Eigure Data}

In order to provide quantitative comparisons among the pole figure data obtained from the various films we performed numerical simulations in which we attempted to match the observed pole intensity distributions using a suitable probability density function. We used the Bingham distribution [ $] 7$, 18], which is of the form:-

$$
F\left(K_{1}, K_{2}, \phi, x\right)=C\left(K_{1}, K_{2}\right) \exp \left[K_{1}\left(L \cdot \mu_{q}\right)^{2}+K_{2}\left(L \cdot \mu_{2}\right)^{2}\right] \ldots \ldots \ldots . . . . .1
$$

where $C\left(K_{1} K_{2}\right)$ is the normalization constant, $\mu_{1}$ and $\mu_{2}$ are two members of an orthogonal triad of unit vectors, and are regarded as parallel to the $\mathrm{N}$ and $\mathrm{T}$ directions in the films respectively. I is a unit vector representing the direction of an observed pole,

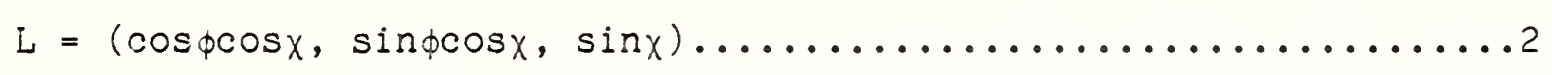

given the above definitions Equation 1 reduces to:

$$
F\left(K_{1}, K_{2}, \phi, x\right)=C\left(K_{1} K_{2}\right) \exp \left[\cos ^{2} x\left(K_{1} \cos ^{2} \phi+K_{2} \sin ^{2} \phi\right)\right] \ldots \ldots \ldots \ldots
$$

The form of the intensity distribution in this model is controlled by only $K_{1}$ and $\mathrm{K}_{2}$. Our simulation efforts consisted of adjusting the values of $K_{1}$ and $K_{2}$ so that the positions of the points at which the intensity was half way between the minimum intensity and maximum intensity along the $\phi=0^{\circ}$ and $\phi=90^{\circ}$ meridians (longitudes) of the simulated pole pigure matched those in the experimental (200) and (020) pole figure data.

The $K_{1}$ and $K_{2}$ values obtained for the (200) and (020) poles for films I, III, $B I$ and $E l$ are given in Table 12. Fig. 31 and Fig. 32 illustrate respectively the contour plots of the simulated (200) and (020) pole data. 
As can be seen from a comparison of the simulated pole fizures (Figs. 31, 32) and the experimental pole figures (Figs. 16,17), the sets of parameters given in Table 12 reproduce the main qualitative features of the experimental pole figure plots, but the latter data have more intensity in the wings of the peaks than is implied by $\mathrm{Eq}$. 1. The functional form of Eq. I would have to be modified to provide for a less rapid fall-off of intensity from the maxima. The functions needed to model the data become even more complex if one seeks to describe features such as the bifurcated maxima in the (020) pole figure of film Fl. Eurthermore in future quantitative studies the matter of correcting the experimental data for background and absorption effects will need to be explored. These considerations notwithstanding, the function given in Eq. I is capable of representing qualitatively the behavior of a wide range of orientation distributions. This is further illustrated by the inclusion in Table 12 of the values of $K_{1}$ and $K_{2}$ for the (200) and (020) pole distributions corresponding to the Transcrystalline, Row(ac) and Row(a) preferred orientations. Comparison of these values with those of the films shows that the BI film is closer to the limiting case of the Transcrystalline orientation than any of the other films. The differences between films $I$ and II are relatively minor with the values of $K_{1}$ and $K_{2}$ for both films occupying intermediate positions between those for the Transcrystalline and Row type preferred orientations. The values of $K_{1}$ and $K_{2}$ for film Fl are closer to those for the Row type orientations.

In summary, the results of the numerical simulations described above are qualitatively consistent with the interpretations (discussed in Section Dii) of the nature of orientations in the four films, and the main differences between them, in terms of the Transcrystalline, Row(ac) and Row(a) modeis. 
The main differences in the $\underline{a}$ and $\underline{b}$ axis orientations among the films are clearly, if qualitatively, reflected in the values of the parameters $\mathrm{K}_{1}$ and $\mathrm{K}_{2}$ in the Bingham-type probability density function (Eq. I) used in the simulations.

E. Summary/Discussion/Conclusions

The various aspects of the structure and properties of films I, III, BI and $\mathrm{Fl}$ investigated in the present study are summarized below where the results for the four films are compared and discussed with reference to various features of films I, III, and BI which have been reported in our previous study [1]. For convenience in this latter connection we have listed in Table 15 the previously obtained data [1] on the methyl group content, molecular weights $\left(M_{W}, M_{n}\right)$, intrinsic viscosity, peak melting temperature, and elongations-to-break (uniaxial stretching in the $M$ and $T$ directions) of films I, III and BI. The corresponding data for film Fl which were determined in the present study, and are described in detail in Appendix B of this report, are also Iisted in Table 15, together with the recently acquired data on the shrinkage behavior exhibited by the four films upon melting (see section $C$ p. 16).

The following similarities and/or differences have been observed among the four films:-

(i) The methyl group content, and hence the branching in the constituent chains in film $\mathrm{El}\left(0.48 \mathrm{CH}_{3} / 100 \mathrm{C}\right.$ atoms $)$ is considerably lower than in films I, III and $\mathrm{BI}\left(2.1 \mathrm{CH}_{3} / 100 \mathrm{C}\right.$ atoms). 
(ii) The molecular weight distribution of film Fl is narrower, and its apparent weight average molecular weight $\left(M_{\mathrm{W}}=129,000\right)$ is lower, than in films $I$, III and $B l$. The values of the apparent molecular weights of films I, III and BI, listed in order of increasing magnitude are as follows: Film BI, $M_{\mathrm{w}}=155000$; film I (three determinations), $M_{W}=202000-216000$; film III (three determinations), $M_{W}=240000-255000$.

(iii) Although the weight average molecular weight of film $F 1$ is lower than those of films I, III and BI, its intrinsic viscosity $(n=1.59 \mathrm{~d} / \mathrm{g})$ is higher. The intrinsic viscosities of the latter three films in order of increasing magnitude, and in accordance with their increasing molecular weights, are: Film B1, $\eta=1.13$ $\mathrm{dl} / 8$; film I, $n=1.23 \mathrm{dl} / \mathrm{g}$; and film III, $n=1.27 \mathrm{dl} / \mathrm{g}$. The departure exhibited by film FI from the expected monotonic increase in viscosity with increase in molecular weight is explicable in terms of the much lower branch content of the constituent chains in that film (see Appendix $B(c)$ ).

(iv) The peak melting temperature of film $F 1\left(122^{\circ} \mathrm{C}-123^{\circ} \mathrm{C}\right)$ is higher than the peak melting temperatures exhibited by films I $\left(106.8^{\circ} \mathrm{C}\right)$, III $\left(106.2^{\circ} \mathrm{C}\right)$ and $\mathrm{BI}\left(105.5^{\circ} \mathrm{C}\right)$. This substantial difference between film $I l$ as compared to the other films can be reasonably attributed to the lower degree of branching in the constituent chains in film Fl. A critical aspect in the construction of heavy-lift balioons is the thermal fusion of adjoining gores. The presumably regulated thermal conditions 
under which this process has traditionally been carried out on lower melting films such as films I, III and BI may need to be modified in the construction of balloons from film Fl.

(v) The weight o crystailinity of film Fl (50.6\%), calculated from density measurements, is slightiy higher than in films I (46.6\%): $\operatorname{III}(46.5 \%)$, and $B I(48.2 \%)$. Crystallinity is governed by the intrinsic stereochemical characteristics of the polymer chains (i.e. branching), the molecular weight, as well as the thermal and other processing parameters (draw ratio, blow ratio) used in film production. The dependence of crystallinity on this multiplicity of variables notwithstanding, it remains somewhat surprising that the crystallinity of film $F I$ is only slightly higher than that in the other films considering that the chains in film Fl are considerably less branched. This matter has not been pursued any further in view of the lack of specific information on the processing variables used in the production of any of the films.

(vi) The (200), (020) and $\{110\}$ pole figures, considered in conjunction with the SAXD data, indicate that the orientation distributions of the $\underline{a}$ and $\underline{c}$ axes in all four films, are peaked in the $M$ direction, as would be expected of the Keller-Machin [7] "row structure" model which is referred to as Row(ac) in this report (See Appendix A, and Section D). These anistropic features of the $\underline{a}$ and $\underline{c}$ axis orientation distributions in relation to the $M$ and $T$ directions vary however among the films. 
(vii) Comparison of the pole figures and SAXD patterns exinibited by the films indicates that in contrast with film Fl in which the Row(ac) type of preferred orientation is the dominant one, its manirestation is less pronounced in films I and III (which are structurally ciosely similar to one another), and least pronounced in film $B I$.

(viii) The orientation distributions in films I, III and BI, a common characteristic of which is that the b-axis distribution is peaked in the $\mathrm{N}$ direction (this feature is more pronounced in film $B I$ than in films I and III), can be reasonably accounted for in terms of an idealized composite orientation model. In this model the crystalline regions in the films are regarded as consisting mainly of two populations of twisted lamellar microcrystals, with the orientation distribution in one population being of the Row(ac) type, and that in the other being Transcrystalline-like (see Appendix A and Section D). The preferred crientation characteristics of the latter population are that the b-axis is preferentially oriented paraliei to $\mathrm{N}$. The $\underline{a}$ and $\underline{\underline{c}}$ axis orientations are isotropic in relation to the $M$ and I directions in the films. Film 31 contains a higher proportion of Transcrystalline orientation relative to the Row(ac) orientation as compared to films I and III. Correspondingly, it is structurally less anisotropic with respect to the $M$ and $T$ directions than films I and III. No evidence of the Transcrystalline orientation was detected in film Fl which is structuraliy the most anistropic among the films in relation to the $M$ and $T$ directions. 
(ix) There is evidence in the pole figures of all four films of the presence of minor component regions having orientations which differ from the Row(ac) and Transcrystalline orientations.

(x) The morphological characteristics exhibited in electron micrographs of the replica of one of the surfaces of film El confirm the "row-structure" nature of the fine texture of that film.

(xi) The birefringence $\left(n_{M}-n_{T}\right)$ of film $E I$ is positive, whereas films I, III and BI exhibit negative birefringence. Great caution must be exercised in interpreting birefringence measurements in films. Birefringence is a function of several factors namely: (a) the orientation characteristics of the crystalline lamellae, (b) the prevailing molecular organization in the disordered interlamellar regions whose contribution to the overall birefringence is not independently predictable, and (c) the fractional contents of crystalline and disordered regions [24]. The refractive index parallel to the caxis in orthorhombic polyethylene, $\left(n_{c}=1.575\right)$ is greater than that parallel to the amaxis $\left(n_{a}=1.514\right)$, and to the b-axis $\left(n_{b}=1.519\right)$ [25]. We note that the positive birefringence exhibited by film $F I$ is qualitatively consistent with the deduction, derived from the pole figures and small angle diffraction patterns, that the orientation distribution of the cmaxis in that film is peaked parallel to the $M$ direction, as is characteristic of the Row(ac) orientation. By the same token films I, III and BI might have been expected to exhibit positive birefringence, but with lower magnitudes than in film Fl, since they contain Row (ac) material in relatively smaller proportions. 
The fact that films I, III and BI are negatively birefringent suggests "overmcompensating" negative contributions to birefringence from the disordered regions.

(xii) The dimensional changes which the films undergo in the $M$ and $T$ directions upon melting at $140^{\circ} \mathrm{C}$ have been examined. Films I, III, and $B I$ shrink in both the $M$ and $T$ directions. Shrinkage in all three films is larger in the $M$ than in the $I$ direction. The values of $R_{M}$ (shrinkage in the $M$ direction) range from 4 to 5 (Table 8 ), and those of $\mathrm{R}_{\mathrm{T}}$ (shrinkage in the $\mathrm{T}$ direction) range from 2.3 to 3.2 . The values of the ratio $R_{M} / R_{T}$ for the three films fall in the following ranges: Film III (1.45-2.14, Table 8), film I (1.33-1.81), and film BI (1.26-1.46). The dimensional changes which film $F 1$ undergoes upon melting differ from those of films $I$, III and $B I$ in two respects. First, it shrinks by a factor of 2-3 more in the $M$ direction $\left(R_{M}=9: 8-13.3\right.$, Table 8$)$. Second, it expands by $25 \%-42 \%$ in the $T$ direction. These various observations are qualitatively consistent with the expectation that shrinkage in the MT plane will tend to be larger in the direction along which the orientation distribution of the chain axes (i.e. the c-axis in the crystalline regions) is peaked. As adduced from the pole figures and the small angle $x$-ray diffraction patterns, the c-axis is preferentially oriented parallel to $M$ in all four films. This feature is a characteristic of Row(ac) material which is the dominant constituent of film Fl $\left(R_{M}=9.8\right.$ to $13.3, R_{M} / R_{T}=13.8$ to 19.3), and occurs in smalles proportion in the three other films, for which $R_{M}$ (4 to 5 ) and $R_{M} / R_{T}(1.33$ to 2.14 ) are expectedly much 
lower. The average values of $R_{M} / R_{T}$ for films $3 I$, I and III are $1.36,1.51$ and 1.71 respectively. The lower value of $R_{M} / R_{T}$ for film BI is consistent with the pole figure and SAXD data which indicate that its orientation characteristics in the MT plane are the least anisotropic of the four films. We can only note the difference in the averages of $R_{M} / R_{T}$ between films $I$ and III. The possibility that this difference reflects relatively subtle differences in orientation between these films remains an open question.

(xiii) The four films were subjected to equal biaxial deformation under inflation at $23^{\circ} \mathrm{C}$ and $-73^{\circ} \mathrm{C}$. At $23^{\circ} \mathrm{C}$ films $I$ and $B I$ deformed by almost equal amounts in the $M$ and $T$ directions near the pole of the bubble. There was no evidence of necking. In contrast both films III and Fl exhibited necking in the transverse direction, and as a result deformed significantly more in the transverse direction than in the machine direction. Film III exhibited several necks over the suriace of the bubble, whereas film Fl exhibited only one neck. For each of the four films the same pattern of behavior was found to occur at $-73^{\circ} \mathrm{C}$.

(xiv) Comparison of all the mechanical measurements made on the four films at $23^{\circ} \mathrm{C}$ indicates that there is a rather good correiation between the results of the equibiaxial inflation experiments, and those from the elongation to break experiments in uniaxial extension (Table 15). In both sets of experiments films 31 and I exhibit balanced (isotropic) derormation in the $M$ and $T$ directions, whereas films III and FI exhibit preferential deformation parallel to $T$ at large strains. 
(xv) The following observations emerge from a consideration of the extension to break data exhibited by the films in uniaxial extension (data in Table 15) in relation to the results of the orientation studies. The ratios $E_{M} / E_{T}$ ( $E_{M}=e x t e n s i o n$ to break in the $M$ direction/extension to break in the $T$ direction) for films films BI, III and $F I$ at $23^{\circ} \mathrm{C}$ are $1.04,0.71,0.56$ respectively. There is an apparent correlation between these ratios and the fact that the orientation of the crystalline regions with respect to $M$ and $T$ is correspondingly least anistropic in $\mathrm{Pilm} B I$ and, in increasing order, more so in films III and Fl. It is evident however that film I $\left(E_{M} / E_{T}=1.02\right)$, which is structurally more closely similar to film III but mechanically akin to film $B I$ at $23^{\circ} \mathrm{C}$, does not fit into this scheme. There are no evident orientation-related trends among the $\Xi_{M} / E_{T}$ ratios of the films at $-73^{\circ} \mathrm{C}$

(xvi) Constant rate of clamp separation, and creep to failure experiments indicate that the differences in molecular weight and/or molecular weight distributions of the polymer in films I, III and Bl, are reflected to some extent in the tensile properties at $23^{\circ} \mathrm{C}$ of unoriented samples prepared by melting the films and allowing them to $c 00 l$ and crystallize under ambiant conditions. Samples made from the polymer with hizhest molecular weight (film III) had the highest tensile strength (18.6 MPa) and the lowest strain to break ( 5.4 in creep). Samples made from the lowest molecular weight material (from $\mathrm{film} \mathrm{BI}$ ) had the lowest tensile strength $(15.3 \mathrm{MPa})$ and the largest strain to break $(6.6$ in creep). 
Appendix A

Orientation Models

The interpretations of the results of the $(200),(020)$, and $\{110\}$ pole figure determinations and the small angle $x-r a y$ diffraction experiments reported in Section $D$, are based on three idealized modeis of preferred orientations (and combinations thereof). These models are referred to as the Transcrystalline, the Row (ac) and the Row(a) modeis respectively. They are described below following a synopsis of some fundamental features of the crystallography and morphology (fine structure) of melt crystaliized polyethylene.

(i) Some Crystallographic and Morphological Characteristics of Melt Crystallized Polyethylene

The unit cell of polyethylene (Fig. 24) is orthorhombic. Its parameters are $a=0.74 \mathrm{~nm}, b=0.493 \mathrm{~nm}, c=0.2534 \mathrm{~nm}, \alpha=\beta=\gamma=90^{\circ}$. The chains are oriented parallel to the craxis. The $(200),(020)$ and $(002)$ poles lie along directions parallel to the $\underline{a}, \underline{b}$, and $\underline{c}$ axes respectively.

Under quiescent conditions (i.e. in the absence of flow) branched and linear polyethylenes crystallize from the molten state in the form of spherulitic aggregates (Fig. 25a) whose radial spans usually vary from circa $1 \mu \mathrm{m}$ to $100 \mu \mathrm{m}$ depending on the conditions of crystallization. The average spherulite size diminishes the lower the crystallization temperature due to the higher spherulite nucleation density (nuclei/unit volume). At sufficiently low crystallization temperatures the dimensions attained by spherulites before they impinge can fall below the level (circa I $\mu \mathrm{m}$ ) at which they can be distinctly resolved under the optical microscope. Detailed descriptions and discussions of the cptical and fine structural characteristics of polyethylene (and other polymer) spherulites can be found 
in references [14] and [15] which include ample bibliographies. We limit ourselves here to a listing of some main characteristics of the morphology and associated crystallographic details of polyethylene spherulites which have a bearing on the various distinguishing features of the preferred orientation models which will be described below.

Polyethylene spherulites consist of a spherically symmetric radiating array of long and narrow crystals (Fig. 25b) which are twisted about the radial direction and which are on the order of 1 m wide or less depending on the crystallization temperature. These crystais are lamellar in character (Fig. 25c), their thickness being typically on the order of $10 \mathrm{~nm}$. They are oriented with their b-axis parallel to the radial direction. The $\mathbb{c}^{-a x i s}$ in the lamellae is oriented normal, or closely so, to the plane of the lamellae within which the chain molecules are folded back and forth between opposite

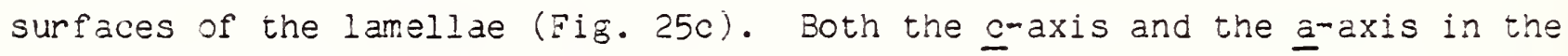
crystals are oriented normal to the radial direction about which the lamellae are twisted, as indicated above. The twist period is the same along every radial path. Correspondingly, upon proceeding along the lamellae from the center to the outer regions of the spherulite along any radial path there is a periodic rotation of the $\underline{a}$ and $\underline{c}$ axes about the radius (Fig. 25b). The disordered regions in the spherulites are sandwiched between neighboring lamellae (Fig. 25c). Included in these disordered regions are the chain folds at the surfaces of the lamellae, chain ends, and interlamellar tie molecules. The thickness and width of the lamellae decrease the lower the crystallization temperature as does the twist period. 
The morphological and crystallographic characteristics of the preferred orientation models described below derive from the structure of spherulites. The main features to bear in mind in this connection is that the b-axis in the twisted lamellae is oriented parallel to the radial direction with the and $c$ axes normal to the radius about which they rotate periodically.

\section{(ii) Transcrystalline Orientation Model}

In this model twisted lamellae similar to the constituent radially oriented lamellae in spherulites are regarded as being oriented with their b-axis paraliel to $N$ (i.e. normal to the MT plane) (see Fig. 26) in the film. Correspondingly, the $\underline{a}$ and $\underline{c}$ axes which are perpendicular to $\underline{b}$ are oriented parallel to the MT plane. Furthermore due to the twisting of the lamellae about $b$, the $\underline{a}$ and $\underline{c}$ axes are randomized in the MT plane. These features are summarized in Table 1l. The idealized (200), (020), (002) and $\{110\}$ pole figures corresponding to these preferred orientation characteristics are also shown in Fig. 26. Note that the (200) and (002) pole figures are identical. The two arcs in the $\{110\}$ pole rigure pass through the points whose coordinates are $\left(\phi=-124^{\circ}, \chi=0^{\circ}\right),\left(\phi=-90^{\circ}, \chi=34^{\circ}\right),\left(\phi=-56^{\circ}, \chi=0\right)$ and $\left(\phi=56^{\circ}\right.$, $\left.x=0^{\circ}\right),\left(\phi=90^{\circ}, \quad \chi=34^{\circ}\right),\left(\phi=124^{\circ}, \quad \chi=0^{\circ}\right)$ respectively.

The transcrystalline orientation is most frequently encountered near the surface of molded specimens which have been rapidly cooled from the molten state. Due to the more rapid cooling at the specimen surface the spherulite nucleation density is much higher than in the interior. With so many nuclei in close proximity to one another the growth of spherulites can only proceed into the interior of the sample along the direction perpendicular to the surface. This results in a surface layer in which the twisted lamellae are oriented with their braxis preferentially parallel to the direction of growth, i.e. normal to the surface of the specimen. Whether extensive 
regions having the transcrystalline orientation exist near the cuter surface of the blown films, or whether this type of preferred orientation of

lamellae arises in some different manner remains an open question which has not been pursued in the present study.

\section{(iii) Row(ac) Orientation}

This is the well established Kellermachin "Row Structure" [7], see Fig. 27(i). Under the influence of extensional flow, there form in a molten extrudate fibrous (diameter of the order of $10 \mathrm{~nm}$ ) nuclei in which the chain molecules are oriented parallel to the extrusion direction. As the extrudate cools, spherulites are nucleated along the length of these fibrils. The developing spherulites which are centered on and lie along the same fibril are however in such close promixity to one another that they can only develop radially along directions perpendicular to the fibril axis, i.e. perpendicular to the extrusion (machine) direction. The successive disclike growths ("cylindrites") which are thus formed along each fibril correspond to diametric cross-sections of spherulites. As in spherulites, the radiating twisted lamellae are oriented with their b-axis parallel to the radial direction in the cylindrites, with the $\underline{a}$ and $\underline{c}$ axes normal to and rotated about the radial direction.

A schematic representation of such row structures as they would be oriented in a film (and as viewed along the $M$ direction) is depicted in Fig. 28 together with the corresponding idealized $(200),(020),(002)$ and $\{110\}$ pole figures. As summarized in Table 11 , and as can be seen from the (020) pole figure, the b-axis is oriented preferentially parallel to the NT plane, and is randomized in that plane. The distributions of the $\underline{a}$ and $\underline{c}$ axis orientations are similar to one another. They are both broadiy peaked in the $M$ direction $\left(x=90^{\circ}\right)$ and are cylindrically symmetrical about that 
direction [7]. The (200) and (002) pole intensities decrease progressively along all meridians (longitudes) with decreasing $x$. The $\{110\}$ poles are distributed along all meridians between latitudes $x=0^{\circ}$ and $x=34^{\circ}$.

(iv) Row(a) Orientation

This model has been discussed by Keller and Machin (Ref. [7], p. 68). While, in common with the Row(ac) model, the lamellae in the cylindrites are oriented with their b-axis parallel to the radial direction, and the a and $\underline{\subseteq}$ axes are normal to that direction, this model differs from the Row(ac) model in the following respects. The lamellae are not twisted, but are oriented with the a-axis parallel to the extrusion (machine) direction, and the craxis perpendicular to that direction [Fig. 27ii]. It has been suggested that this type of row structure is formed under conditions of higher stress than attain the Row(ac) structure [7].

A schematic representation of such Row(a) structures as they would be oriented in a film (and as viewed along the $M$ direction) is depicted in Fiz. 29 together with the corresponding idealized (200), (020), (002) and $\{110\}$ pole figures. As summarized in Table 11 , the a axis is oriented parallei to $M$, and the $\underline{b}$ and $\underline{c}$ axes are oriented parallel to the $N \mathrm{~m}$ plane and are randomized in that plane. The $\{110\}$ poles are uniformly distributed around the $x=34^{\circ}$ latitlide.

The pole figures corresponding to the Transcrystalline, Row (ac), and Row(a) orientations are shown collectively in Fig. 30.

It should be noted that the preferred orientation characteristics of the $\underline{a}, \underline{b}$, and $\underline{c}$ axes relative to $\mathrm{M}, \mathrm{T}$, and $\mathrm{N}$ in the Transcrystalline and Row(a) models correspond respectively to the hypothetical orientations depicted in Fig. 25a and Fig. 25b in our previous report [1]. 
Appendix $B$

Film Fl: Branching, Molecular Weight Distribution (from Size Exclusion Chromatography), Intrinsic Viscosity, Melting/Crystallization (from Differential Scanning Calorimetry), Density/Crystallinity, Birefringence, Tensile Properties at $23^{\circ} \mathrm{C}$ (Uniaxial Extension in the $M$ and $T$ Directions)

As additional background for comparing the structural characteristics and physical properties of film El with those of films I, III and BI, the features listed above, which had been previously examined for the latter three films [I], were also determined for the "newer" film FI.

\section{(a) Branching: Methyl Croup Content}

The FTIR method of analysis was similar to that used for the other polyethylene films [1]. The sample was prepared by hot pressing six layers of film at $130^{\circ} \mathrm{C}$. The thickness of the sample was $4.6 \pm 0.2 \mathrm{mils}$ as determined with a micrometer caliper. The IR spectrum in the frequency region between 1330 and $1400 \mathrm{~cm}-1$ differed significantly from those obtained from the cther films indicating a lower methyl group content. By resolving the complex band profile shown in Fig. 37 according to the method of Rueda, Balta Calleja and Hidalgo [19] the peak absorption of the methyl band at $1378 \mathrm{~cm}^{-1}$ was determined. From this quantity and the film thickness the methyl group content per 100 carbon atoms was calculated using the expression $\varepsilon\left(\mathrm{CH}_{3} / 100 \mathrm{C}\right)=0.085 \%-.09$

where $k$ is the peak absorption divided by the thickness in $\mathrm{cm}$. The methyl group content was determined to be 0.48 per 100 carbon atoms, or approximately $1 / 4$ the value reported for films I, III and BI [I]. 
(b) Size Exclusion Chromatography (SEC)

With the same apparatus and bank of columns used previously to examine the Category I, III, BI and other fiIms [1] SEC runs were carried out at $130^{\circ} \mathrm{C}$ in $1,2,4$ trichlorobenzene on the $F I$ film, as well as on the Category I and III films as a crosscheck with the previous work. A recalibration, necessary because the columns had not been used for some time, indicated that no change had taken place. As before, the chromatograms extended to the exclusion limit for these columns which is about 4 million for linear polyethylene.

A method for calculating molecular weights of branched whole polymers, requiring several assumptions, has been given in the literature [20]. It is assumed that the extent of branching is independent of the molecular weight of the species making up the distribution, an assumption which would not be expected to be generally true and which has been shown to be incorrect for low density polyethylene [21]. In addition the relationships used to derive the dependence of the number of branch points on the radius of gyration [22] apply to a specific type of branching which does not necessarily occur in low density polyethylene. For this reason, no attempt was made to use this method to calculate molecular weights.

The calculations of molecular weight were carried out for the polymers within the calibration range, and assuming the polyethylene is linear. Because of this latter assumption the calculated molecular weights obtained in the present series of measurements (Series C) and those obtained earlier for films I, III, and BI (Series A, Series B, see Table 2, reference [1]), all of wich are listed in Table 13, are referred to as apparent molecular weights. The correct molecular weights are likely to be higher because of the effect of branching and because extremely high molecular 
weight material was excluded from fractionation by the columns; some of this extremely high molecular weight material might include microgels, known to occur in branched polyethylenes.

The apparent molecular weight values obtained for films I and III at different times fall within the expected error range of the experiments. An overlay of chromatograms of films I, III, and EI (Fig. 38) shows that the FI film has a narrower molecular weight distribution than the other two. For example, at an elution volume of $33 \mathrm{ml}$, which according to the column calibration corresponds to a molecular weight of 420,000 , the peak height, which is proportional to the amount of component of that molecular weight present in the film, is only one half as high in the Fl film as in the film I. This lower content of high molecular weight component results in the $\Xi 1$ film having a weight average molecular weight of 129,000 compared to 200,000 and 255,000 for films I and III respectively and 154600 for the 31 ilm. The number average molecular weights of the films are not too far different from each other, ranging from 21,000 to 30,000 .

(c) Intrinsic Viscosity

The relative flow times of several dilute solutions of the Fl film of different concentrations at $130^{\circ} \mathrm{C}$ in $1,2,4$ trichlorobenzene were measured with a capillary viscometer in the manner described in the previcus report [1]. The data were extrapolated to zero concentration to give a limiting viscosity number or intrinsic viscosity, $[n]$.

The observed values previously measured [1] for films I, III and 31 are given along with that of $F I$ in Table 13. In the case of the Fl film it was found necessary to increase the dissolution temperature from the more customary 135-140 C range, used previously for the other films, to about $160^{\circ} \mathrm{C}$ for one hour to effect complete solution. 
The value of $[\eta]=1.59$ for film $F l$ is substantially higher than the values found for the other three films which were 1.23 (film I), 1.27 (film III) and 1.13 (film BI).

According to the Mark-houwink relation,

$$
[\eta]=\mathrm{MM}^{\alpha} \text {, }
$$

(where $K$ and $\alpha$ are empirical constants which depend on the polymer, the solvent, and the temperature) the viscosity increases monotonically with molecular weight. Hence on the basis of the dilute solution viscosity measurements alone one would be led to conclude that Fl has a higher molecular weight than films I, III, and Bl films. This is in apparent contradiction to the molecular weights obtained by SEC shown in Table 13, but can be explained in the light of the considerably lower methyl group content (and hence branching) in the chains of film Fl as compared to those in films I, II and $B I$ (see Appendix $B(a)$ above).

It is well known that solutions of polymers with long chain branching have a lower viscosity than linear polymers of the same molecular weight. This is because the branched chain molecule is more compact and consequently has a smaller hydrodynamic volume than an unbranched chain random coil, which in a good solvent is more extended and occupies a larger volume. Since viscosity is a measure of hydrodynamic volume the viscosity will be smaller for a branched polymer than for a linear one of the same molecular weight. By the same token, polymer having fewer branches may exhibit a higher intrinsic viscosity than a highly branched one even though the molecular wieight of the latter is greater, which appears to be the case for the Fl film compared to the other three films. 


\section{(d) Melting/Crystallization: Differential Scanning Calorimetry (DSC)}

As was the case in our earlier screening of films I, III, $B I$ as well as others [1], the melting and crystalization behavior of samples of film $E I$ were probed with a differential scanning calorimeter using heating and cooling rates of $20^{\circ} \mathrm{C} / \mathrm{min}$. Each sample was subjected to two consecutive heating and cooling cycles as follows: The film specimen, initially cooled to $-40^{\circ} \mathrm{C}$ was heated at $20^{\circ} \mathrm{C} / \mathrm{min}$ to a temperature $\left(140^{\circ} \mathrm{C}\right)$ above the specimen melting range. It was then cooled at $20^{\circ} \mathrm{C} / \mathrm{min}$ to $-40^{\circ} \mathrm{C}$ and then was subjected to a second (similar) heating and cooling cycle. DSC curves exhibited by a film specimen upon heating and cooling through two consecutive cycles are shown in Fig. 39. The peak melting temperatures exhibited by two specimens in the first heating cycle were $122.4^{\circ} \mathrm{C}$ and 122. $6^{\circ} \mathrm{C}$. In both specimens a pronounced shoulder was observed on the low temperature side of the melting isotherm (Fig. 39a) at circa $115^{\circ} \mathrm{C}$. The exothermic peak observed in the first cooling cycle occurred at $104.6{ }^{\circ} \mathrm{C}$ and $104.7^{\circ} \mathrm{C}$ respectively (Fig. 39b). In the second heating cycle (Fig. 39c) the melting endotherm was narrower than that in the first cycle, $1 . e$. there was no evidence of a pronounced shoulder below the peak melting temperature which occurred at $122.6^{\circ} \mathrm{C}$ in one sample and 121.8 in the other. Upon cooling for the second time the samples exhibited an exothermic peak at $104^{\circ} .7^{\circ}$ and $104.6^{\circ} \mathrm{C}$ (Fig. 39d). No attempt was made to investigate the origins of the shoulder in the melting endotherm exhibited by the specimens in the first heating cycle. Melting and partial recrystalization and/or changes in contact between the specimen and the pan containing it as a result of the pronounced shrinkage which Iilm Fl urdergoes upon melting (see section $C$ of this report) may be among the possible causes of the shoulder. 
The main aspect of the results summarized above is that the peaks of the melting endotherm and the crystallization exotherm exhibited by the Fl film both occur at higher temperatures than the main polymer melting and crystalization peaks exhibited by films I, BI and II which occurred (see table 5, reference [1]) in the range of $105.5^{\circ} \mathrm{C}-106.8^{\circ} \mathrm{C}$ (melting) and $91.9^{\circ} \mathrm{C}-94.4^{\circ} \mathrm{C}$ (crystalization). These substantial differences between the Fl film and the other three films are consistent with the considerably lower degree of branching [see Appendix $B(a)$ above] in the constituent chains of film Fl.

\section{(e) Density: Crystallinity}

The density of two specimens of the Fl film was determined at $23 \pm 0.1^{\circ} \mathrm{C}$ using a water/ethanol density gradient column. Appropriate precautions were taken to deaerate the specimens prior to immersion in the columns. Within experimental error $( \pm 0.0005 \mathrm{~g} / \mathrm{cc})$ the density of both specimens was found to be the same, namely $0.9225 \mathrm{~g} / \mathrm{cc}$. The corresponding weight crystallinity was calculated to be $50.6 \%$ assuming, as was done previously [1] for the other films, that the densities of purely crystalline polyethylene (i.e. the unit cell density) and the density of entirely amorphous polyethylene are $1.000 \mathrm{~g} / \mathrm{cc}$ [13b] and $0.8547 \mathrm{~g} / \mathrm{cc}$ [23] respectively. In comparison, the densities of films I, III and Bl were in the range $46.2 \%-48.2 \%$.

\section{(f) Birefringence}

Assuming, on the basis of measurements provided by NASA, that the thickness of film Fl is $16.5 \mu \mathrm{m}(0.65 \mathrm{mil})$, its birefringence in the MT plane was measured in six randomly chosen regions in an area of about $20 \mathrm{~cm} x 20 \mathrm{~cm}$. The birefringence, $\Delta n=\left(n_{M}-n_{T}\right)$, where $n_{M}$ and $n_{T}$ are the refractive indices parallel to the $M$ and $T$ directions respectively was found to be +0.0016 in 
each case, i.e, $n_{M}>n_{T}$ in contrast with films I, III and BI. In the latter three films $\Delta \mathrm{n}$ was negative, i.e, $\mathrm{n}_{\mathrm{M}}<\mathrm{n}_{\mathrm{T}}$, and was in the range $(-0.0009)$ to $(-0.0019)$

(g) Tensile Tests on Film Fl at $23^{\circ} \mathrm{C}$

Tensile tests were conducted at $23^{\circ} \mathrm{C}$ on four specimens of the film $\mathrm{Fl}$, two cut paraliel to the machine direction and two cut parallel to the transverse direction. The procedures used were those described in Section $\mathrm{H}(\mathrm{i})$ in reference [1]. The results are summarized in Table 14. A comparison between the results for the film FI and those for films I, III, and $\mathrm{BI}$ (Table 21 (Reference [1]) reveals the following differences in behavior:

(i) The yield stress is somewhat higher in both the $M$ and $T$ directions for the film Fl than for the films I, III, or BI.

(ii) The stress at break is significantly higher for the film $F 1$ in the $M$ direction than for any of the other three films.

(iii) The strain at break is much greater for the film $I I$ in the $T$ direction than for any of the other three films.

An additional set of experiments was done to examine the creep to failure behavior of the film Fl under constant load conditions at $23^{\circ} \mathrm{C}$. Two creep tests were done, one using a tensile specimen cut parallel to the machine direction, and a second one cut parallel to the transverse direction. The experiment was performed as follows. Initially the specimen was subjected to a small constant load and the creep strain measured as a function of time until the creep curve reached a plateau (creep strain nearly constant with time). The appliec load was then increased by a small increment and the creep strain was again determined until a plateau value was reached. This procedure was repeated until failure occurred. The results 
were the following. The specimen cut parallel to the machine direction failed at a strain of about 3.5 under an applied stress of $30 \mathrm{MPa}$. On the other hand, the specimen cut along the transverse direction failed at a strain of 5.75 under an applied stress of $12.5 \mathrm{MPa}$. When compared to the results for the specimens stretched at a constant rate of clamp separation (Table 14), the large differences observed between the two sets of results would, as was the case for the remolded unoriented material (Section $B(4)$ ), indicate that considerable material was pulled out of the clamps during the constant rate of clamp separation experiment. 
References

1. Khoury, F., Crissman, J. M., Fanconi, B. M., Wagner, H. L., Bolz, L. H., Harding, C. A., NBSIR 84-2989 (NASA), Issued 1985.

2. Volungis, R. J., and Stein, R. S., J. Polymer Sci. 20, 199 (1956).

3. Holmes, D. R., and Palmer, R. P., J. Polymer Sci. 31, 345 (1958).

4. Aggarwal, S. L., Tilley, G. P., and Sweeting, O. J., J. Appl. Poiymer Sci, 1, 91 (1959, J. Polymer Sci. 51, 551 (1961).

5. Krigbaum, W. R. and Roe, R.-J., J. Chem. Phys. 41, 737 (1964).

6. Lindenmeyer, P. H. and Lustig, S., J. Appl. Polymer Sci., 9, 227 (1965).

7. Keller, A. and Machin, M. J., J. Macromol. Sci. Bl, 41 (1967).

8. Desper, C.R., J.Appl. Polymer Sci. 13, 169 (1969).

9. Maddams, W. F. and Preedy, J. E., J. Appl. Polymer Sci. 22, 2721 (1978); iciem 22, 2739 (1978); idem 22, 2761 (1978).

10. White, J. L. and Spruieli, J. E., Polymer Eng. Sci. 21, 859 (1981).

11. Choi, K.-J., Spruiell, J. E., and White, J. L., J. Polymer Sci. Polymer Phys. Ed. 20, 27 (1982).

12. Among the difficulties mentioned by Lindenyer and Lustig, as well as Keller and Machin is that, due to the intrinsically very low intensity of the (002) reflections, it is often not possible to obtain well resolved (002) pole figures. This problem was also encountered in the early stages of the present study and was not explored any further.

13. Bunn, C.W., (a) Chemical Crystallography, p. 233, Oxford University Press (1949) and (b) Trans. Faraday Soc. 39, 482 (1939).

14. Khoury, F. and Passaglia, E., in "Treatise on Solid State Chemistry," Vol. 3, (Hannay, B. N. Editor), Chapter 6, Plenum Press N.Y. (1976).

15. Bassett, D. C., "Principles of Polymer Morphology", Cambridge University Press, N.Y. (1981).

16. Vonk, C. G., in "Small Angle X-ray Scattering", (Gleiter, 0 . and Kratky, 0., Editors), Chapt. 13, p. 436, Academic Press, N.Y. (1982).

17. Bingham, C., "Distributions on the Sphere and the Projective Plane", PhD Thesis, Yale University (1964). 
18. Hardia, K. V., Statistics of Directional Data, Academic Press, N.Y., pp. 212-247 (1972).

19. Rueda, D. R., Balta'-Calleja, F. H., and Hidalzo, A., Spectrochemica Acta 35A, 847 (1979).

20. Drott, E. E., and Mendelson, R. A., J. Polymer Sci., Part A-2, 8 , 559 (1973).

21. Wagner, H. L. and McCrackin, E. L., J. Appl. Polymer Sci., 21, 2833 (1977).

22. Zimm, B. H., and Stockmayer, W. H., J. Chem. Phys. 17, 1301 (1949).

23. Davis, G. T., Eby, R. K., J. Appl. Phys. 44, 4274 (1973).

24. Stein, R. S. and Wilkes, G. L., in "Structure and Properties of oriented Polymers", Chap. 3, (I. M. Ward, Editor), Wiley, N.Y. (1975).

25. It is commonly assumed, to a good approximation, that the refractive indices of an ideal orthorombic polyethylene crystal are the same as in single crystals of normal paraffins, and that $n_{a}=1.514, n_{b}=1.519$, and $\mathrm{n}_{\mathrm{C}}=1.575$, Bunn, C. W. and Danbeny, R. De P., Trans. Faraday Soc. $\underline{50}$, 1173 (1954).

26. Hoffman, J. D., Davis, G. T., and Lauritzen Jr., J. I. in "Treatise on Solid State Chemistry", Vol. 3, (Hannay, B. N., Editor), Chapter 7 (see Fig. 14), Plenum Press, N.Y. (1975). 
TABLE 1

Comparison between Biaxial Deformation under Inflation Experiments and Elongation at Break in Uniaxial Extension Experiments at $23^{\circ} \mathrm{C}$. $R$ is the Ratio of the Strain in the Transverse Direction to that in the Machine Direction.

$$
\begin{aligned}
& \text { Film } \quad R_{B} \quad R_{u} \\
& \begin{array}{lll}
I & 0.94 & 0.98
\end{array} \\
& \begin{array}{lll}
B 1 & 1.06 & 0.96
\end{array} \\
& \begin{array}{lll}
\text { III } & 1.54 & 1.40
\end{array} \\
& \begin{array}{lll}
E 1 & 2.20 & 1.80
\end{array}
\end{aligned}
$$


TABLE 2

Range of Values of True Stress (a) During Inflation of Films at Three Levels of Applied Pressure at $23^{\circ} \mathrm{C}$

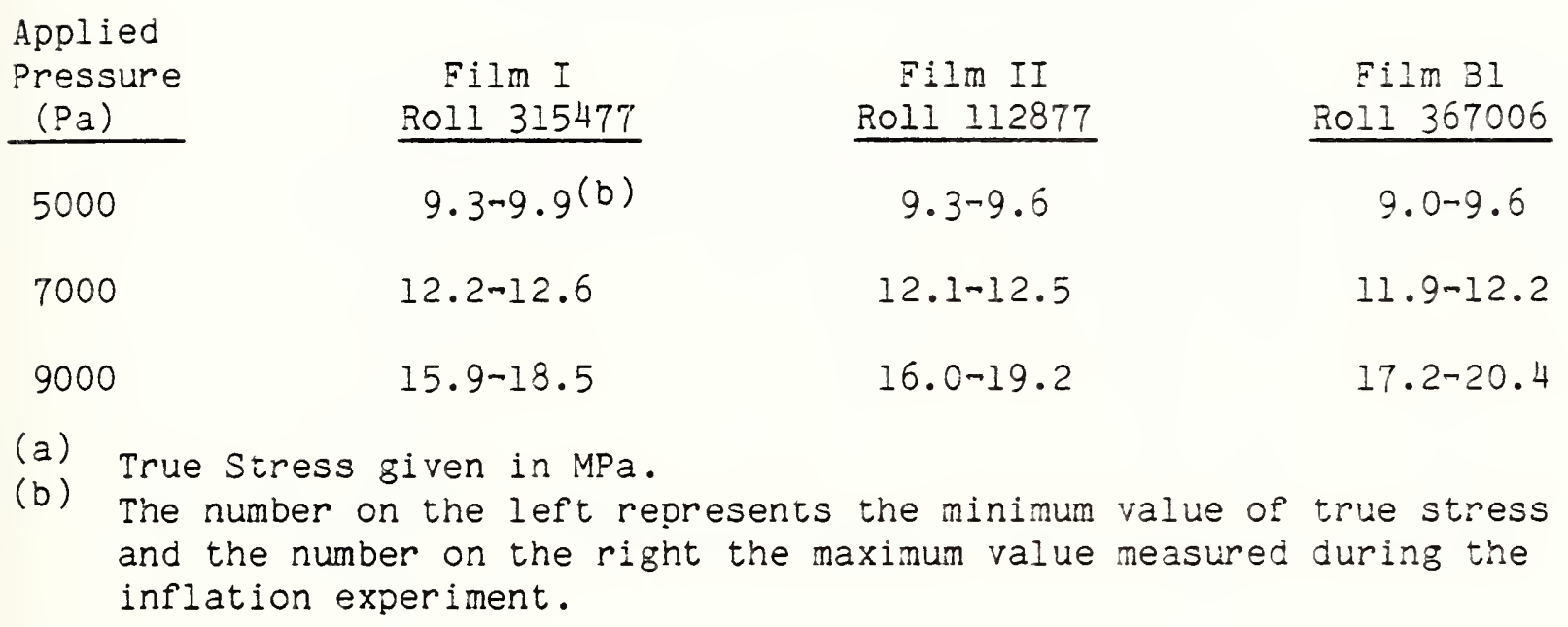


TABLE 3

$\frac{\text { Range of Values of True Stress (a) for Each Film at }}{\text { Five Levels of Applied Pressure at }-73^{\circ} \mathrm{C}}$

Five Levels of Applied Pressure at $-73^{\circ} \mathrm{C}$

Applied

Pressure

$(\mathrm{kPa})$

24

27

30

33

34
Film I Rol1 315477

Sample 1

$42 \cdot 3-42 \cdot 9^{(b)}$

$46.7-46.8$

$52 \cdot 9-53 \cdot 0$

$60.6-84.4$

(c)
Film III

Rol1 112877

Sample 1

$42 \cdot 5-42.7$

$46.9-46.9$

$52 \cdot 6-52 \cdot 6$

$58 \cdot 9-60.0$

(c)
Film 31 Rol1 367006

Sample 1

$42.5-42.9$

$46.9-47.1$

$52.0-52.0$

$57.9-59.2$

$>80$

(a) True stress given in MPa.

(b) The number on the left represents the minimum value of true stress and the number on the right the maximum value measured during the inflation experiment.

(c) Specimen failed before 2 minutes. 
TABLE 4

$\frac{\text { Summary of Tensile Tests at } 23^{\circ} \mathrm{C} \text { on }}{\text { Unoriented Specimens Remolded From Balloon Film }}$

\begin{tabular}{|c|c|c|c|c|c|c|}
\hline Film & $\begin{array}{c}\text { Roll } \\
\text { Number } \\
\end{array}$ & $\begin{array}{c}\text { Specimen } \\
\text { Number } \\
\end{array}$ & $\begin{array}{l}\text { Yield } \\
\text { Stress } \\
\text { (MPa) } \\
\end{array}$ & $\begin{array}{c}\text { Strain } \\
\text { at } \\
\text { Yield }\end{array}$ & $\begin{array}{l}\text { Tensile } \\
\text { Strength } \\
\text { (MPa) }\end{array}$ & $\begin{array}{c}\text { Strain } \\
\text { at } \\
\text { Break (b) }\end{array}$ \\
\hline I & 315477 & 1 & 12.0 & 0.13 & - & - \\
\hline I & 315477 & 2 & 11.8 & 0.14 & - & - \\
\hline I & 315477 & 3 & 11.6 & 0.14 & - & - \\
\hline I & 315477 & 4 & - & - & 17.8 & 13.6 \\
\hline I & 315477 & 5 & - & - & 14.7 & 10.5 \\
\hline I & 315477 & 6 & - & - & 17.9 & 14.1 \\
\hline I & 315477 & 7 & - & - & 18.2 & 14.1 \\
\hline III & 112877 & 8 & 11.4 & 0.14 & - & - \\
\hline III & 112877 & 9 & 11.3 & 0.12 & - & - \\
\hline III & 112877 & 10 & 11.0 & 0.14 & - & - \\
\hline III & 112877 & 11 & - & - & 20.2 & 15.8 \\
\hline III & 112877 & 12 & - & - & 15.6 & 14.7 \\
\hline III & 112877 & 13 & - & - & 18.8 & 10.5 \\
\hline III & 112877 & 14 & - & - & 19.2 & 14.5 \\
\hline III & 112877 & 15 & - & - & 19.4 & 14.3 \\
\hline $\mathrm{BI}$ & 367006 & 16 & 12.0 & 0.12 & - & - \\
\hline $\mathrm{BI}$ & 367006 & 17 & 12.2 & 0.13 & - & - \\
\hline$B 1$ & 367006 & 18 & 11.8 & 0.13 & - & $\sim$ \\
\hline $\mathrm{Bl}$ & 367006 & 19 & 12.0 & - & 13.7 & 9.25 \\
\hline$B I$ & 367006 & 20 & 11.7 & - & 14.2 & 10.9 \\
\hline $\mathrm{BI}$ & 367006 & 21 & 11.7 & - & 16.6 & 14.0 \\
\hline $\mathrm{Bl}$ & 367006 & 22 & 11.7 & - & 14.7 & 11.2 \\
\hline $\mathrm{BI}$ & 367006 & 23 & 11.6 & - & 17.4 & 15.1 \\
\hline
\end{tabular}

(a) Strain rate $991 \stackrel{0}{\circ}$ per minute.

(b) The values shown in this column are based on the clamp separation at failure. They are, therefore, an over estimate of the true elongation at break since a considerable amount of material is pulled out of the clamps (see text). 
TABLE 5

$\frac{\text { Average Values of Tensile Properties of }}{\text { Remolded Balloon Film at } 23^{\circ} \mathrm{C} \text {, as }}$
$\frac{\text { Determined from Constant Rate of Clamp }}{\text { Separation Experiments }}$

\begin{tabular}{|c|c|c|c|c|c|}
\hline Film & $\begin{array}{c}\text { Roll } \\
\text { Number } \\
\end{array}$ & $\begin{array}{l}\text { Average } \\
\text { Yield } \\
\text { Stress } \\
\text { (MPa) } \\
\end{array}$ & $\begin{array}{l}\text { Average } \\
\text { Strain } \\
\text { at Yield } \\
\end{array}$ & $\begin{array}{l}\text { Average } \\
\text { Tensile } \\
\text { Strength } \\
\text { (MPa) } \\
\end{array}$ & $\begin{array}{c}\text { Average } \\
\text { Strain } \\
\text { at Break(a) }\end{array}$ \\
\hline$I$ & 315477 & 11.8 & 0.14 & 17.2 & 13.1 \\
\hline III & 112877 & 11.2 & 0.13 & 18.6 & 14.0 \\
\hline $\mathrm{Bl}$ & 367006 & 11.8 & 0.13 & 15.3 & 12.1 \\
\hline
\end{tabular}

(a) The values shown in this column are based on the clamp separation at failure. They are, therefore, an over estimate of the true elongation at break since a considerable amount of material is pulied out of the clamps (see text). 
TABLE 6

Time to Failure under Creep for Specimens of Remolded Balloon Film at $23^{\circ} \mathrm{C}$

Applied

Stress

Time to Failure (minutes)

(MPa)

Film I Film III Eilm BI

12.5

$1.6 \times 10^{4}$

$6.5 \times 10^{2}$

$2.0 \times 10^{3}$

15.0

$1.0 \times 10^{3}$

$2.4 \times 10^{2}$

$2.0 \times 10^{2}$ 
TABLE 7

Maximum Strain Under Creep for

Specimens of Remolded Balloon Film at $23^{\circ} \mathrm{C}$

Applied

Stress

(MPa)

Film III

Maximum Strain

10.0

$3.83^{(a)}$

FiIm I

Film BI

12.5

4.71

$4.10(a)$

$4.94(a)$

15.0

5.39

5.16

5.85

15.0

$5.75(b)$

6.55

(a) Failure did not occur. The value shown represents the creep strain after $10^{4}$ minutes.

(b) Three specimens of film I tested at $15 \mathrm{MPa}$ pailed prior to one minute under load. 
TABLE 8

Film Shrinkage at $140^{\circ} \mathrm{C}^{*}$

\begin{tabular}{|c|c|c|c|c|c|}
\hline Film & $\begin{array}{c}\text { Roll } \\
\text { Number } \\
\end{array}$ & $\begin{array}{c}\text { Gore } \\
\text { Number }\end{array}$ & $\underline{R_{M}}$ & $\stackrel{\mathrm{R}_{\mathrm{I}}}{-}$ & $\begin{array}{l}\text { Film Thickness } \\
\text { (mil) }\end{array}$ \\
\hline III & 111958 & 121 & 3.97 & 2.71 & 0.8 \\
\hline III & 111958 & 121 & 4.11 & 2.60 & \\
\hline III & 112578 & 101 & 4.16 & 2.61 & 0.8 \\
\hline III & 112578 & 101 & 4.07 & 2.56 & \\
\hline III & 112618 & 130 & 4.51 & 2.79 & 0.8 \\
\hline III & 112618 & 130 & 4.62 & 2.79 & \\
\hline III & 112673 & - & 4.10 & 2.35 & 1.0 \\
\hline III & 112673 & - & 4.29 & 2.35 & Cap \\
\hline III & 112674 & - & 4.00 & 2.31 & 1.0 \\
\hline III & 112674 & - & 4.14 & 2.33 & Cap \\
\hline III & 112861 & 173 & 4.32 & 2.82 & 0.8 \\
\hline III & 112861 & 173 & 4.00 & 2.83 & \\
\hline III & 112877 & - & 4.45 & 2.19 & 0.8 \\
\hline III & 112877 & - & 5.00 & 2.33 & \\
\hline III & 112877 & - & 4.65 & 2.65 & 0.8 \\
\hline III & 112877 & 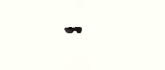 & 4.52 & 2.67 & end of roll \\
\hline III & 112880 & 142 & 4.80 & 2.87 & 0.8 \\
\hline III & 112880 & 142 & 5.00 & 2.99 & \\
\hline III & 112881 & - & 4.38 & 2.42 & 0.8 \\
\hline III & 112881 & - & 4.48 & 2.40 & \\
\hline III & 112882 & - & 4.76 & 2.32 & 0.8 \\
\hline III & 112882 & - & 4.80 & 2.27 & \\
\hline III & 112884 & - & 4.65 & 2.33 & 1.0 \\
\hline III & 112884 & - & 4.74 & 2.42 & \\
\hline IV & 311071 & - & 4.22 & 2.45 & 0.8 \\
\hline IV & 311071 & - & 4.12 & 2.39 & \\
\hline IV & 311597 & - & 4.59 & 2.21 & 0.7 \\
\hline IV & 311597 & - & 4.96 & 2.35 & \\
\hline IV & 311926 & - & 4.80 & 2.50 & 0.8 \\
\hline IV & 311926 & - & 4.72 & 2.40 & \\
\hline
\end{tabular}


Table 8 (cont'd)

\begin{tabular}{|c|c|c|c|c|c|c|}
\hline Film & $\begin{array}{c}\text { Roll } \\
\text { Number }\end{array}$ & $\begin{array}{c}\text { Gore } \\
\text { Number }\end{array}$ & $\mathrm{R}_{\mathrm{M}}$ & $\mathrm{R}_{\mathrm{T}}$ & Film & $\begin{array}{l}\text { Thickness } \\
\text { (mil) } \\
\end{array}$ \\
\hline IV & 312445 & - & 5.21 & 2.29 & \multirow{2}{*}{\multicolumn{2}{|c|}{0.7}} \\
\hline IV & 312445 & - & 4.76 & 2.59 & & \\
\hline$I I$ & 313865 & 53 & 5.00 & 2.11 & \multirow{3}{*}{\multicolumn{2}{|c|}{0.8}} \\
\hline II & 313865 & 53 & 4.80 & 2.50 & & \\
\hline II & 313865 & 53 & 4.72 & 2.59 & & \\
\hline II & 313890 & 137 & 5.26 & 2.49 & & \multirow[t]{2}{*}{0.8} \\
\hline II & 313890 & 137. & 5.17 & 2.53 & & \\
\hline II & 313915 & 22 & 4.44 & 2.38 & & \multirow[t]{2}{*}{0.8} \\
\hline II & 313915 & 22 & 4.80 & 2.47 & & \\
\hline I & 315420 & - & 4.72 & 2.67 & & \multirow[t]{2}{*}{0.7} \\
\hline I & 315420 & - & 4.80 & 2.65 & & \\
\hline I & 315441 & - & 4.00 & 3.00 & & \multirow[t]{3}{*}{0.7} \\
\hline I & 315441 & - & 4.27 & 3.04 & & \\
\hline I & 315441 & - & 4.32 & 2.95 & & \\
\hline I & 315453 & - & 4.15 & 2.64 & & \multirow[t]{3}{*}{0.7} \\
\hline I & 315453 & - & 4.12 & 2.70 & & \\
\hline I & 315453 & - & 4.29 & 2.59 & & \\
\hline I & 315477 & - & 4.15 & 2.95 & & \multirow[t]{2}{*}{0.7} \\
\hline I & 315477 & - & 4.07 & 3.06 & & \\
\hline B1 & 367006 & - & 4.00 & 3.16 & & \multirow[t]{3}{*}{0.8} \\
\hline B1 & 367006 & - & 4.29 & 3.15 & & \\
\hline B1 & 367006 & - & 4.38 & 3.00 & & \\
\hline E1 & - & - & 10.8 & 0.75 & & \multirow[t]{6}{*}{0.7} \\
\hline F1 & - & - & 9.8 & 0.71 & & \\
\hline F1 & - & - & 12.2 & 0.79 & & \\
\hline E1 & - & - & 13.2 & 0.69 & & \\
\hline E1 & - & - & 12.0 & 0.70 & & \\
\hline F1 & - & - & 13.3 & 0.80 & & \\
\hline
\end{tabular}


TABLE 9

Summary of Shrinkage Measurements*

$\begin{array}{llll}\text { Film } & \frac{\left\langle R_{\mathrm{M}}\right\rangle^{* *}}{} & \underline{\left\langle\mathrm{R}_{\mathrm{T}}\right\rangle^{* *}} & \left\langle\mathrm{R}_{\mathrm{M}}\right\rangle \mid\left\langle\mathrm{R}_{\mathrm{T}}\right\rangle \\ \text { III } & 4.46 & 2.61 & 1.71 \\ \text { IV } & 4.69 & 2.40 & 1.95 \\ \text { II } & 4.88 & 2.44 & 2.00 \\ I & 4.29 & 2.84 & 1.51 \\ \text { B1 } & 4.22 & 3.11 & 1.36 \\ \text { F1 } & 11.9 & 0.74 & 15.1 \\ \text { Cap material excluded } & & & \\ \text { Average values } & & & \end{array}$


TABLE 10

Ratio $I(\max ) / I(\min ) *$ for the various pole Eigures

$\begin{array}{cccc}\text { FiIm } & (200) & (020) & (110) \\ \text { I } & 6.8 & 3.9 & 4.5 \\ \text { III } & 5.4 & 3.9 & 3.9 \\ \text { B1 } & 4.9 & 4.4 & 3.2 \\ \text { E1 } & 7.7 & 4.5 & 8.3\end{array}$

* I(max) and $I(\min )$ are respectively the highest and lowest pole intensities in the data recorded for each pole figure. 
Preferred Orientation Characteristics of the $a, b$ and $c$ Crystallopraphic Axes Relative to the $M, T$ and $N$ Directions.

Trancrystalline Orientation: b-axis parallel to $\mathrm{N}$, a and $\underline{c}$ axes 1 ie in the MT plane and are randomly oriented in that plane.

Row(ac) Orientation: $\underset{\text { and }}{c}$ axes preferentially parallel to $M$, b-axis lies in the NT plane and is randomly oriented in that plane.

Row(a) Orientation: amaxis parallel to $M, \underline{b}$ and $\underline{c}$ axes lie in the NT plane and are randomly oriented in that plane. 
TABLE 12

Bingham Distribution Parameters $\left(K_{1}, K_{2}\right)$

(200) pole

$\underline{\text { Film }}$

B1

III

I

F1

Transcrystalline model

Row (ac) and Row (a)
$\mathrm{K}_{1} \quad \mathrm{k}_{2}$

$-0.5 \quad-4.0$

$-1.7 \quad-4.7$

$-1.8 \quad-4.1$

$-3.2-3.8$

$0 \quad-|K|$

$-|K|-|K|$
(020) pole

$K_{1} \quad K_{2}$

$5.5 \quad 10.6$

$7.3 \quad 9.5$

$9.1 \quad 11.9$

$12.9 \quad 12.4$

$0\left|\mathrm{~K}^{\prime}\right|$

$\left|K^{\prime}\right| \quad\left|K^{\prime}\right|$ 
TABLE 13

Apparent Molecular Weights and Intrinsic Viscosicy Measurements

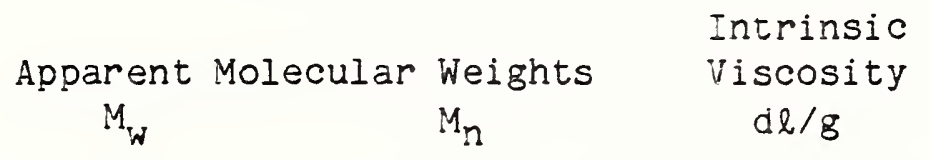

Film I

Series A

Series B

Series $C$

216,000

22,300

1.23

202,000

23,100

208,000

21,600

Film III

Series A

Series $B$

Series C

253,000

20,900

1.27

255,000

30,100

240,000

25,000

Film B1

Series B

154,600

22,400

1.13

Film F1

Series C

129,000

26,000

1.59

Series A and Series B data are from reference [1]. 
TABLE 14

Tensile Properties of the F1 Balloon Film at $23^{\circ} \mathrm{C}$

\begin{tabular}{|c|c|c|c|}
\hline \multirow[b]{2}{*}{ Property } & \multicolumn{2}{|c|}{ Direction } & \multirow[b]{2}{*}{$\mathrm{M} / \mathrm{T}$} \\
\hline & Machine & Transverse & \\
\hline \multirow{2}{*}{$\begin{array}{l}\text { Yield Stress } \\
\text { (MPa) }\end{array}$} & 16.6 & 14.5 & \multirow[t]{2}{*}{1.12} \\
\hline & 16.6 & 15.1 & \\
\hline \multirow[t]{2}{*}{ Strain at Yield } & 0.23 & 0.15 & \multirow[t]{2}{*}{1.37} \\
\hline & 0.18 & 0.15 & \\
\hline \multirow{2}{*}{$\begin{array}{l}\text { Stress at Break } \\
\text { (MPa) }\end{array}$} & 59.0 & 26.8 & \multirow[t]{2}{*}{1.82} \\
\hline & 35.6 & 25.2 & \\
\hline \multirow[t]{2}{*}{ Strajn at Break } & 6.70 & 10.52 & \multirow[t]{2}{*}{0.55} \\
\hline & 4.95 & 10.52 & \\
\hline
\end{tabular}


TABLE $15^{*}$

Summary of Some of the Characteristics of Films I, III, BI and FI

I

III

31

F1

Mol.wt. Mw

$202 \mathrm{~K}-216 \mathrm{~K}$

$240 K-255 K$

$148 \mathrm{~K}-155 \mathrm{~K}$

$129 \mathrm{~K}$

$M n$

$21 \cdot 6 \mathrm{~K}-23 \cdot 1 \mathrm{~K}$

$25 K-30.1 K$

$21.5 K-22.4 K$

$26 \mathrm{~K}$

$\mathrm{CH}_{3} / 100 \mathrm{C}$

2.1

2.1

2.1

0.48

Intr. Visc.

1.23

1.27

1.13

1.59

(de/g

Density ( $g / c c)$

$0.916(5)$

$0.916(3)$

$0.919(0)$

$0.922(5)$

$0.917(0)$

$0.917(0)$

$0.919(0)$

$0.922(5)$

Crystallinity

Wt. ( $\left(\begin{array}{l}0 \\ 0\end{array}\right)$

$46.6 \%$

$46.5 \%$

$48.2 \%$

$50.6 \%$

Melt Peak ${ }^{\circ} \mathrm{C}$

106.8

106.2

105.5 .

122.5

DSC heating rate

$20^{\circ} \mathrm{C} / \mathrm{min}$.

Shrink.Ratio $\mathrm{M} / \mathrm{T}$

1.51

1.87

1.36

16.1

Strain at

4.62

4.45

4.91

5.85

Break $\left(23^{\circ} \mathrm{C}\right) \quad T$

4.54

6.24

4.70

10.50

Strain at $M$

3.19

3.27

2.63

4.34

3.82

$4.55^{* *}$

2.01

Birefringence

$-0.0018$

$-0.0011$

$-0.0017$

$+0.0017$

$\left(\mathrm{M}_{\mathrm{M}}-\mathrm{N}_{\mathrm{T}}\right)$

* Most of the data on films I, II and BI were reported in reference [1] NSBF data 
。 
Dentaldam Rubber

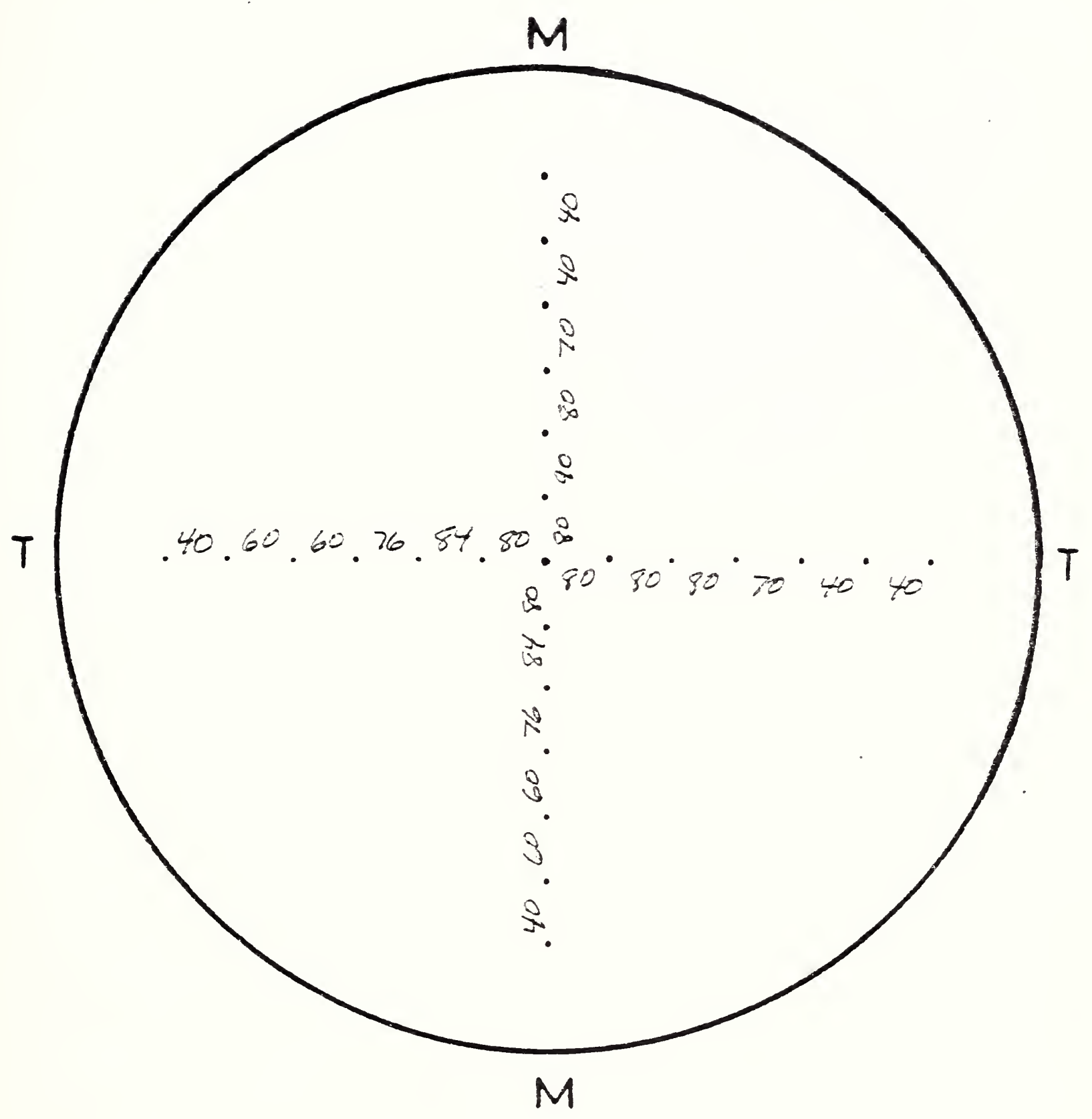

Fig. I. Deformation under inflation at $23^{\circ} \mathrm{C}$ of a thin sheet of dentaldam rubber. The numbers indicate the jercent strain between each set of marks. 

CAT. I ROLL $3: 5$

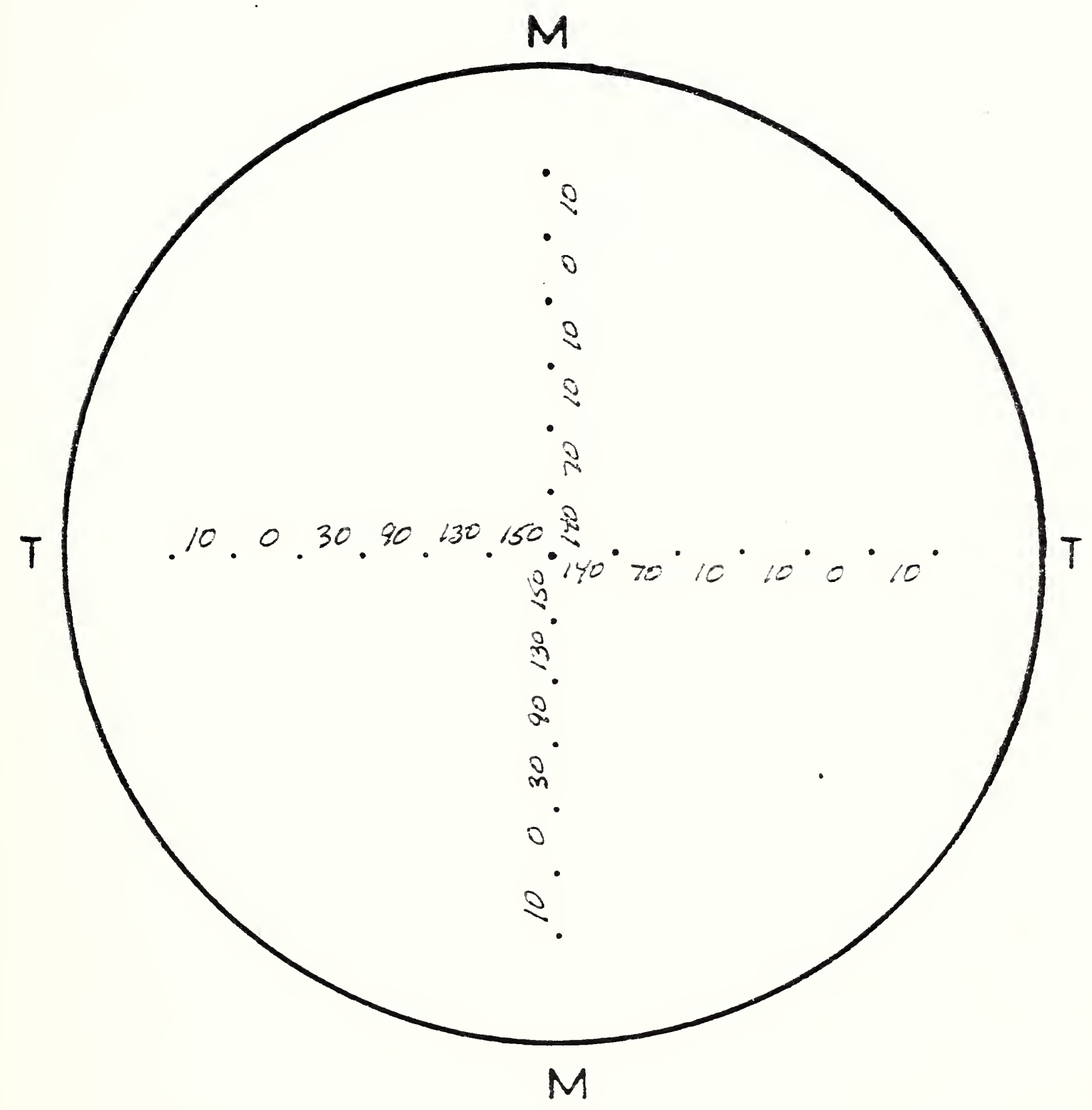

Fig. 2. Deformation under inflation at $23^{\circ} \mathrm{C}$ of the Cat. I film inflated to a condition just short of failure. The numbers indicate the percent strain between each set. of marks. 



\section{CAT. 31 ROLL 367006}

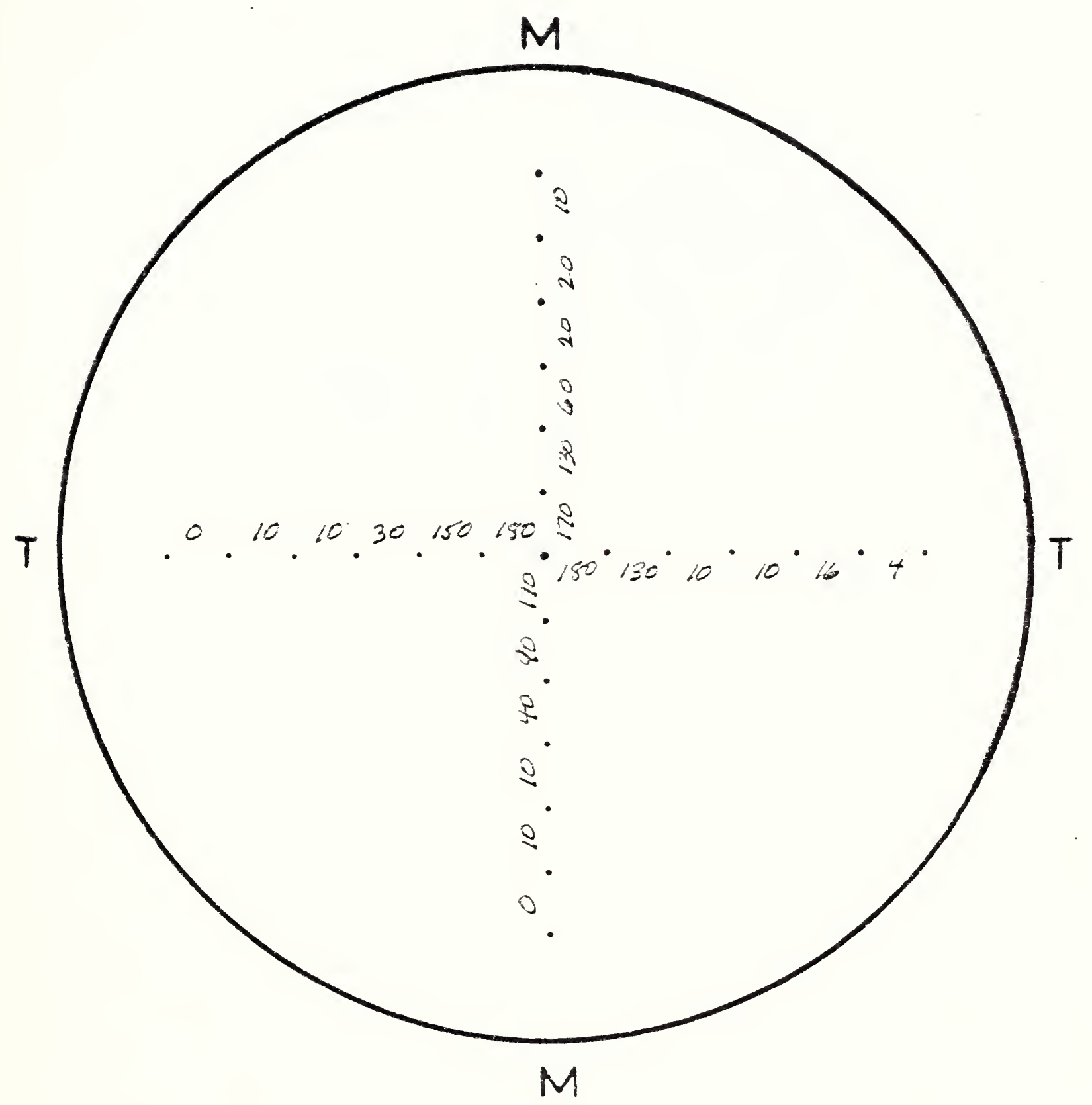

Eig. 3. Deformation under inilation at $23^{\circ} \mathrm{C}$ of the Cat. 31 film inflated to a condition just short of failure. The numbers indicate the percent strain between each set of marks. 
CAT. III ROLL HEE:

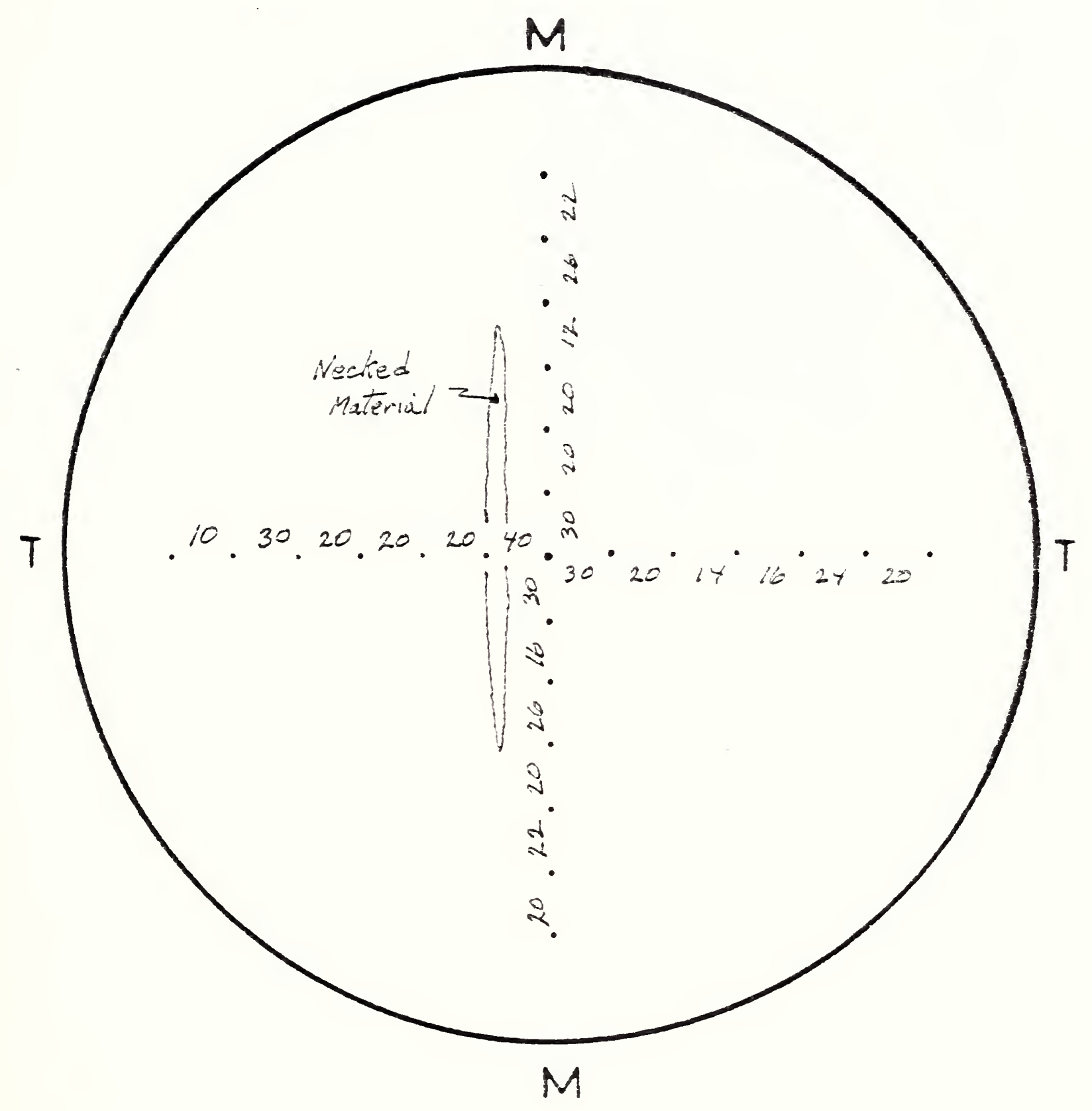

Tig. 4a. Deformation under inflation at $23^{\circ} \mathrm{C}$ of the Cat. III film. The film was inflated to the point where necking first occurred. 



\section{CAT. III ROLL "WE"?}

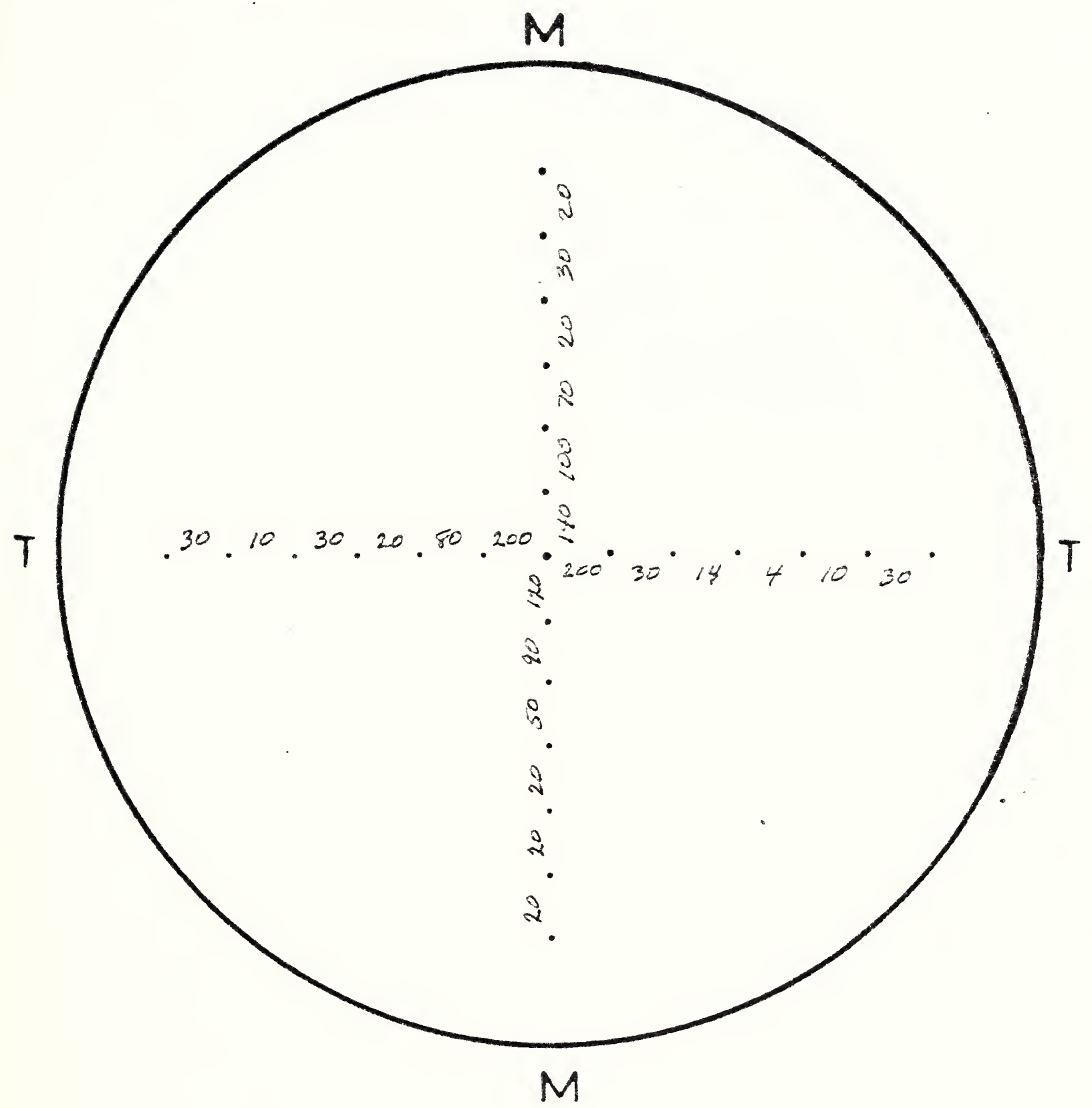

Fig. 4b. Deformation under inflation at $23^{\circ} \mathrm{C}$ of the Cat. III film inflated to a condition just short of failure. At this stage of inflation several necks were visible in the region nearest the pole. 

CAT. FI ROLL

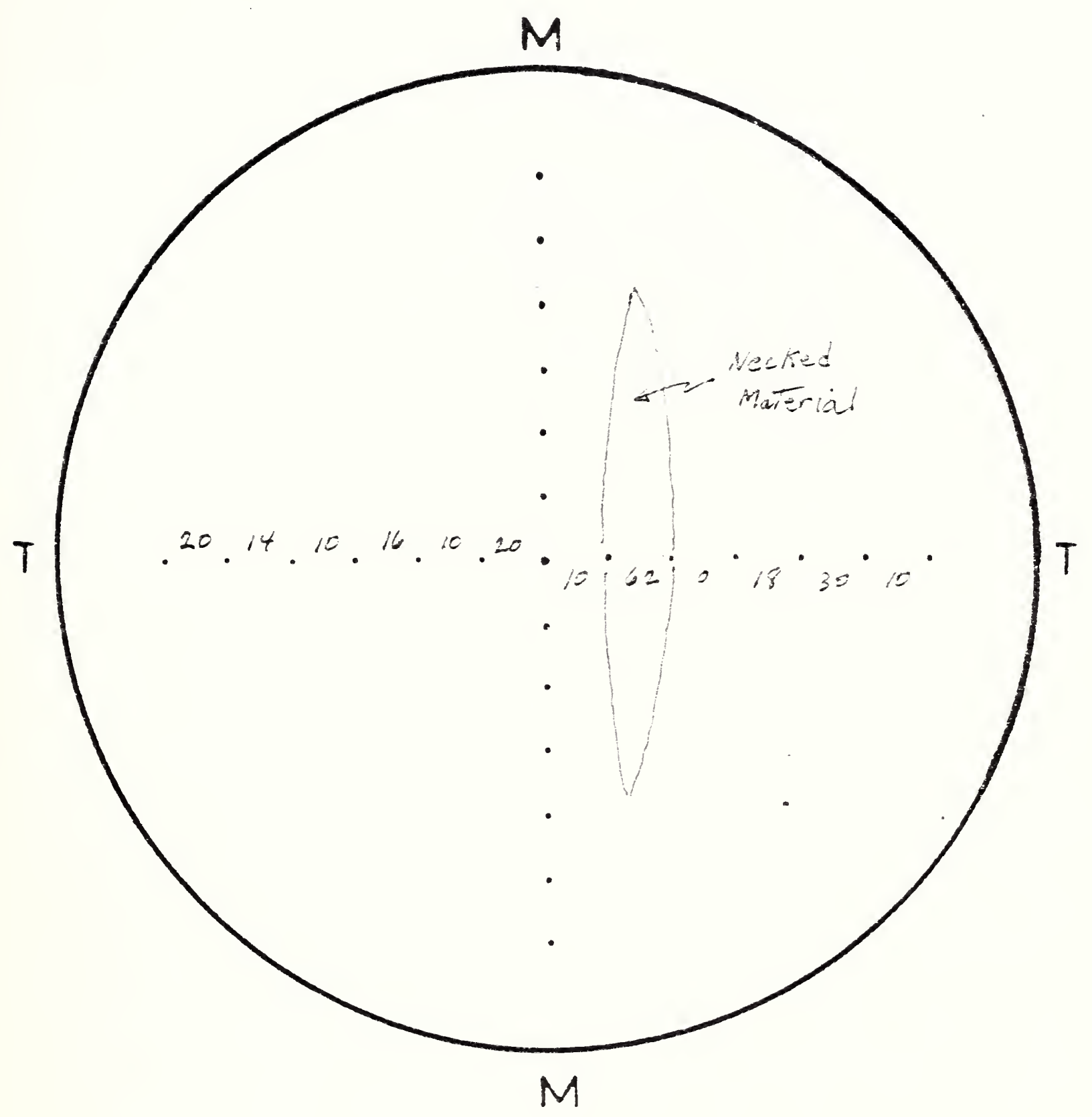

Fig. 5a. Deformation under inflation at $23^{\circ} \mathrm{C}$ of Cat. Fl film. The film was inflated to the point where necking first occurred. Note that the neck did not occur in the region nearest the pole. 

CAT. FI ROLL

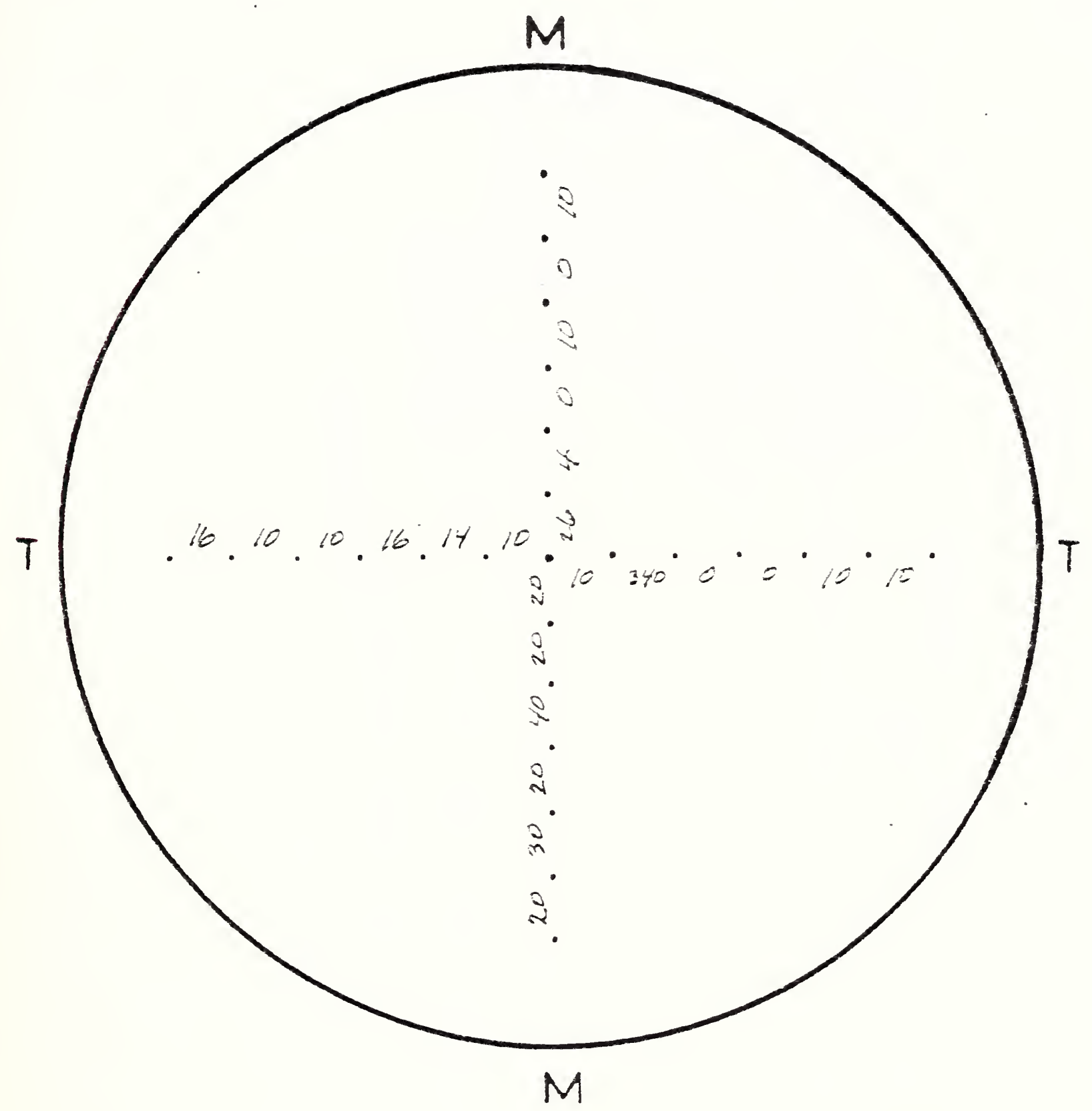

Fig. 5b. Deformation under inflation at $23^{\circ} \mathrm{C}$ of Cat. Fl film inflated to a condition just short of fallure. Note that only one neck has appeared and nearly all the deformation in the transverse direction has occurred in the region between the second and third mark on the right hand branch. 



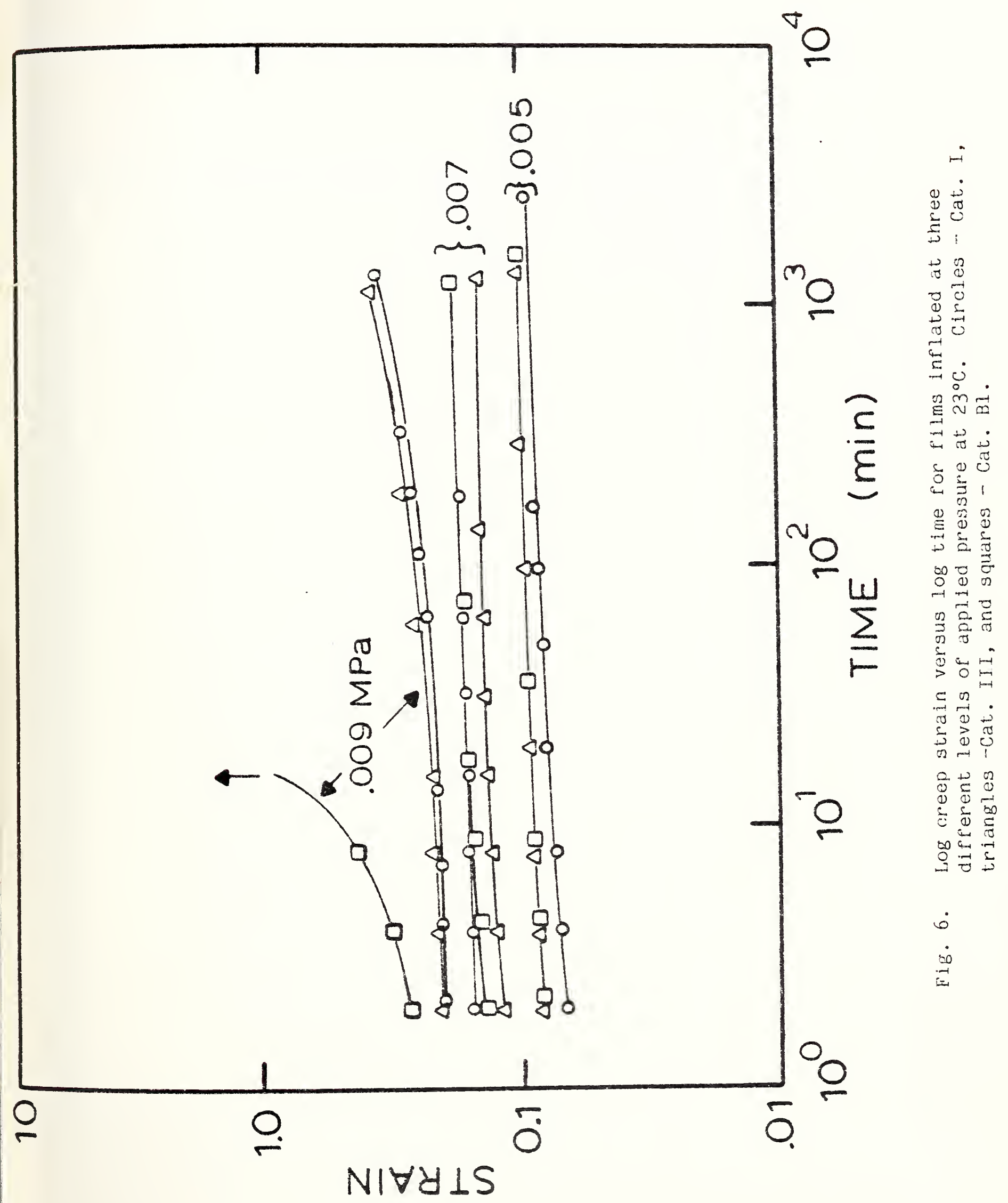





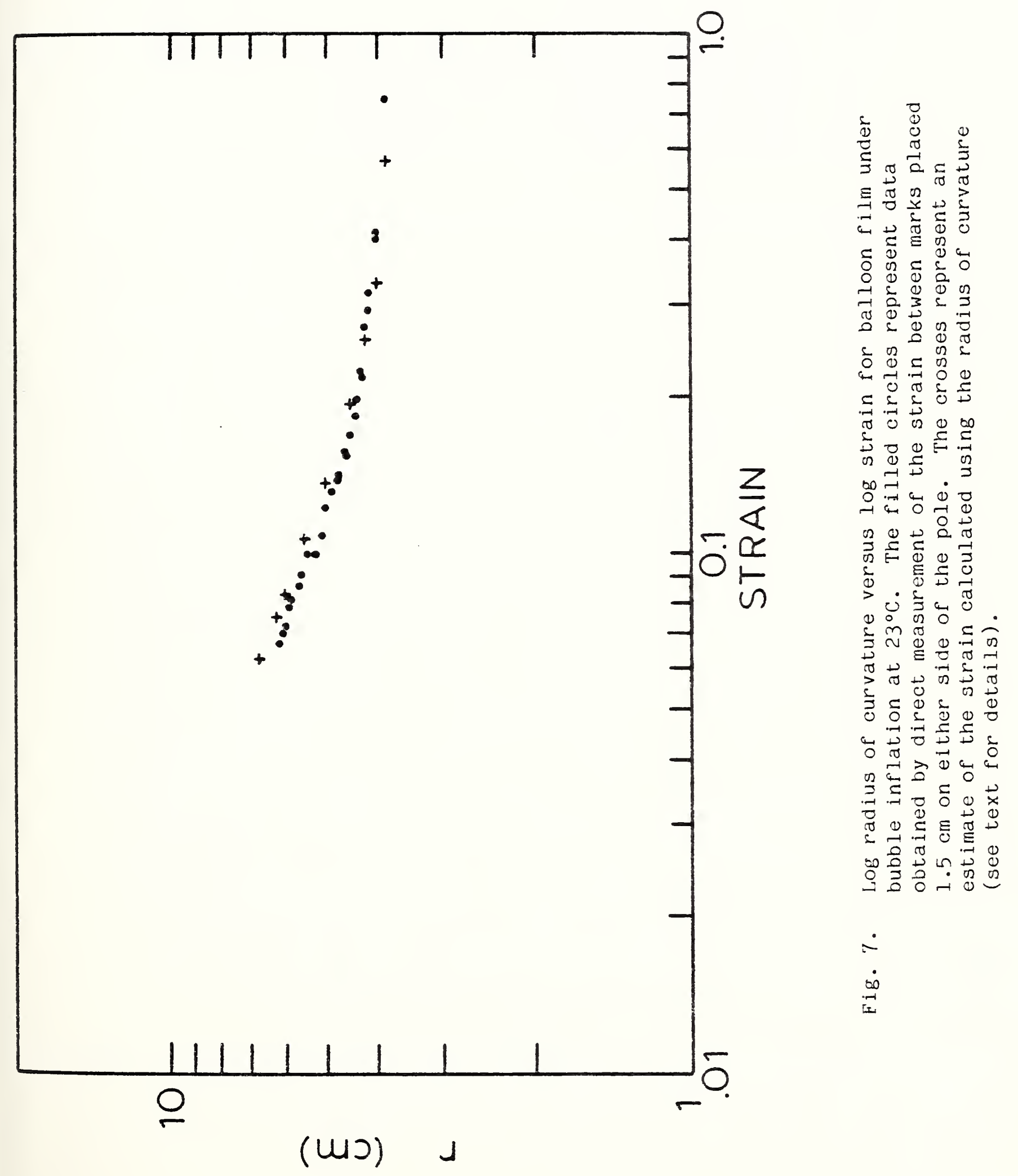




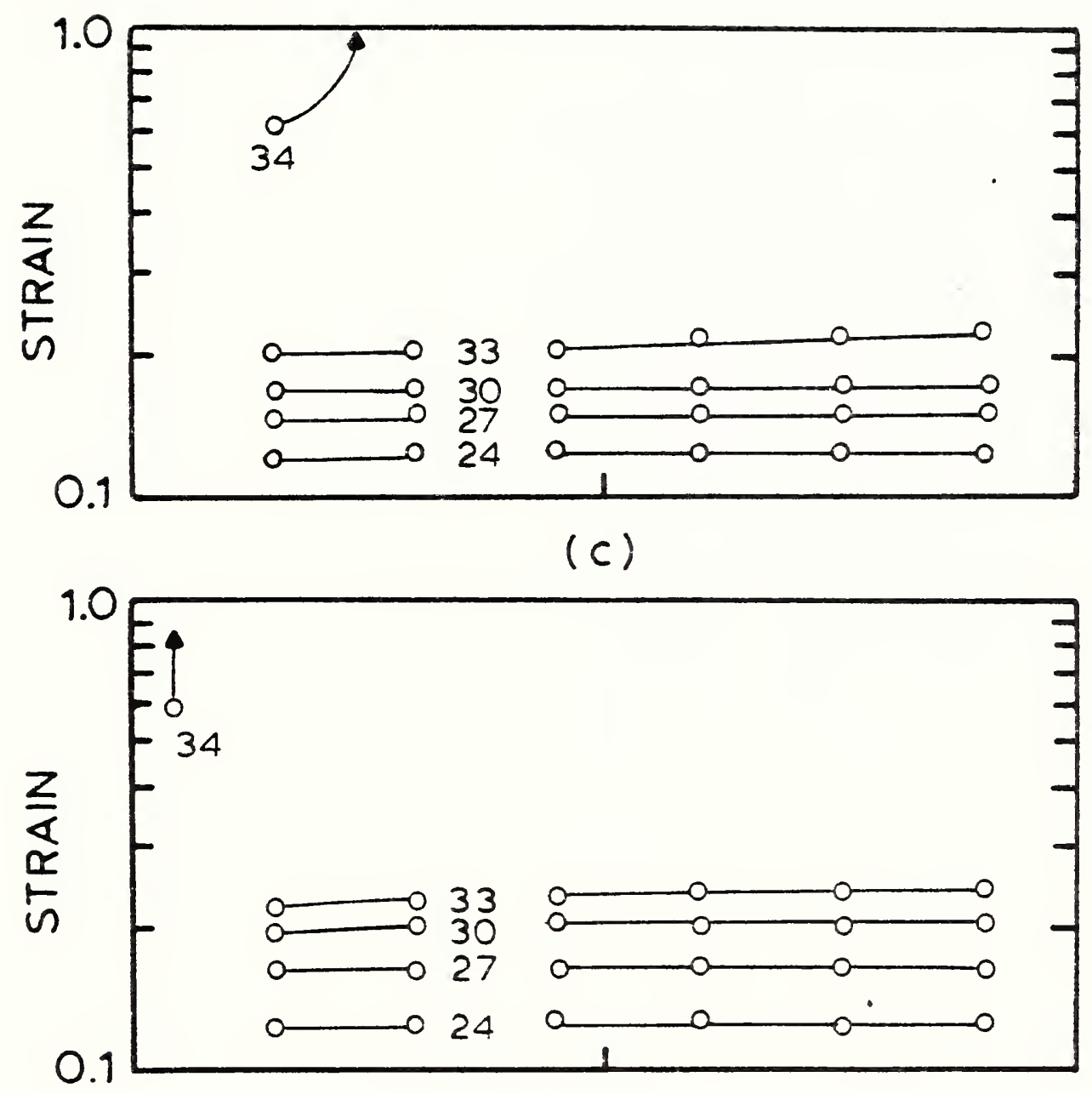

(b)

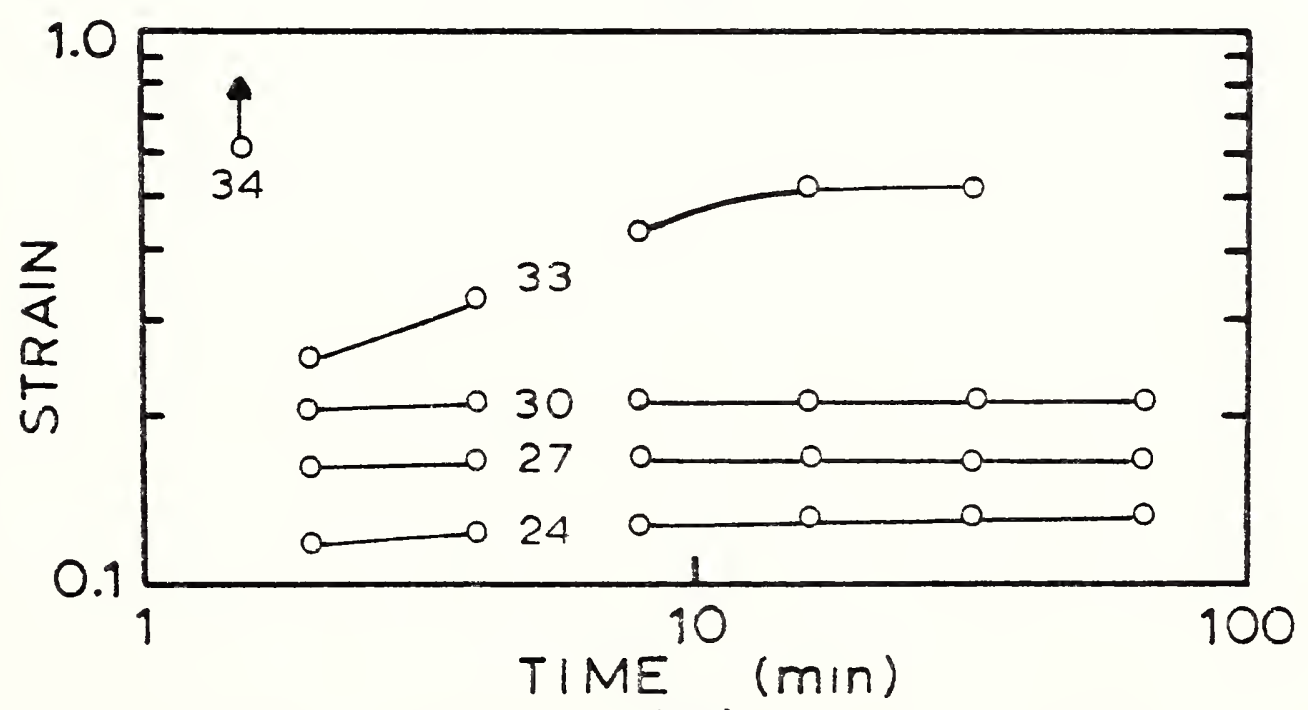

(a)

Fig. 8. Log creep strain versus log time for films under bubble inflation at different levels of constants applied pressure ( $\mathrm{kPa}$ ) at $-73^{\circ} \mathrm{C}$. (a) Cat. I, RoII 315477, (b) Cat. III, Roll 112877, and (c) Cat. BI, ROII 367006 . 



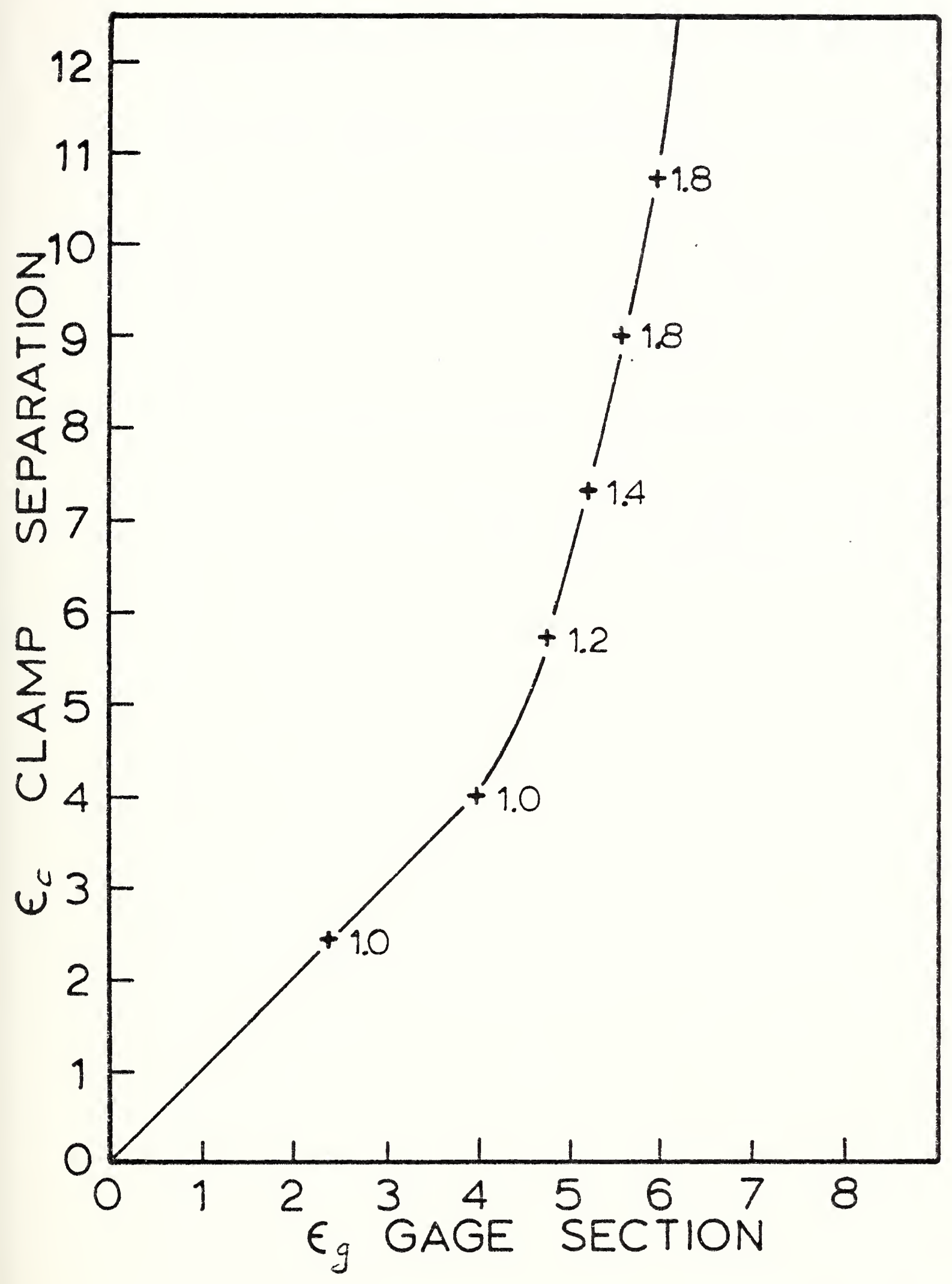

Fig. 9. Strain as determined from the clamp separation $\left(\varepsilon_{c}\right)$ versus strain as determined from the gage section $\left(\varepsilon_{g}\right)$ from a constant rate of clamp separation experiment. The polymer is remolded balloon film. The numbers next to the crosses indicate the ratio $\varepsilon_{c} / \varepsilon_{g}$. 


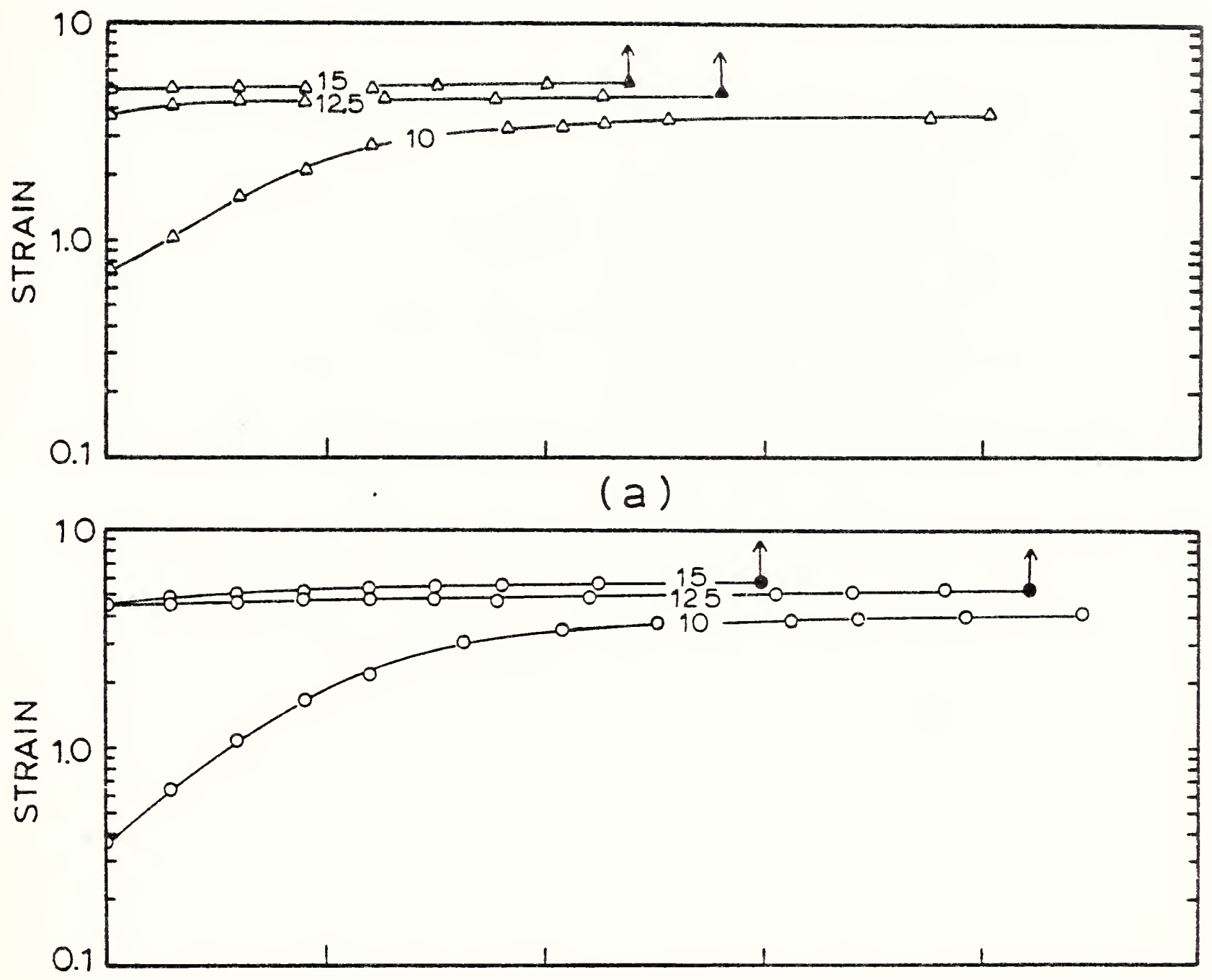

(b)

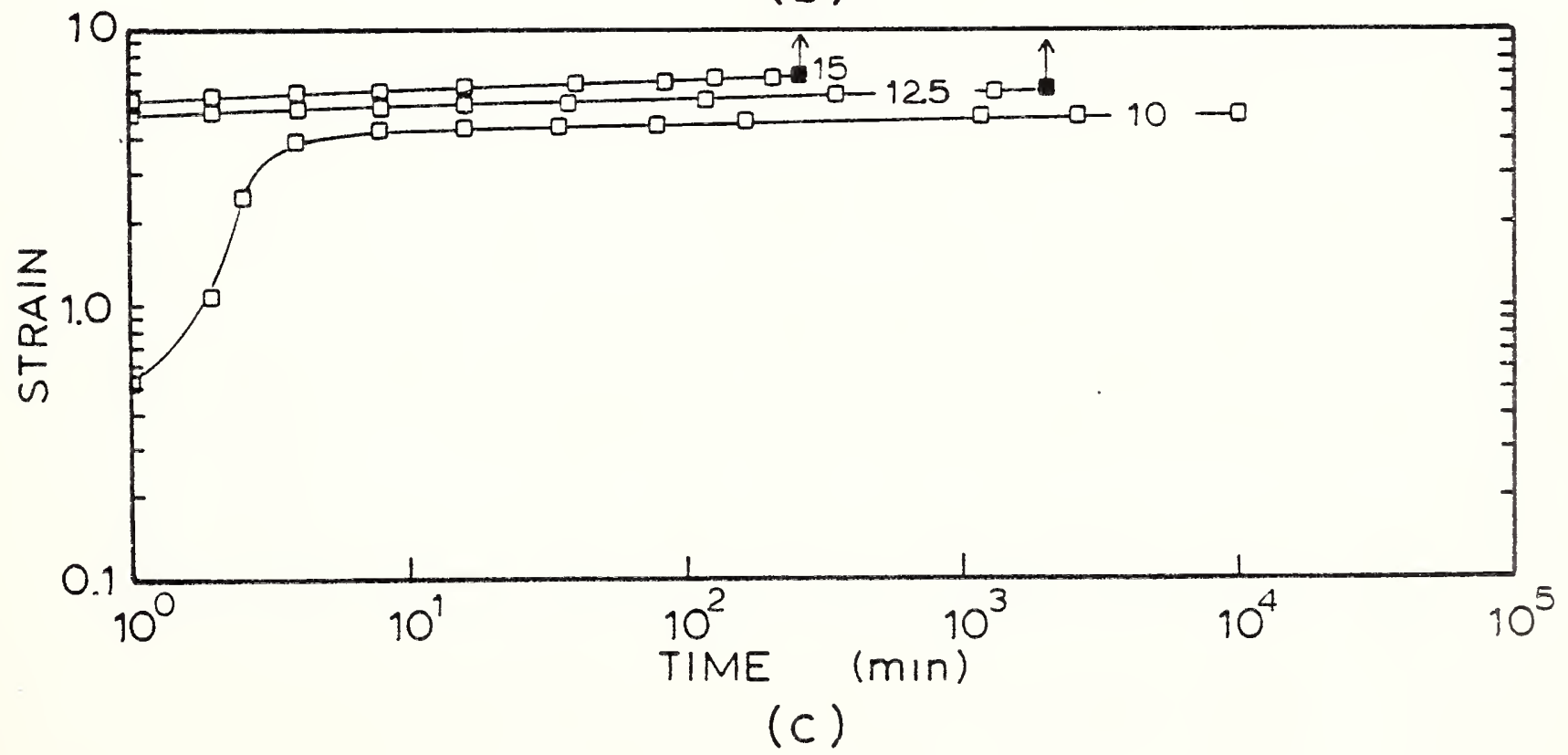

Fig. 10. Log creep strain versus log time for specimens of unoriented remolded balloon film. The numbers shown indicate the applied engineering stress (MPa) for experiments done in uniaxial extension. (a) Cat. III, (b) Cat. I, and (c) Cat. BI. The arrows indicate failure. 


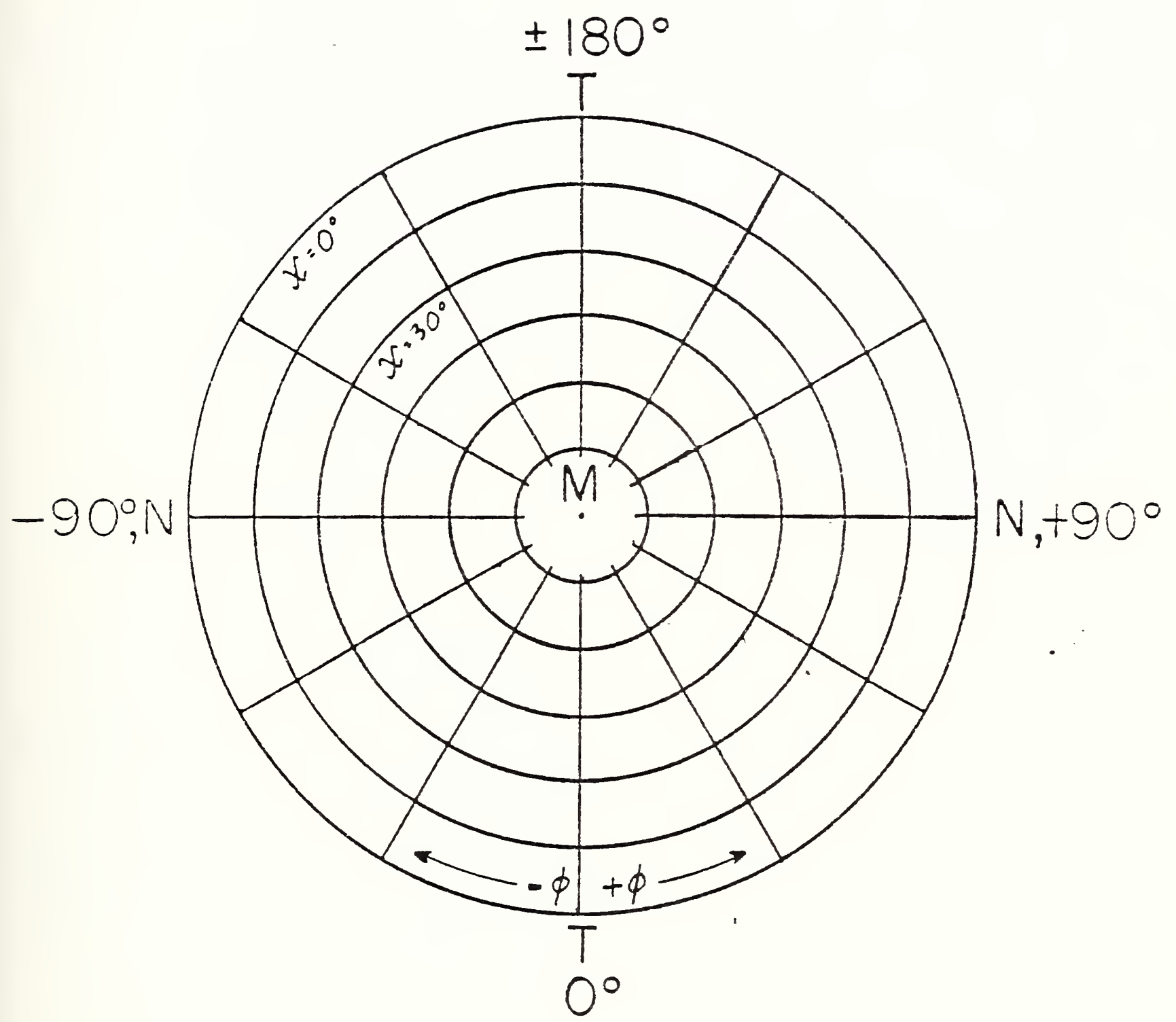

Fig. 11. Azimuthal equidistant projection of the reference hemisphere (see text) in relation to the $M$, $T$, and $N$ directions in the film. The radial lines and concentric circles are respectively the projections of the longitudes, 0 , and latitudes $x$ of the hemisphere. $M$ is normal to the plane of projection. 


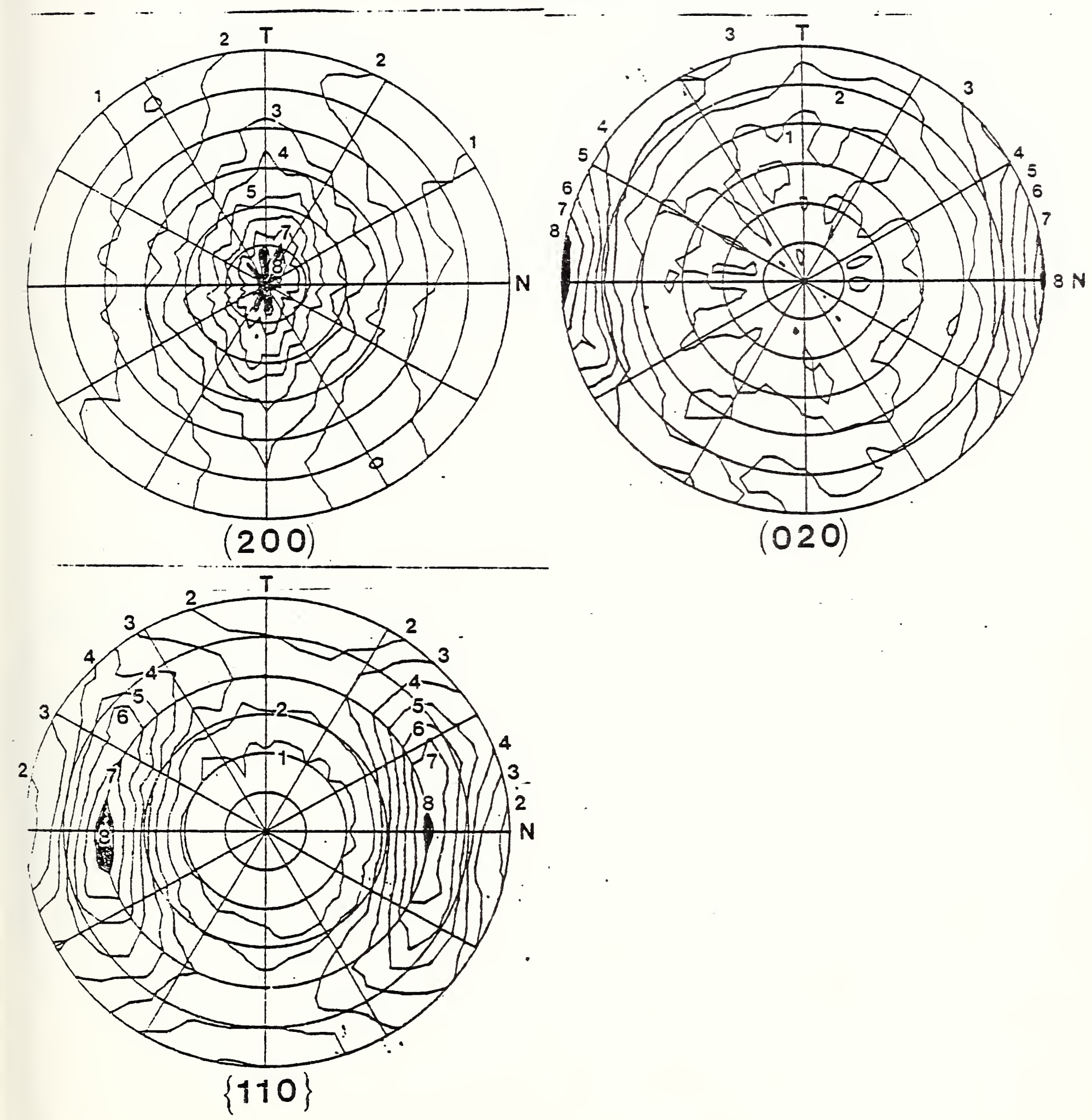

Fig. 12. (200), (020) and \{110\} pole figures of Cat.I f11m. 


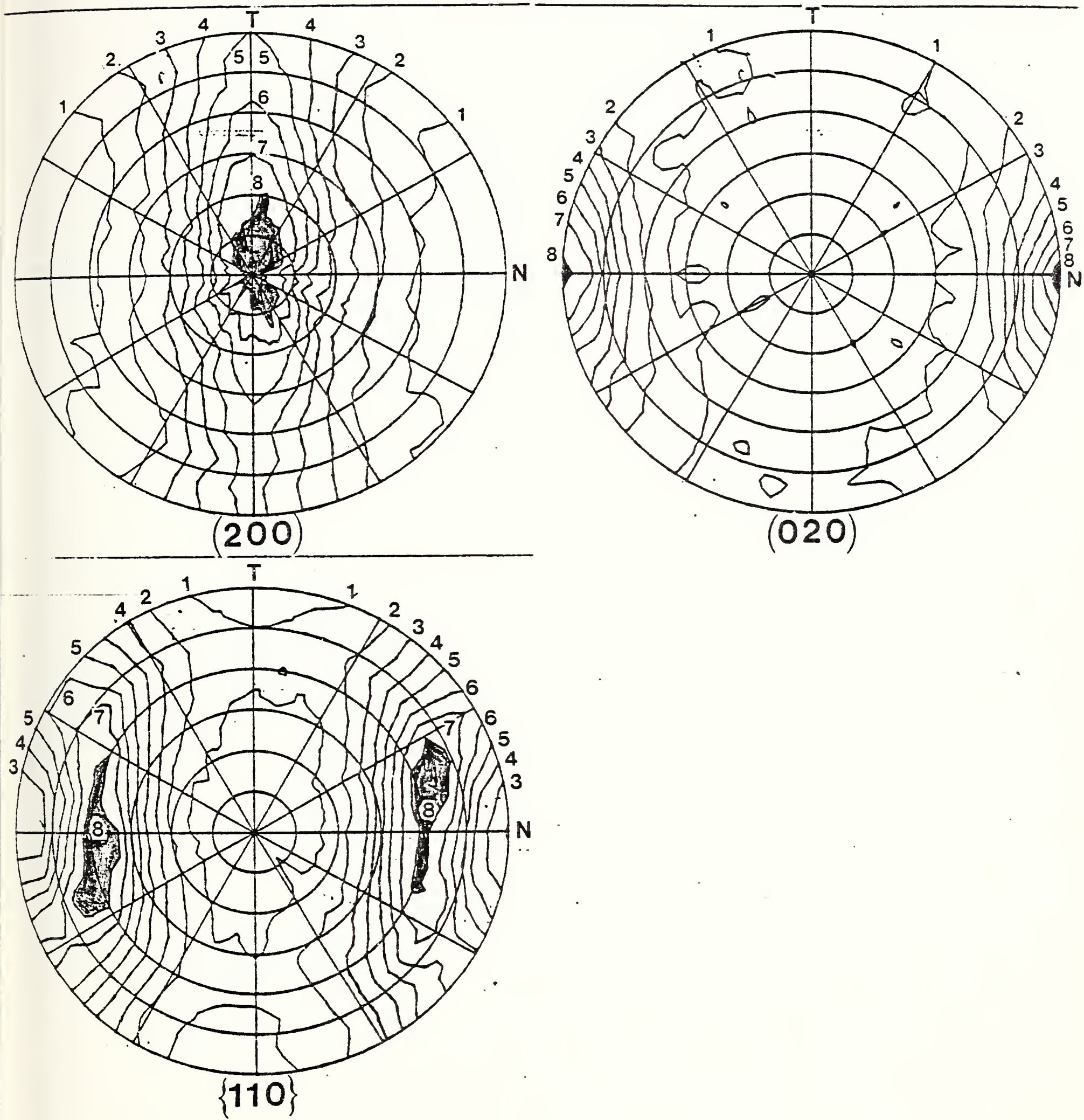

F18. 14. (200), (020) and $\{110\}$ pole figures of pilm BI. 


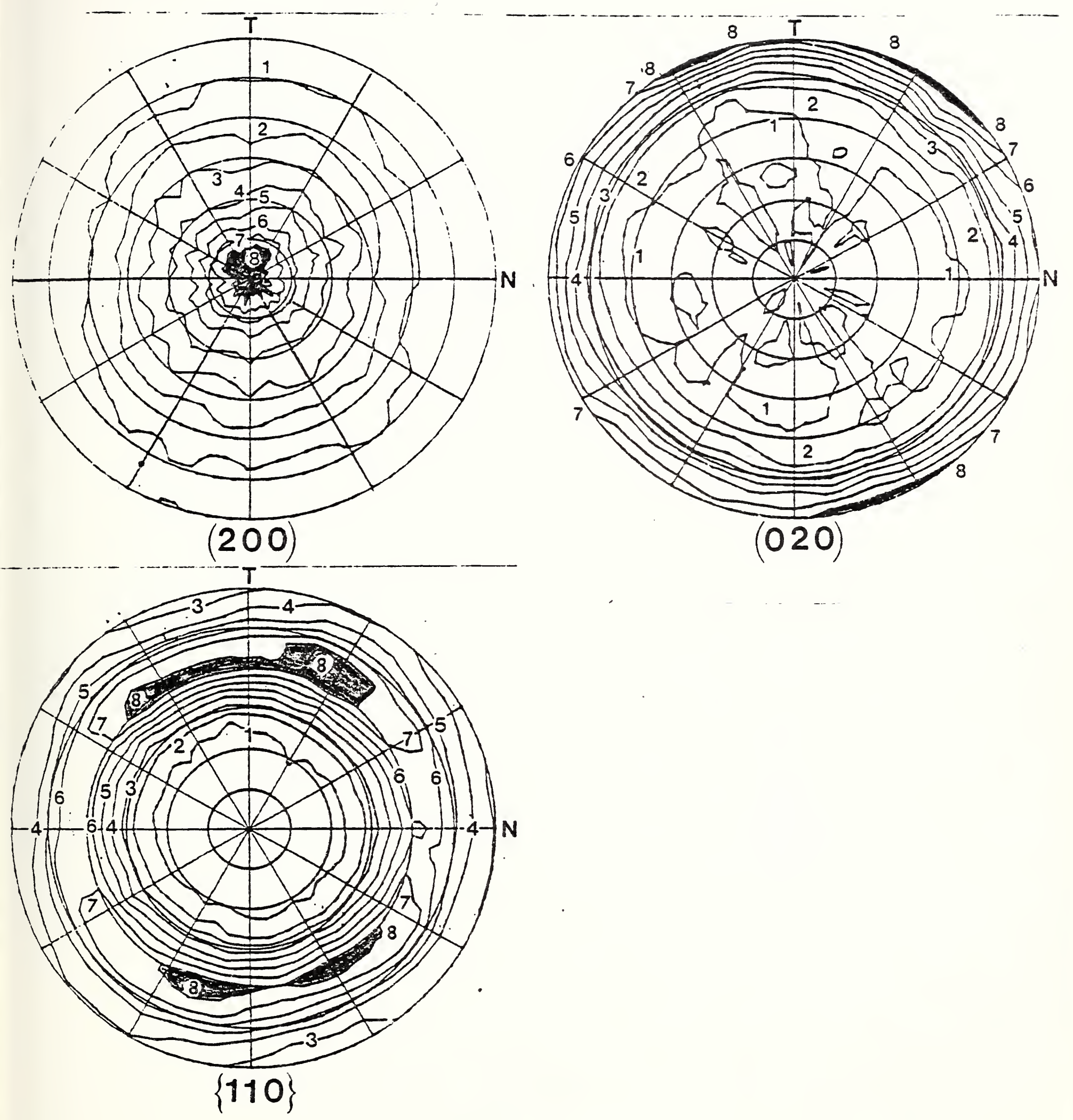

F1g. 15. (200), (020) and $\{110\}$ pole figures of film Fl. 


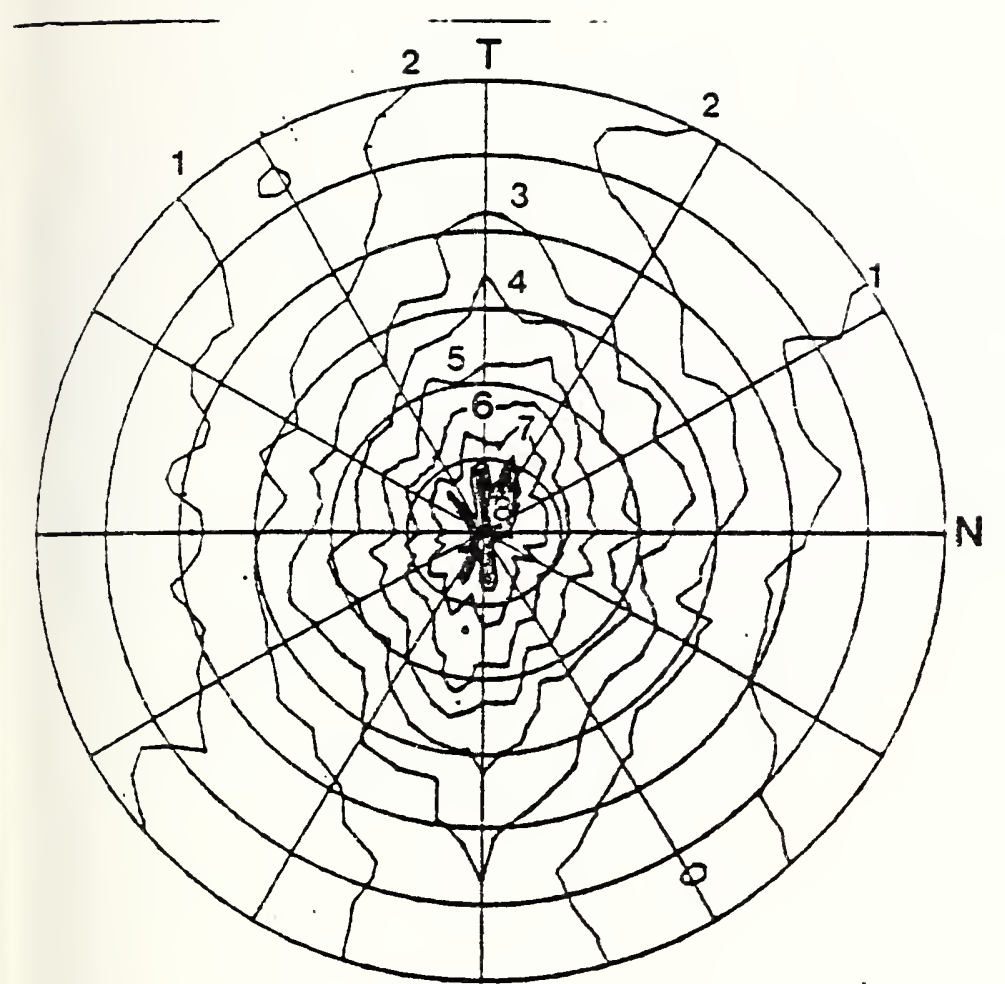

Film 1
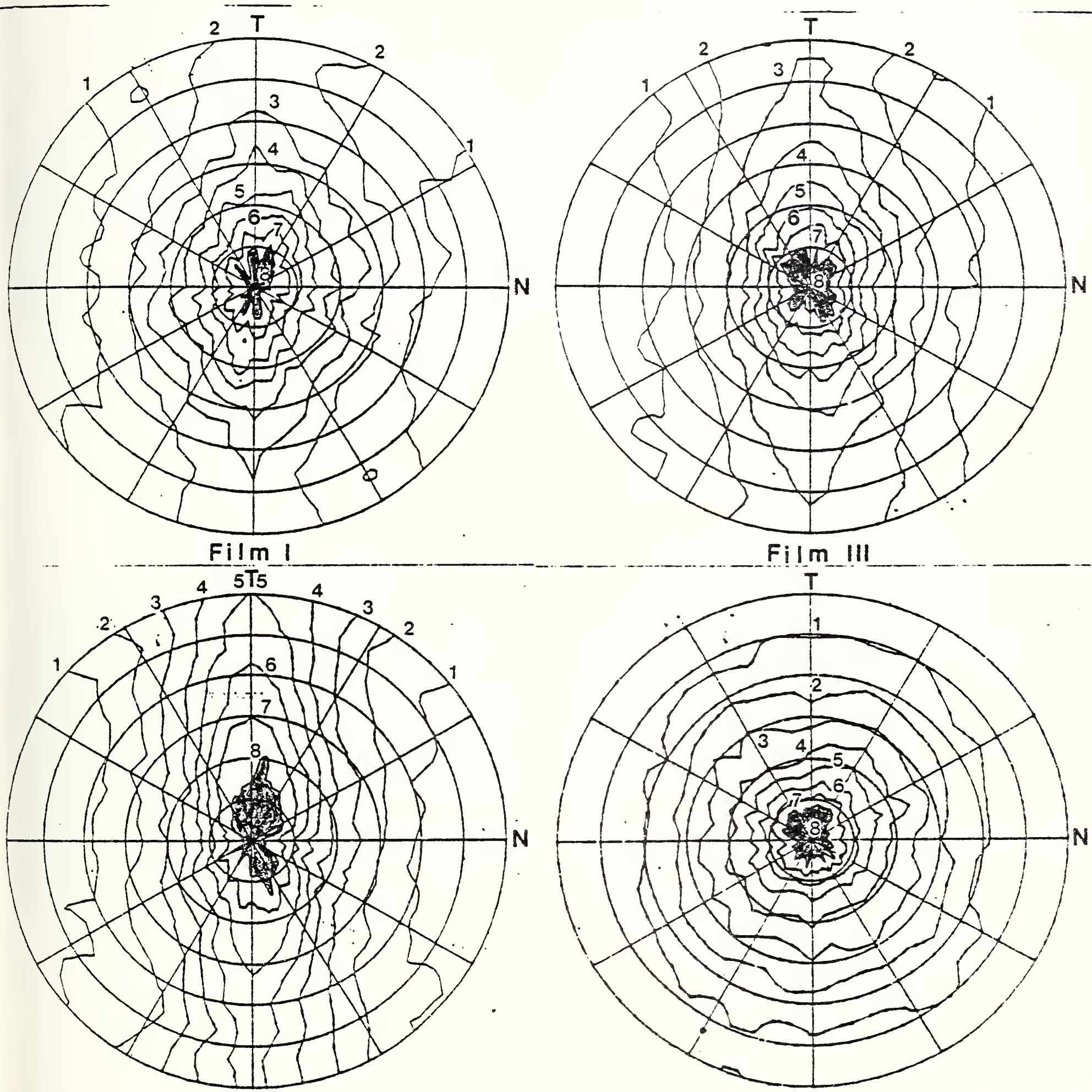

Film B I

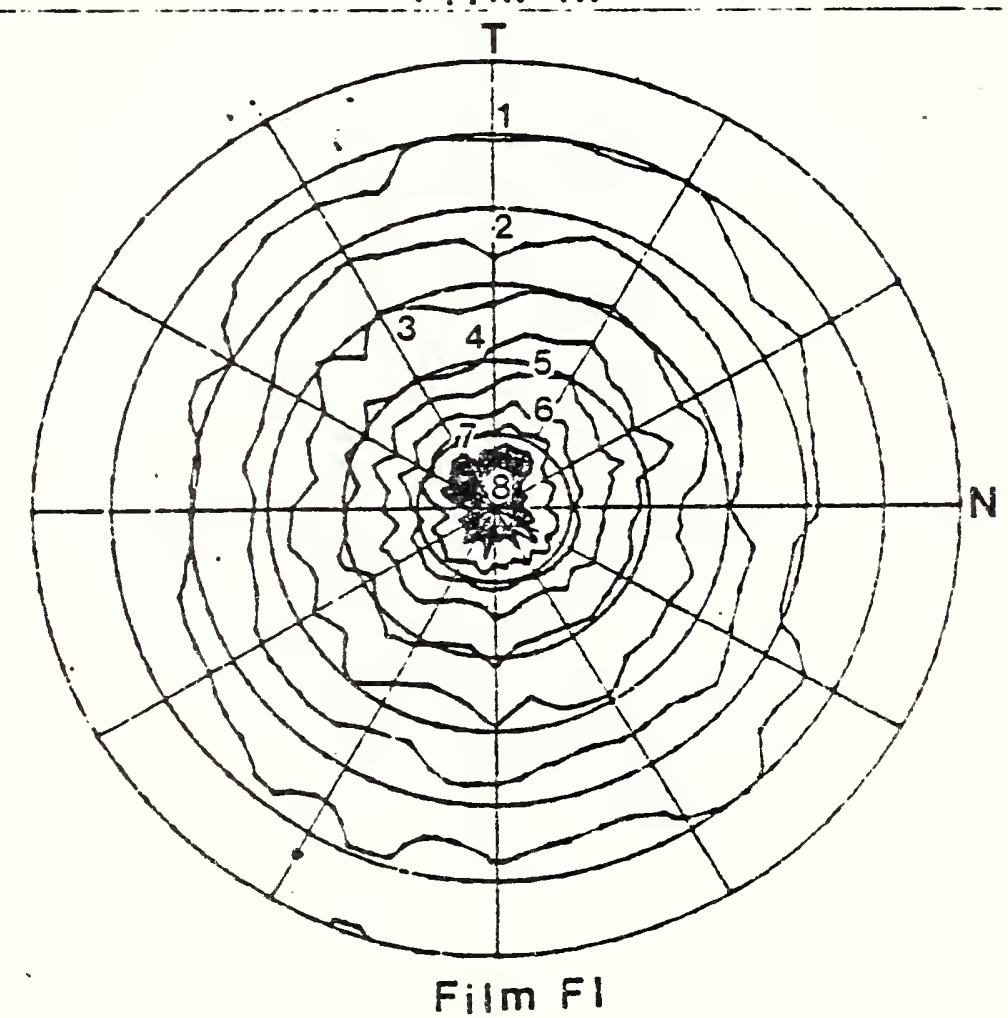

Fig. 16. (200) pole flgures of films I, III, BI and FI. 



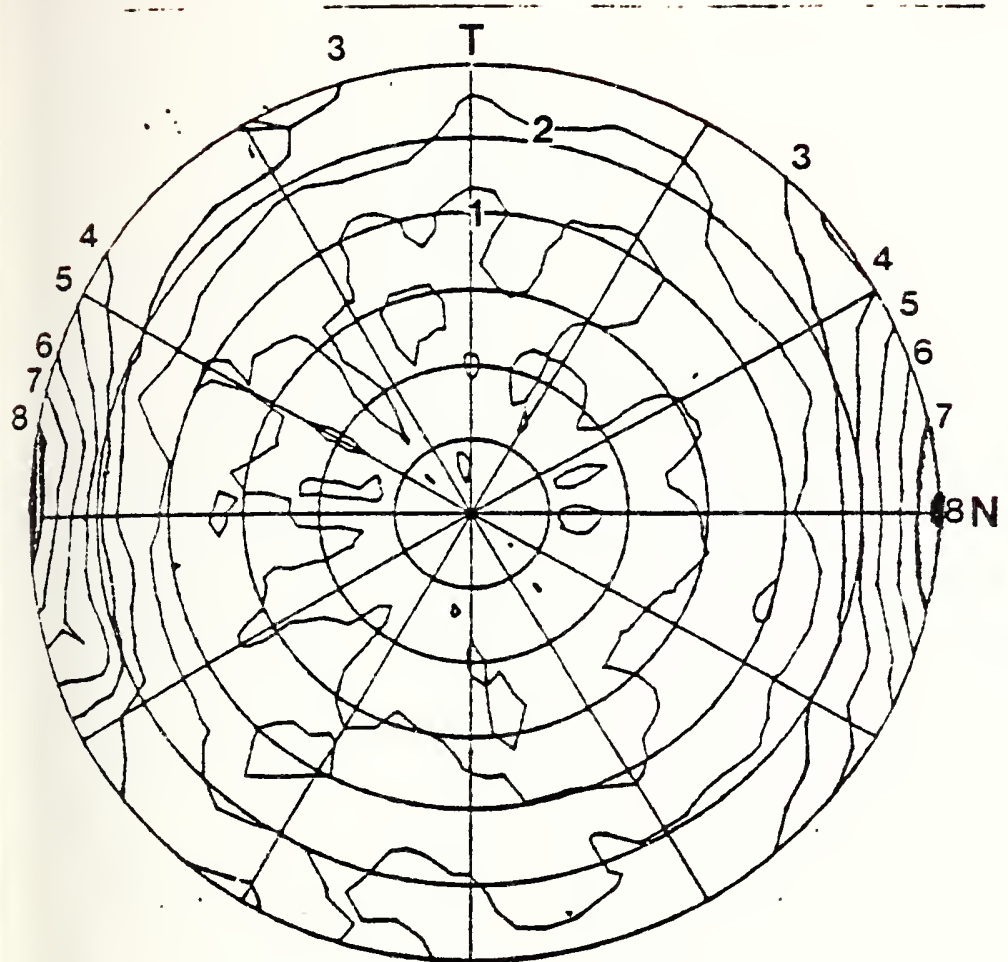

Film I

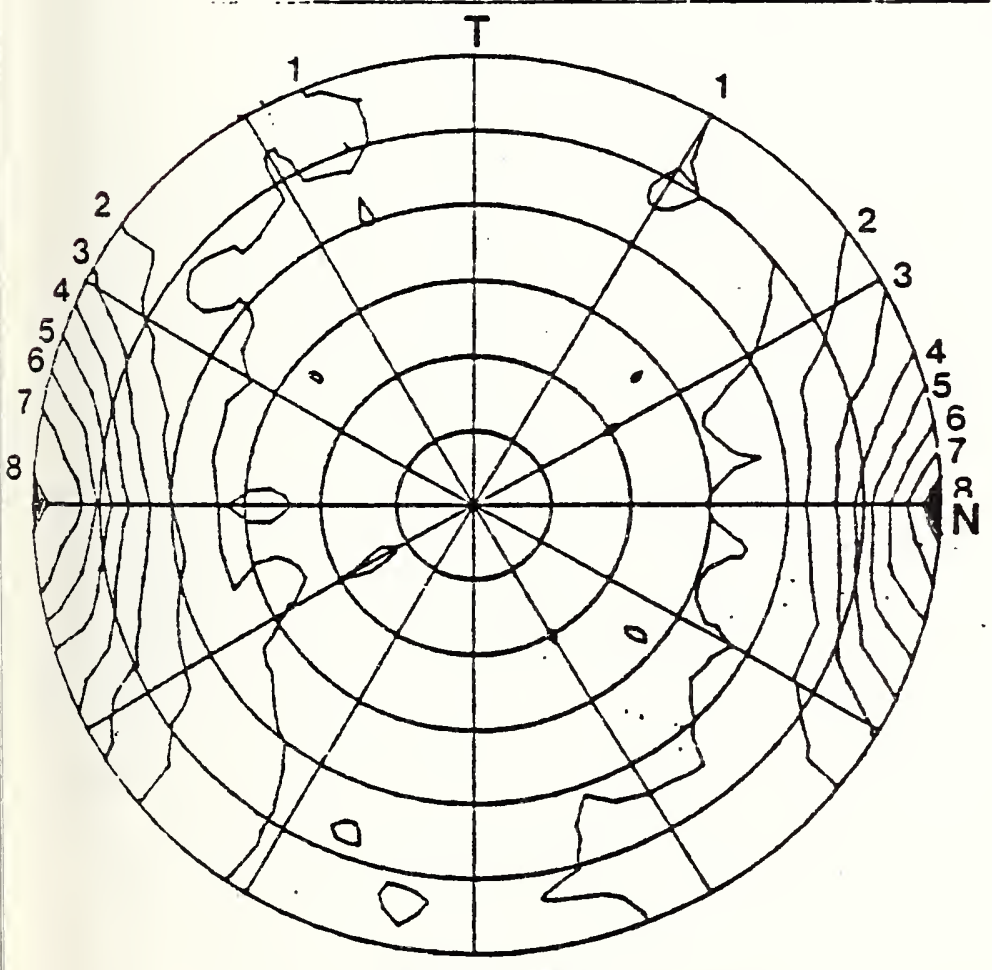

Film BI

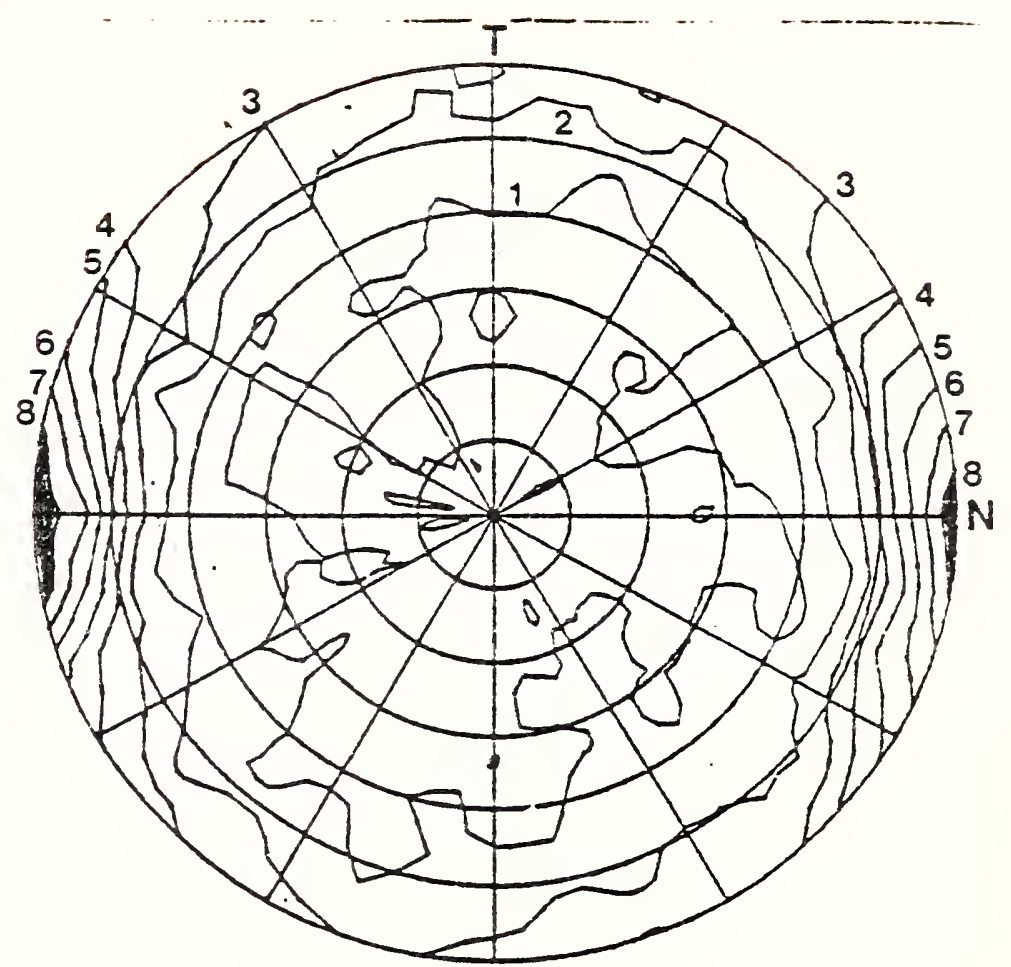

Film III

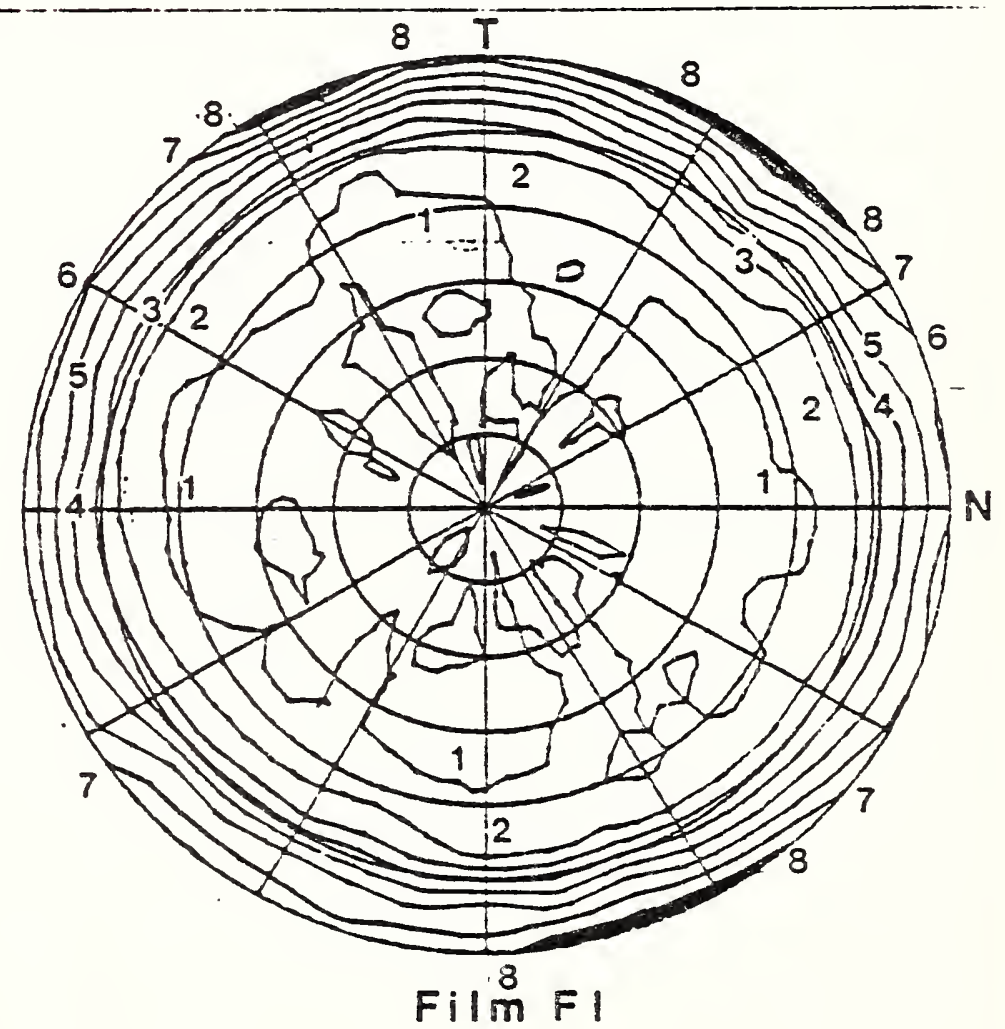

F1g. 17. (020) pole figures of films I, III, BI, and FI. 


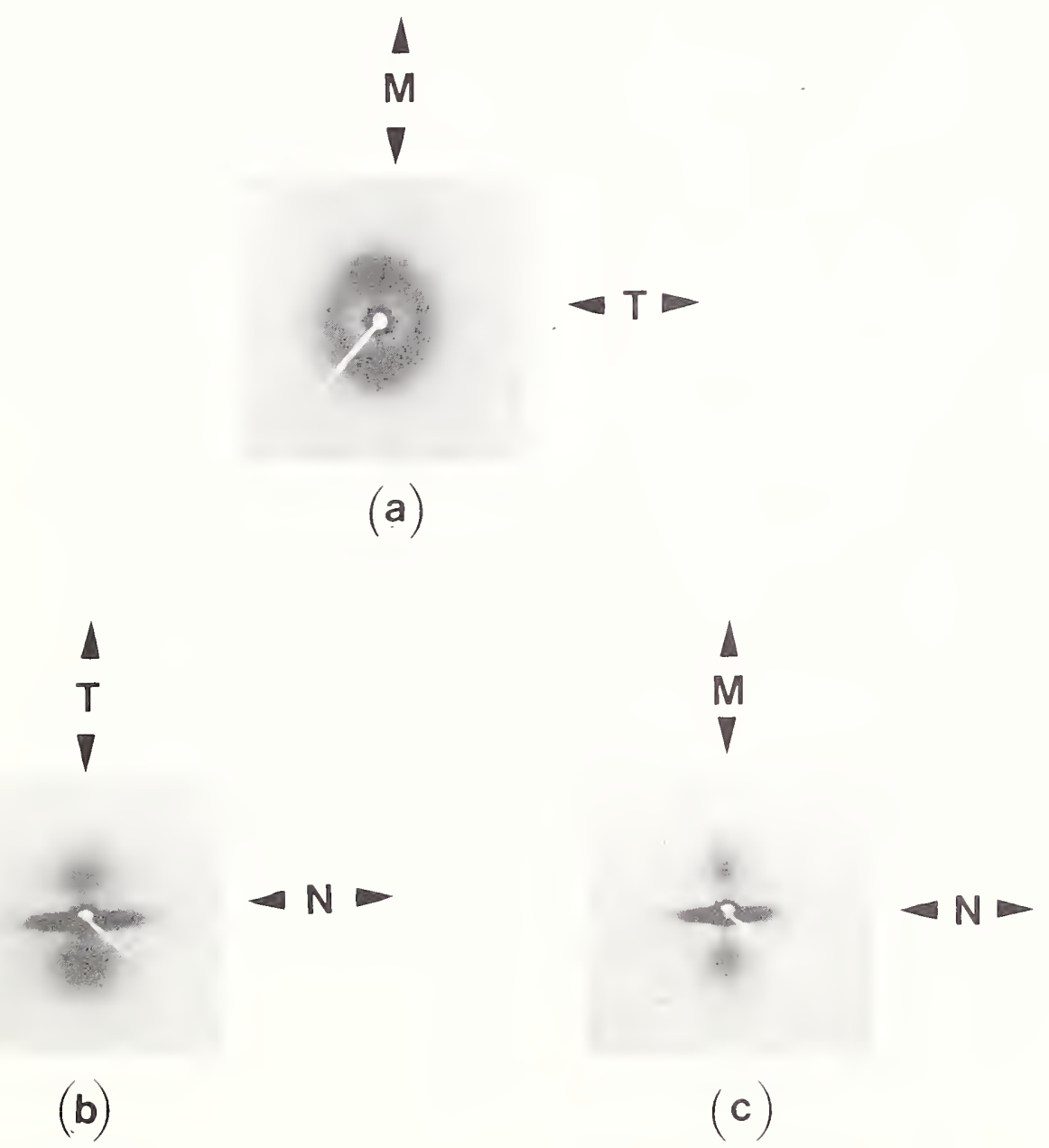

Fig. 19. Small angle x-ray diffraction patterns of Cat. I film. (a) X-ray beam parallel to $\mathrm{N}$, (b) X-ray beam parallel to $M$, (c) X-ray beam parallel to $\mathrm{T}$. 


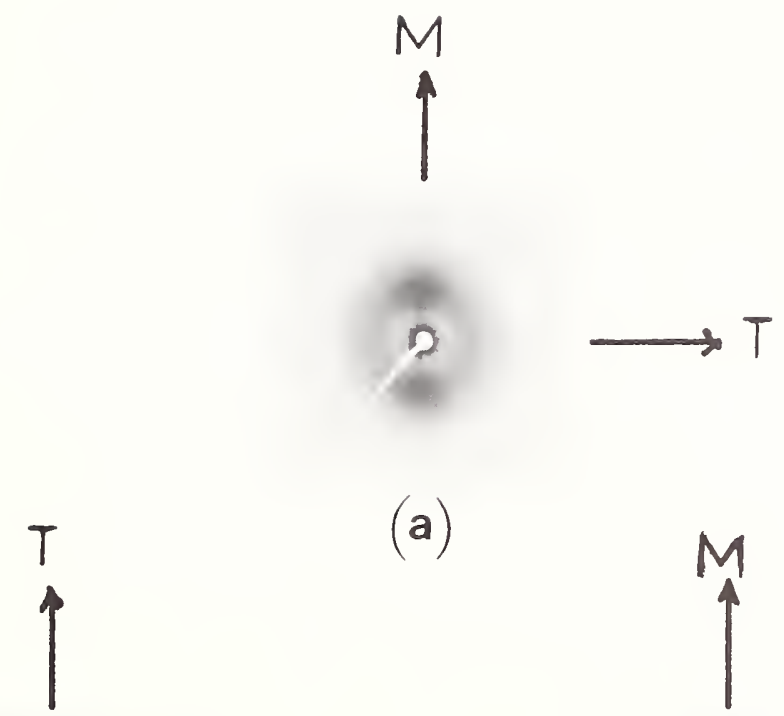

(a)
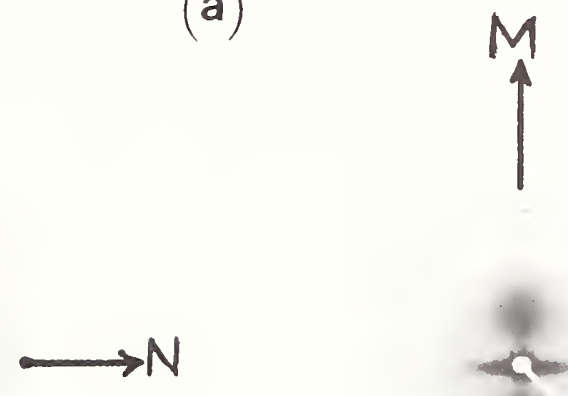

(b)

(c)

Fig. 20. Small angle $x$-ray scattering patterns exhibited by Cat. III film. (a) incident beam parallel to N. (b) X-ray beam parallel to M. (c) X-ray beam parallel to $T$. 
$\underset{M}{\Delta}$

c $\Delta T$

(a)
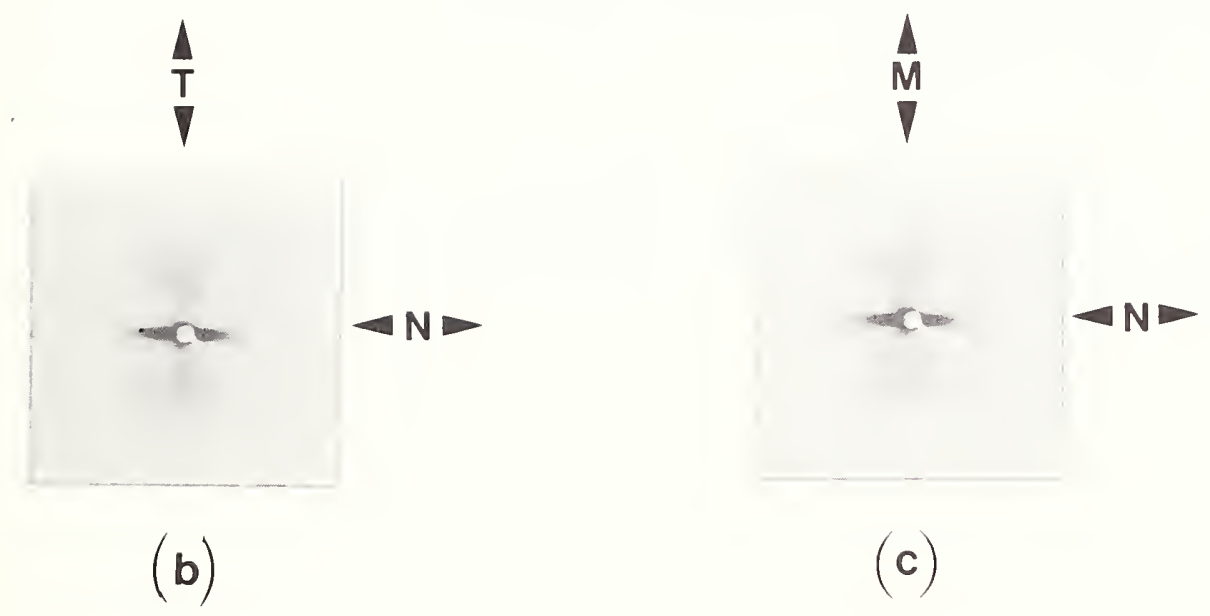

Fig. 21. Small angle $x$-ray scattering patterns exhibited by the Bl film.

(a) Incident $x$-ray beam parallel to $N$. (b) $X$-ray beam parallel to $M$. (c) X-ray beam parallel to $\mathrm{T}$. 



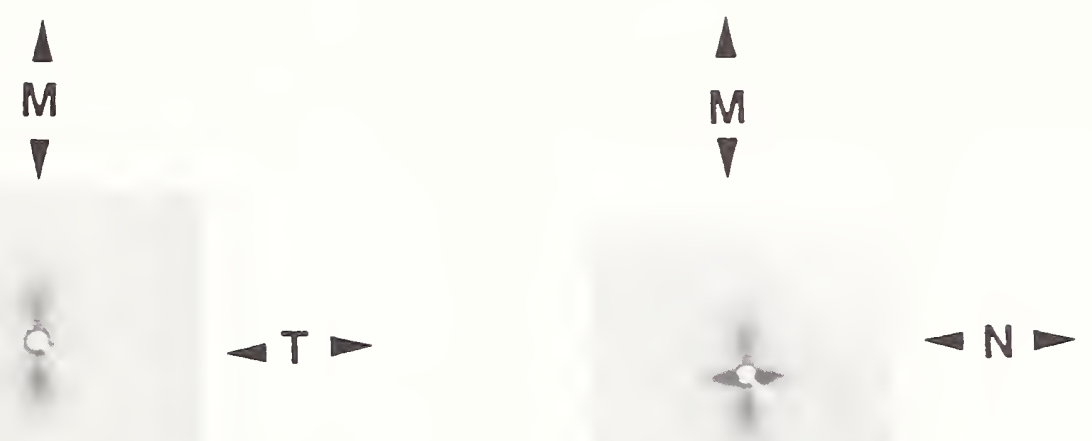

F18. 22. Small angle x-ray diffraction patterns from f1Im Fl. Incident beam in (a) parallel to $\mathrm{N}$ direction, (b) parallel to $\mathrm{T}$ direction. 



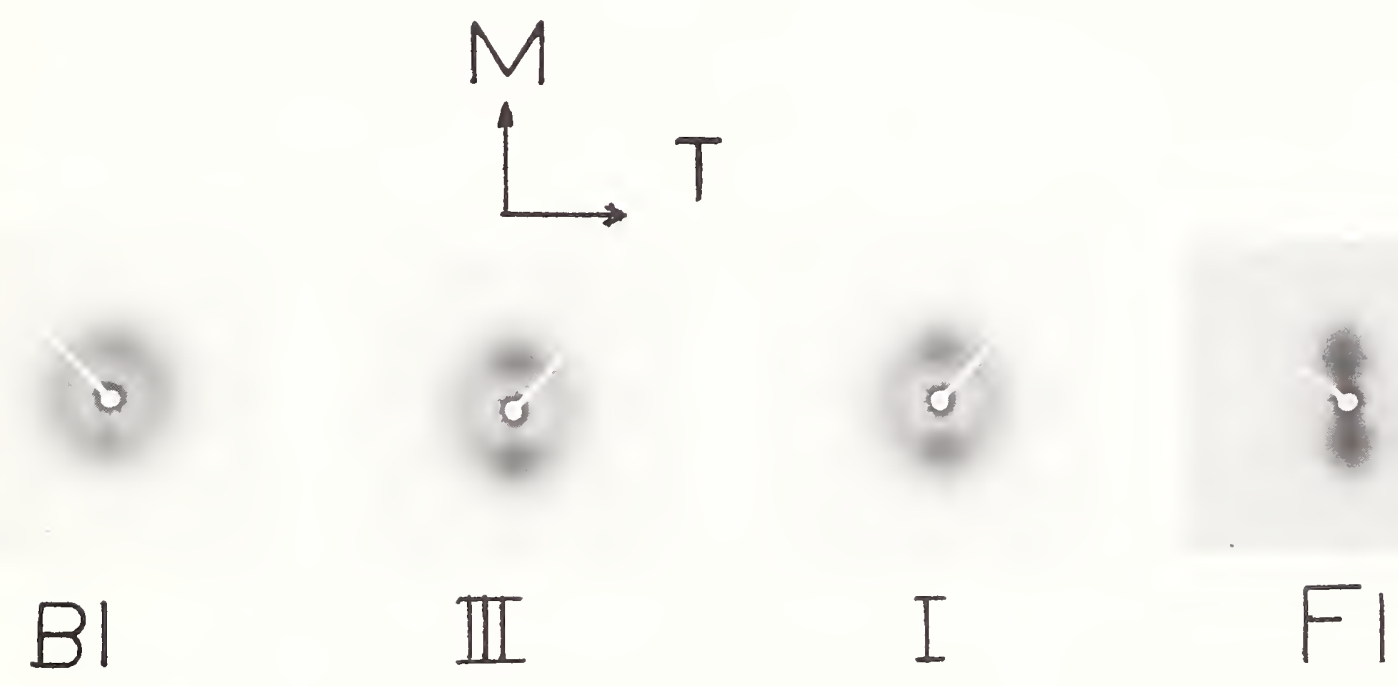

Fig. 23. Small angle x-ray diffraction patterns of films BI, III, I and F1 x-ray beam parallel to $\mathrm{N}$. 



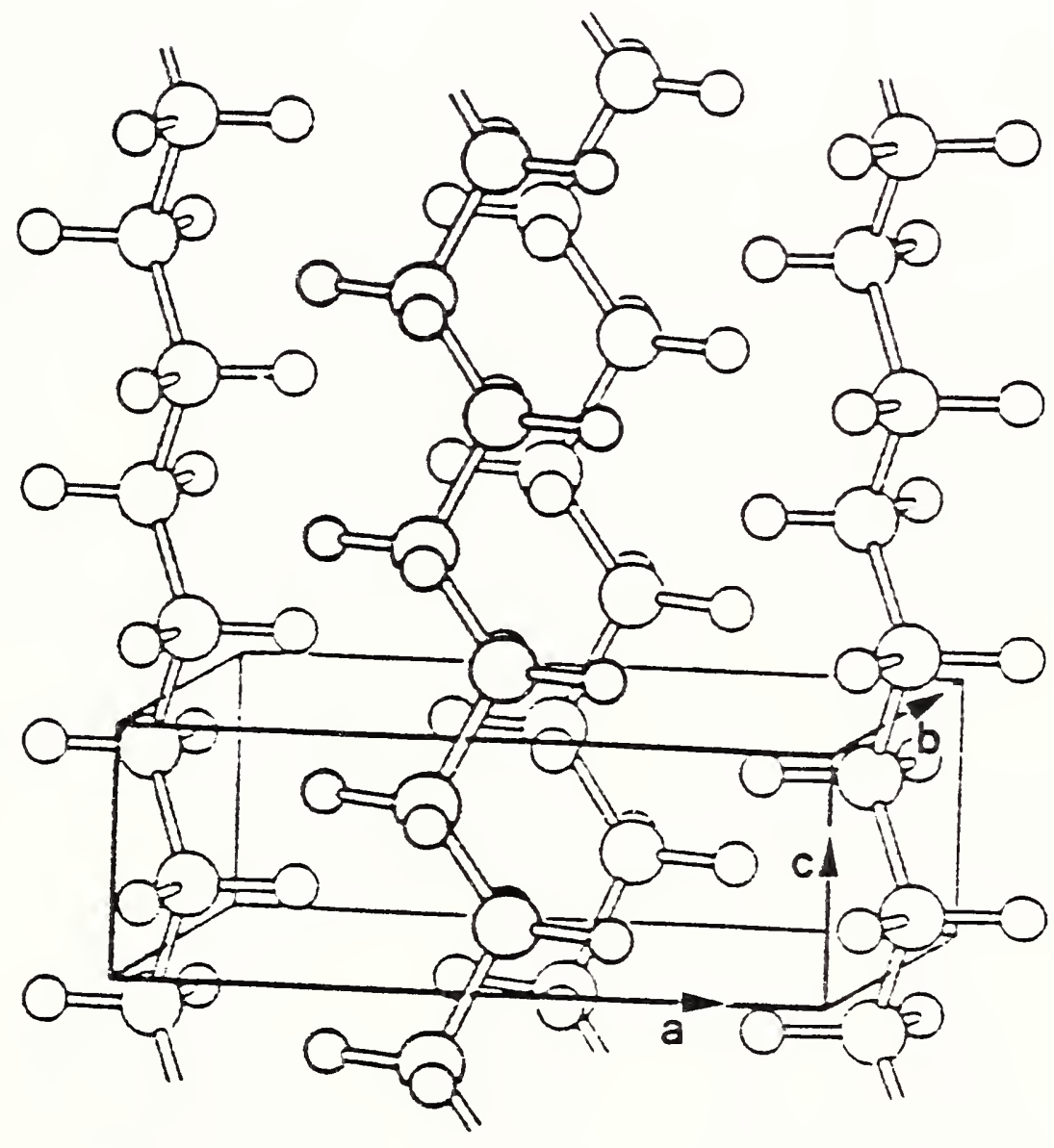

[ig. 24. Orthorhomblc unit cell of Polyethylene, after Bunn [13]. 



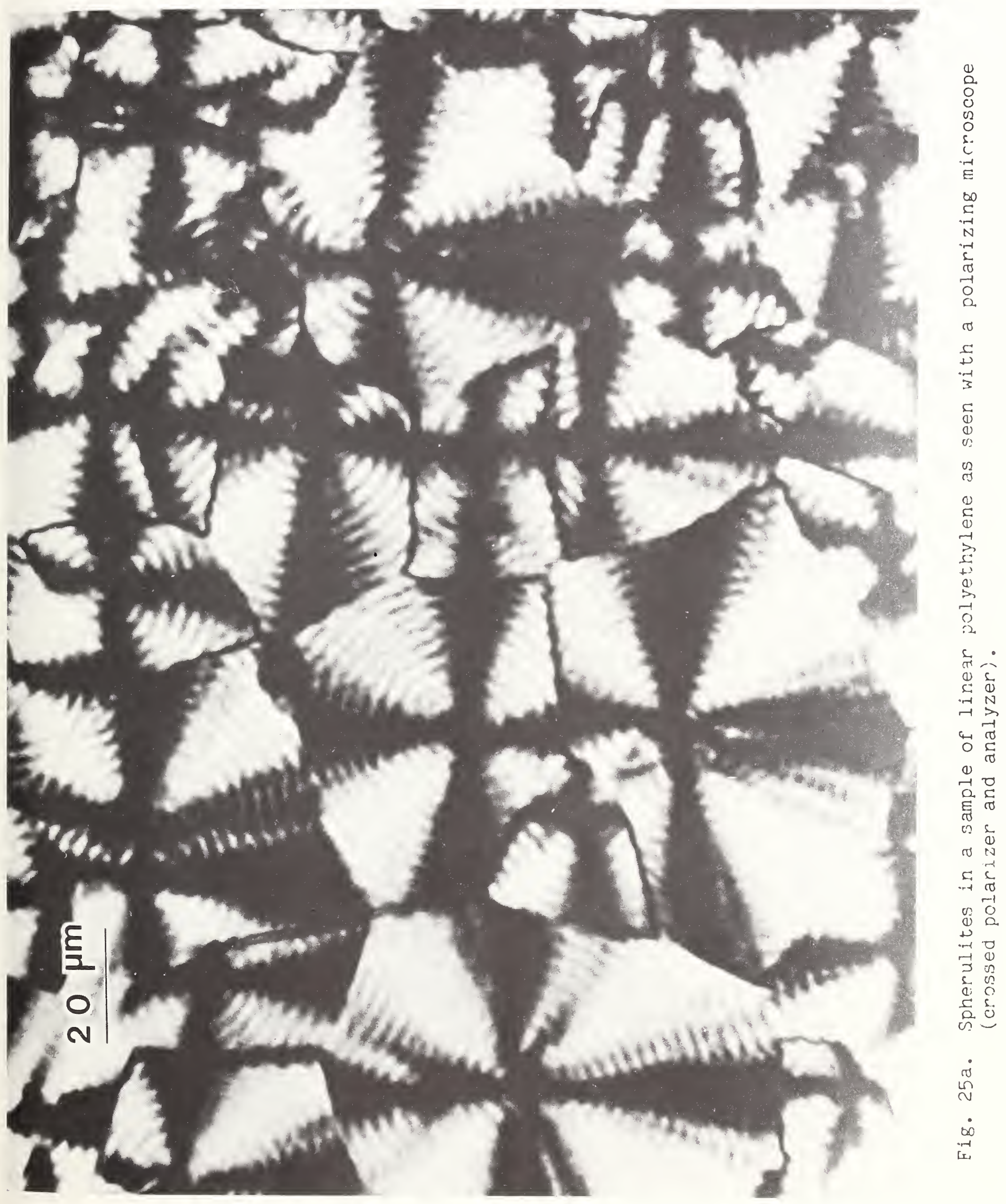





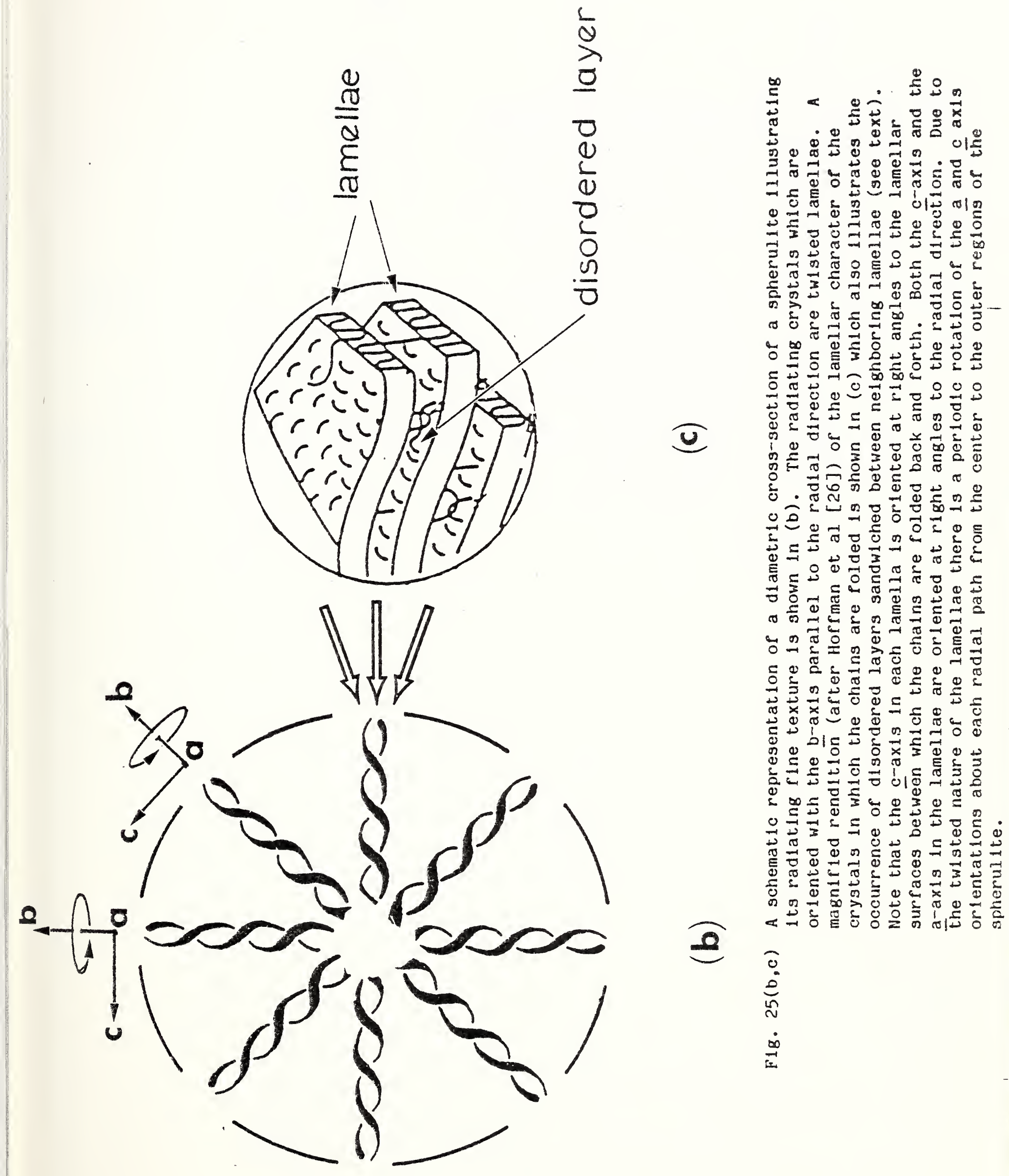




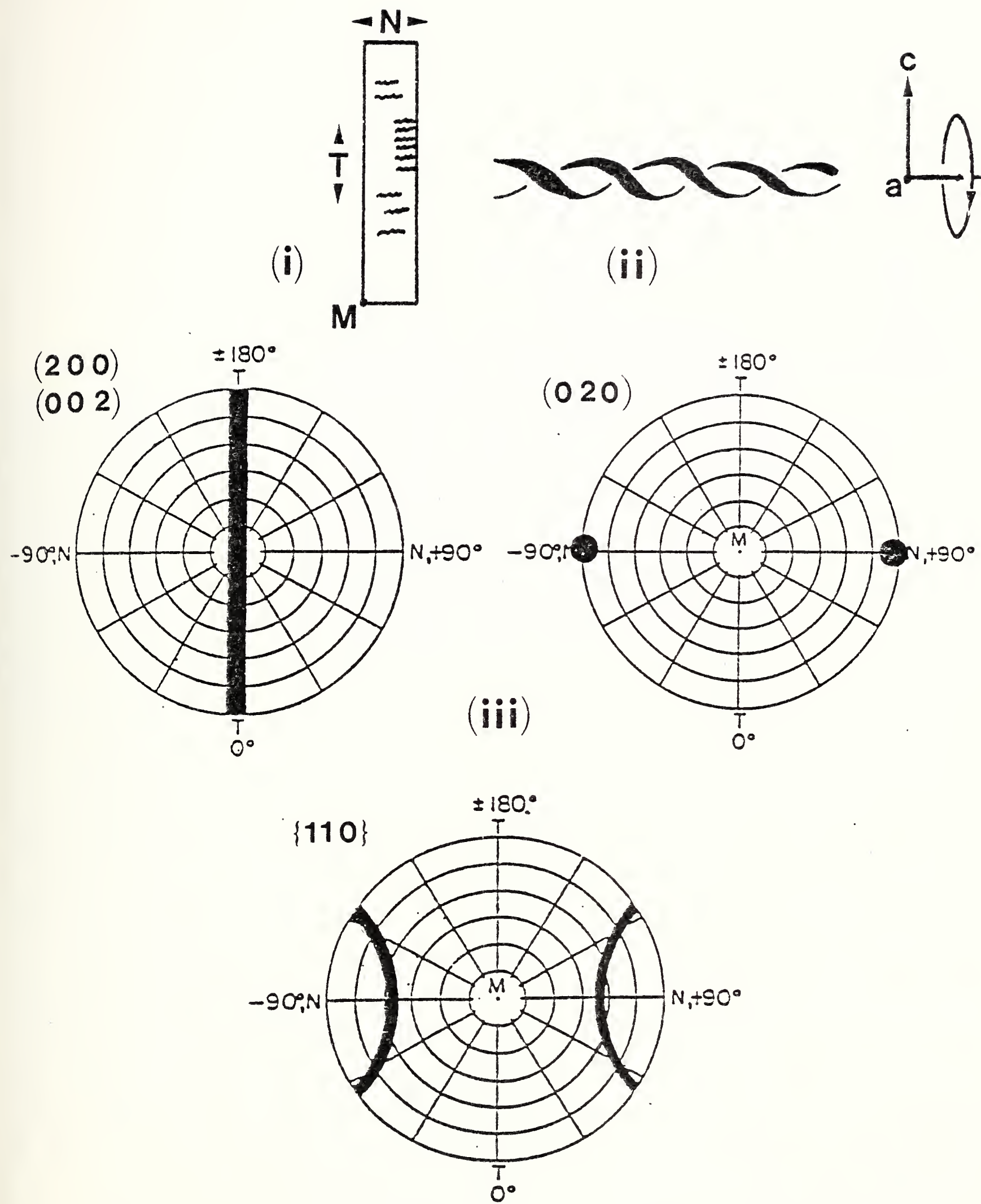

FIB. 26 (1) Schematic representation of Iranscrystaline tinisted iameliae as seen from the wachine (M) direction. (11) Mantifiet 1llustration of twisted lamellae which are orlented with their b-axis parallel to the $\mathrm{N}$ difection. Note the periodic potation of the $a$ and $c$ axis orientations along the length of the twisted lameliae, $\overline{1}$.e. about the $N$ direction. Whether extensive regions having the transcrystalline orientation exist near the outer surface of the blown I:I四, or whether regions where this orlentation prevalls are dispersed in the illm remains an open question (see text). (111) The (200), (020), (002) and $\{110\}$ pole Plgures corresponding to the Transcrystailine orientation relative to the $M, I$ and $N$ directions in the pilm. 



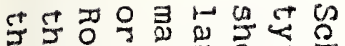

-

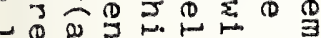

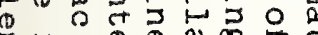
उ世-

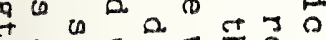

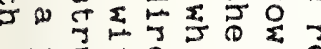

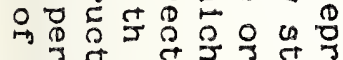

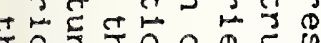
ग० J - 0 ता क थ

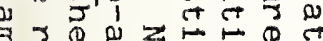

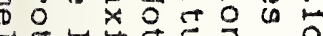

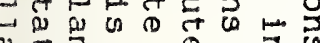
त范 0 D

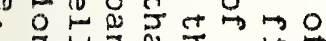

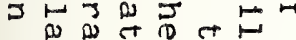
0 吕

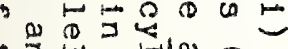

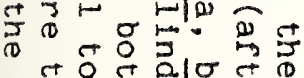

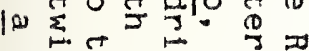

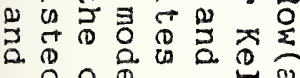

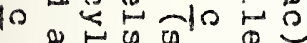
(2) 5 क ⿻ 丨

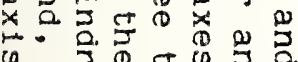
๑ ว 욱

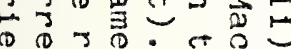

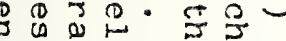

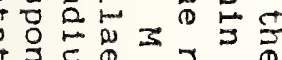
造它穴 类

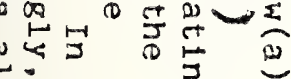
- $\rightarrow$ 更
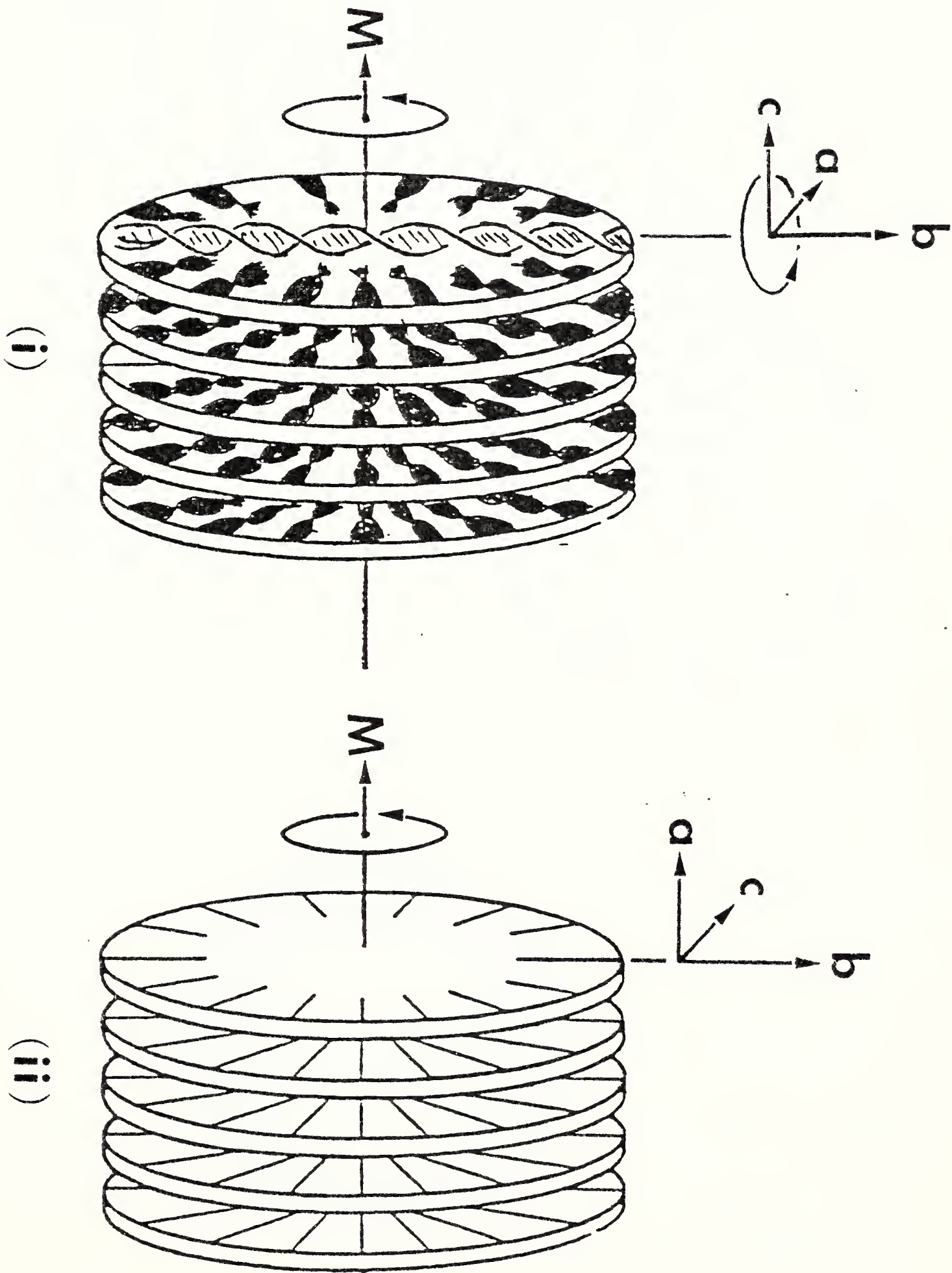


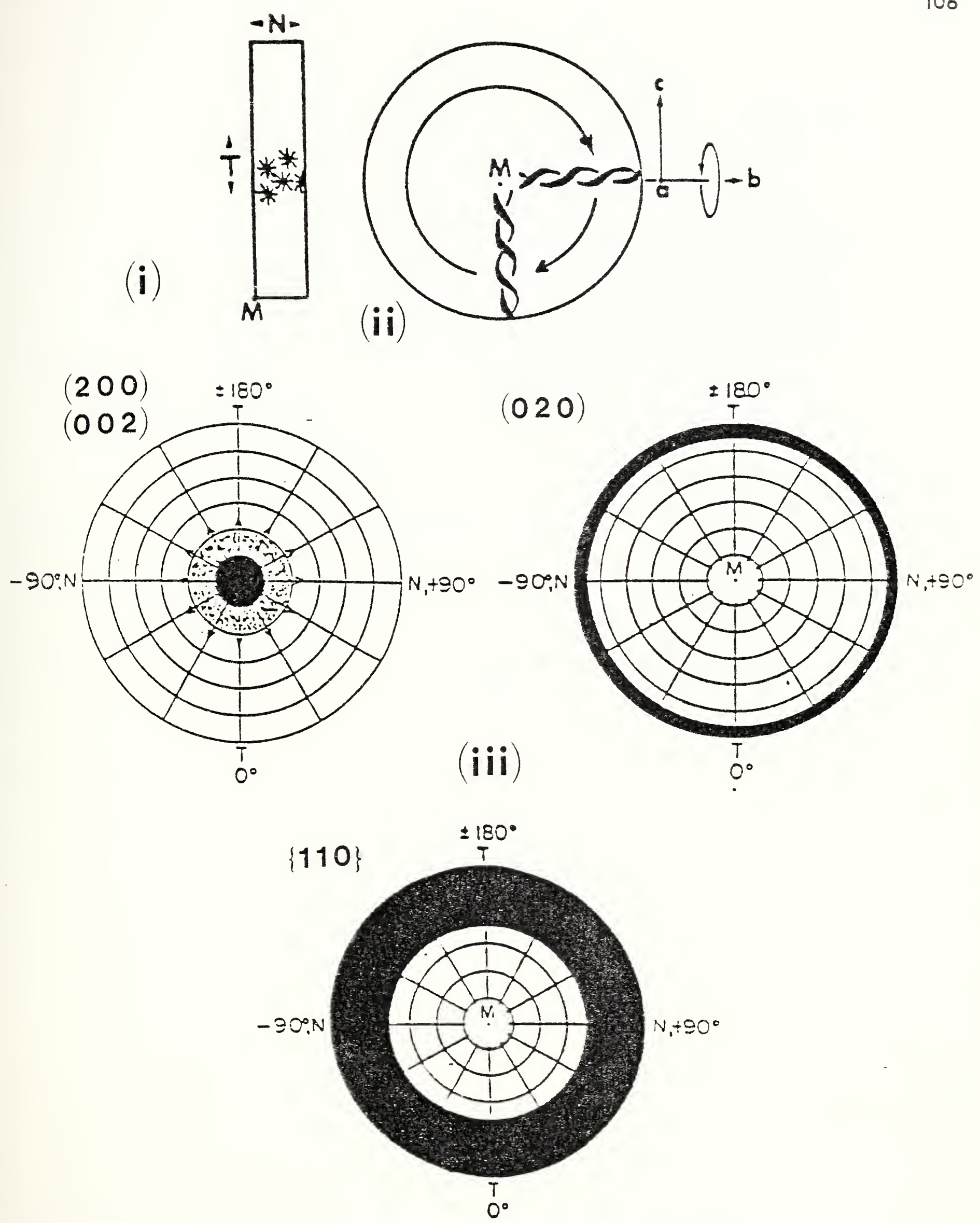

F18. 28 (i) Schematic representation of the Row(ac) type of structure as seen from the machine (ii) direction. (ii) orientation characteristics of the corstituent tisted lamellae in the cylindrites (see FIg. 27) relative to the radial direction. (iii) The (200), (020), (002) and \{110\} pole figures corresponding to preferred orientation characteristics of the Row(ac) structure relative to the $M, T$, and $N$ directions in the Plin (see text). 


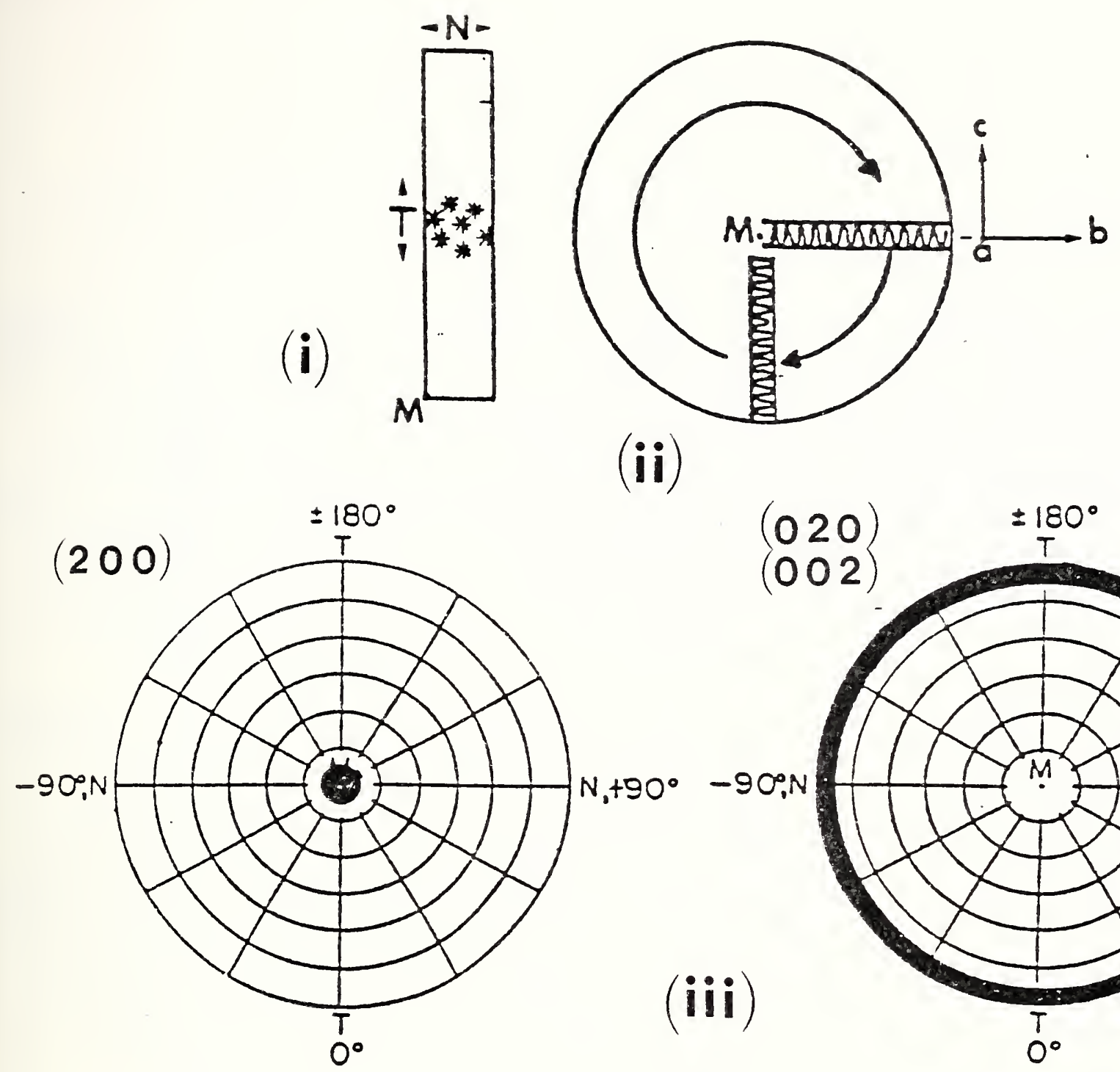

(ii)
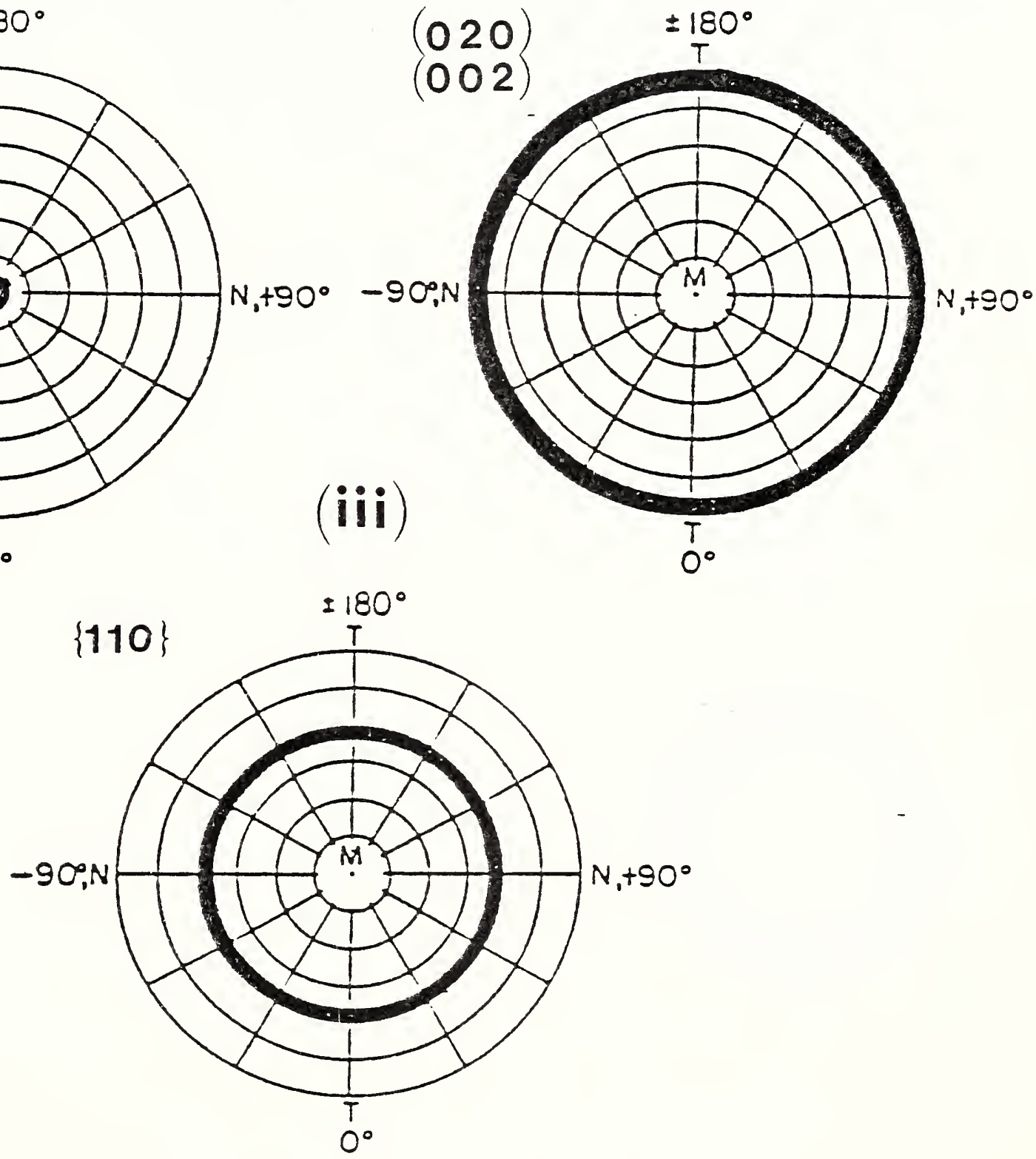

Fis. 29 (i) Schematic representation of the Row(a) type of structure as seen from the machine (M) direction. (ii) Orientation characteristics of the constituent lamellae in the cylindrites (see Fig. 27b) relative to the radial direction. (iii) The (200), (020), (002) AND $\{110\}$ pole figures corresponding to the preferred orientation characteristics of the Row(a) structure relative to the $M, T$, and $N$ directions in the film (see text). 

Transcrystalline
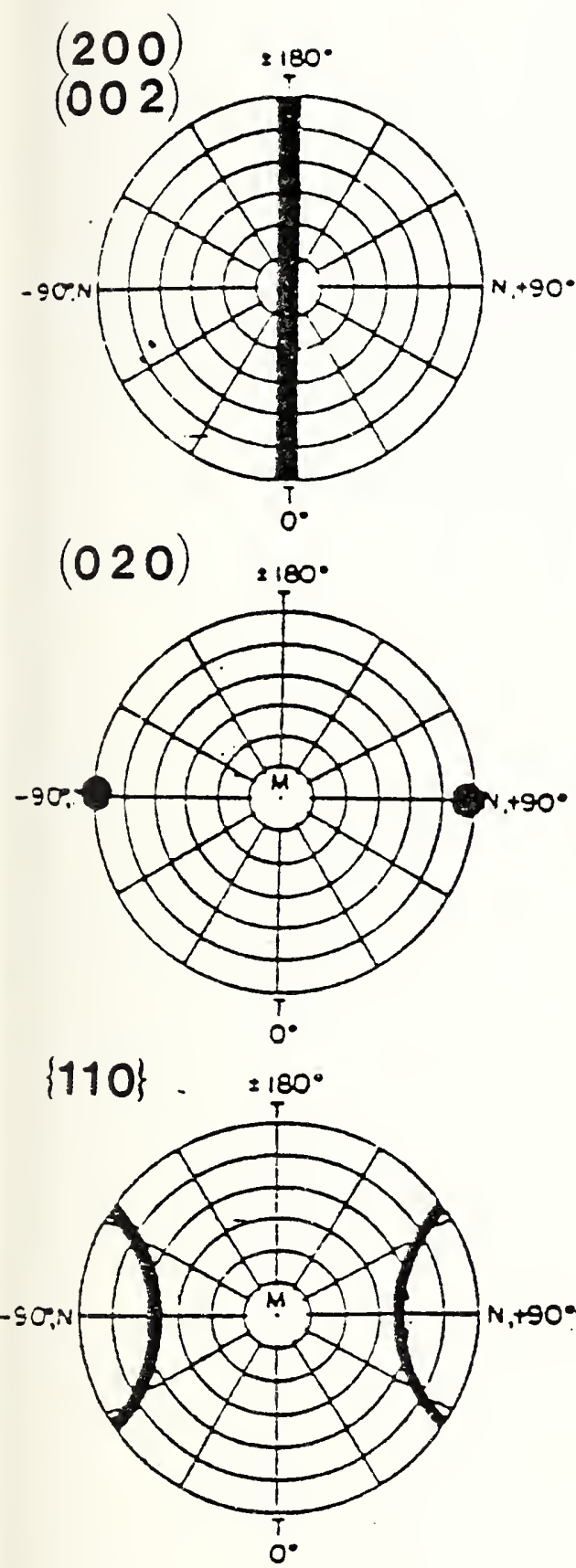

Row (a)
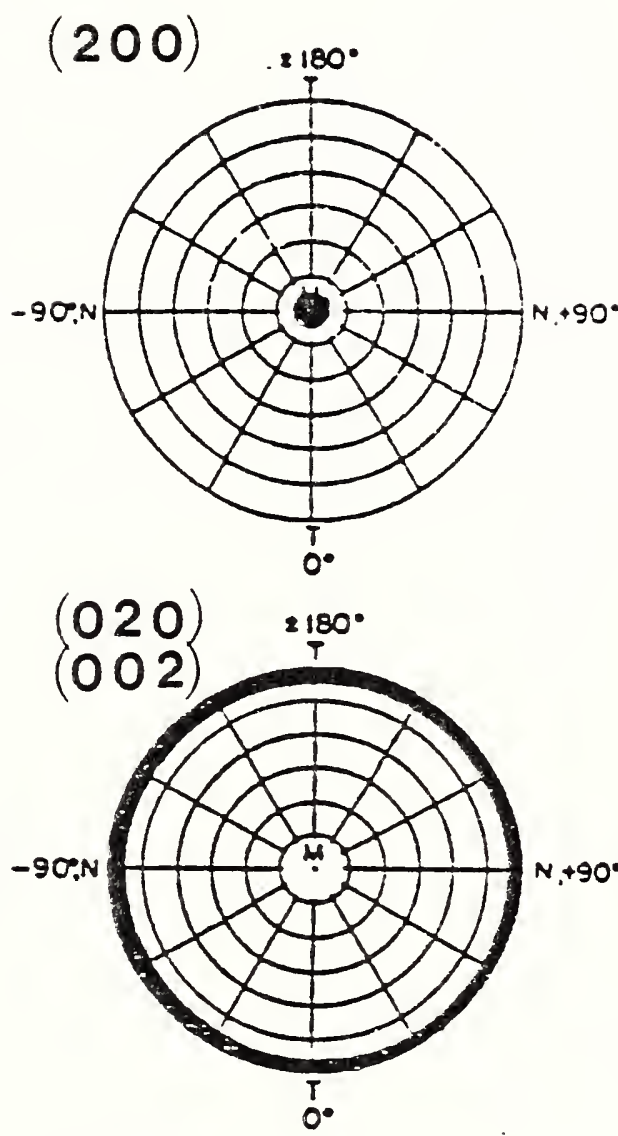

$\{110\}$

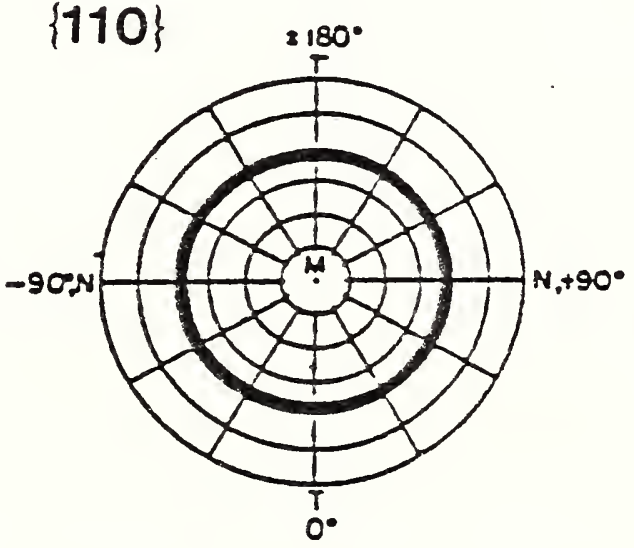

Row (ac)
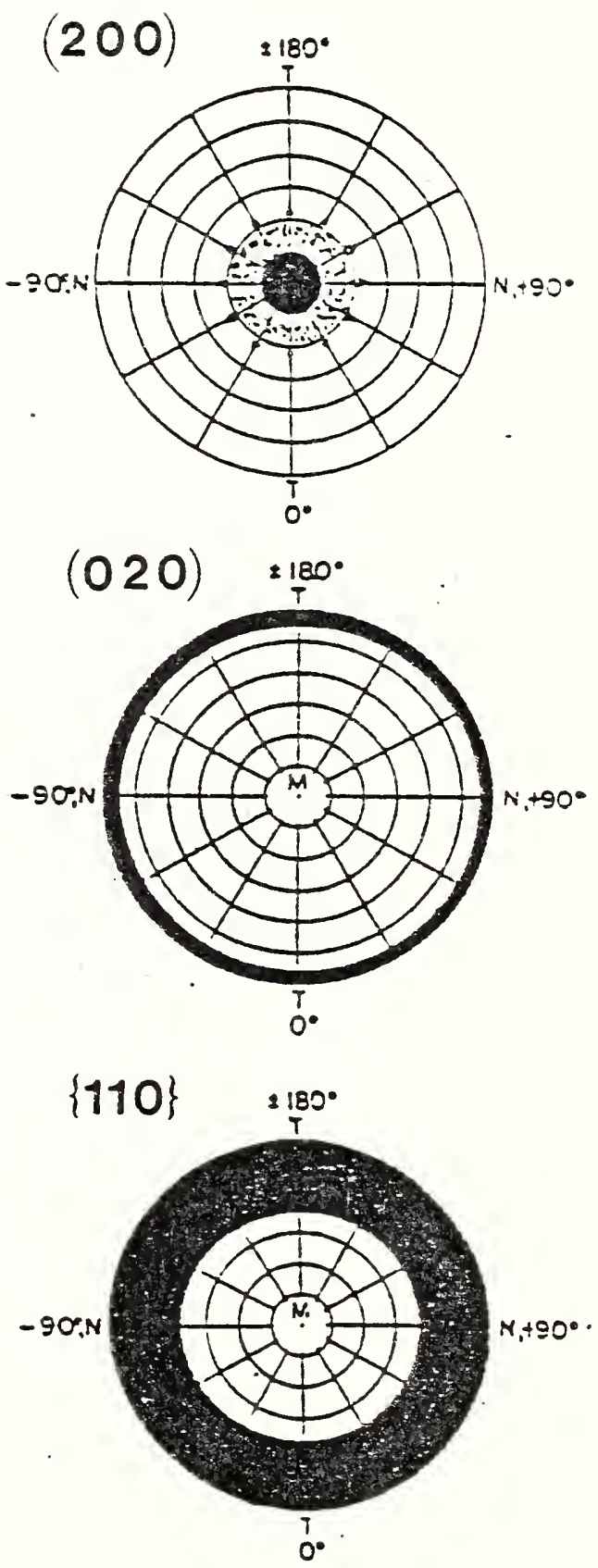

Fig. 30 The (200), (020), (002) and $\{110\}$ pole flgures corresponding to the Transcrystaline, Row(a), and Row(ac) model ortentations in the films. 


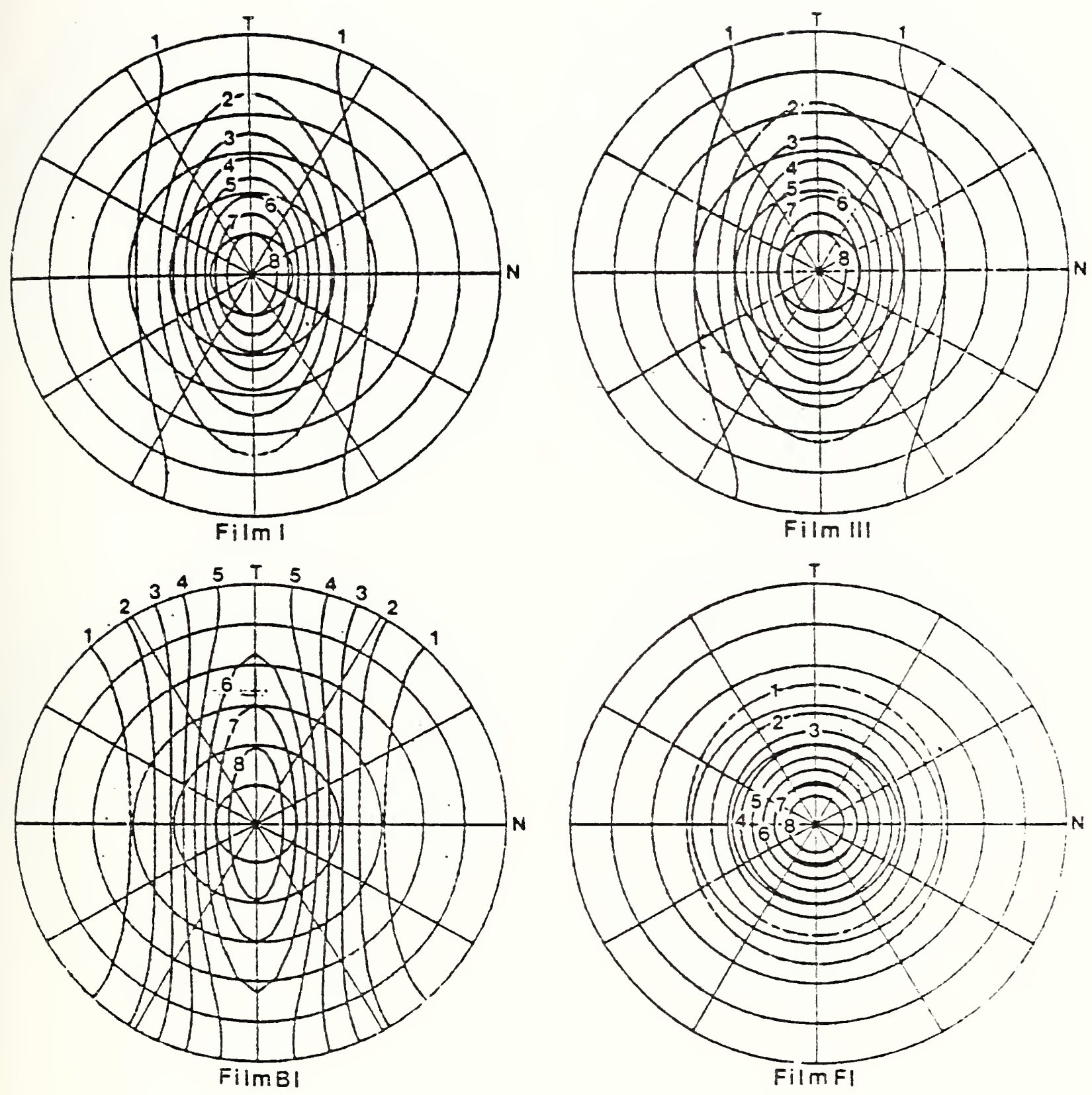

718. 31. Pole :18ures representing the results of the numerica: siaulations of the (200) pole intensity oletributions in the Cat. I. Gat. I:I. $B I$ and FI flims. 


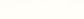



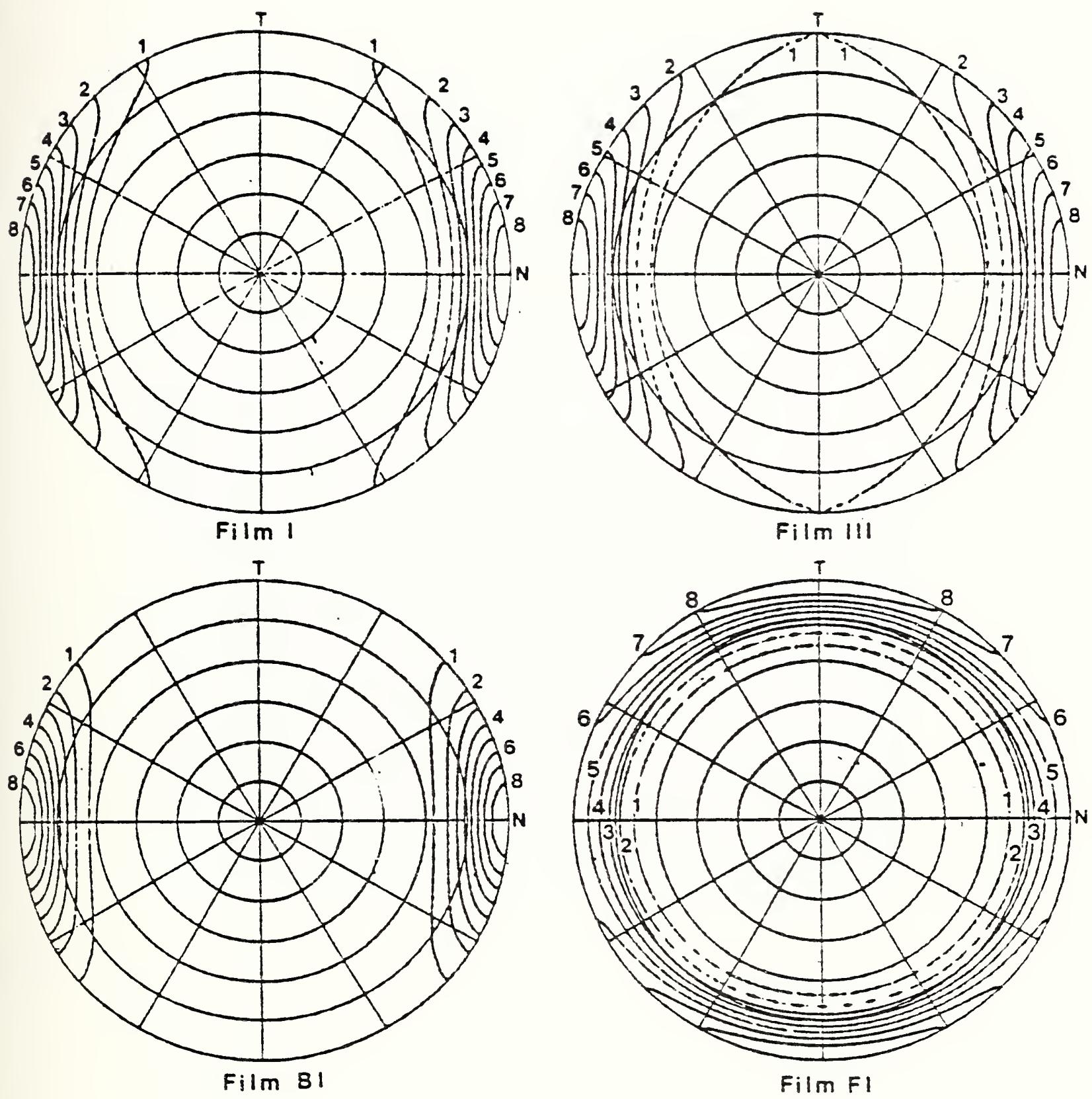

518. 32. Pole ilgures representing the results of the numerical simulations of the (020) pole intenglty distributions in the Cat. I, Cat. III, B1, and 5 iriles. 



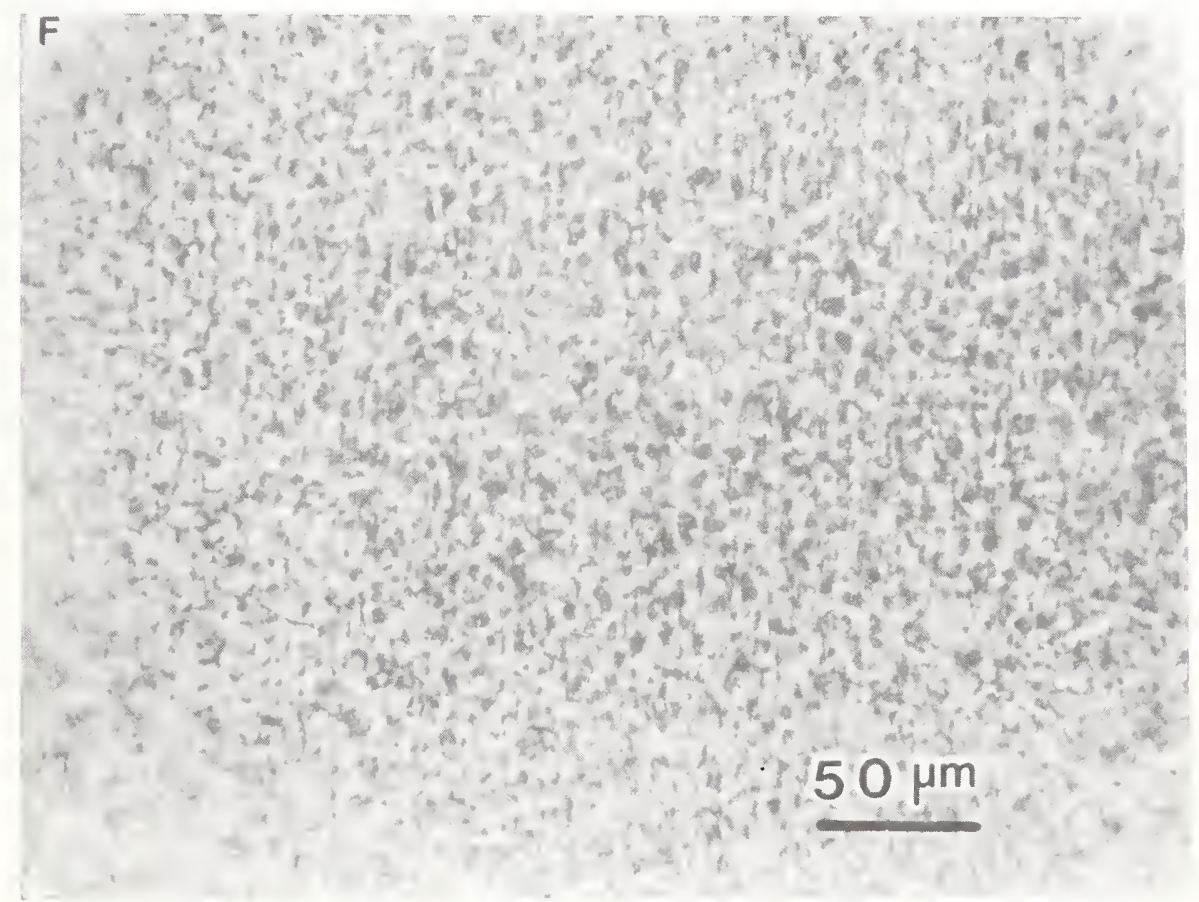

Fig. 33. Phase contrast light optical micrograph of film Fl. Machine direction (M) is vertical. Note overall mottied appearance and iajintiy discernible fine striations runring parallel to machine direction. 


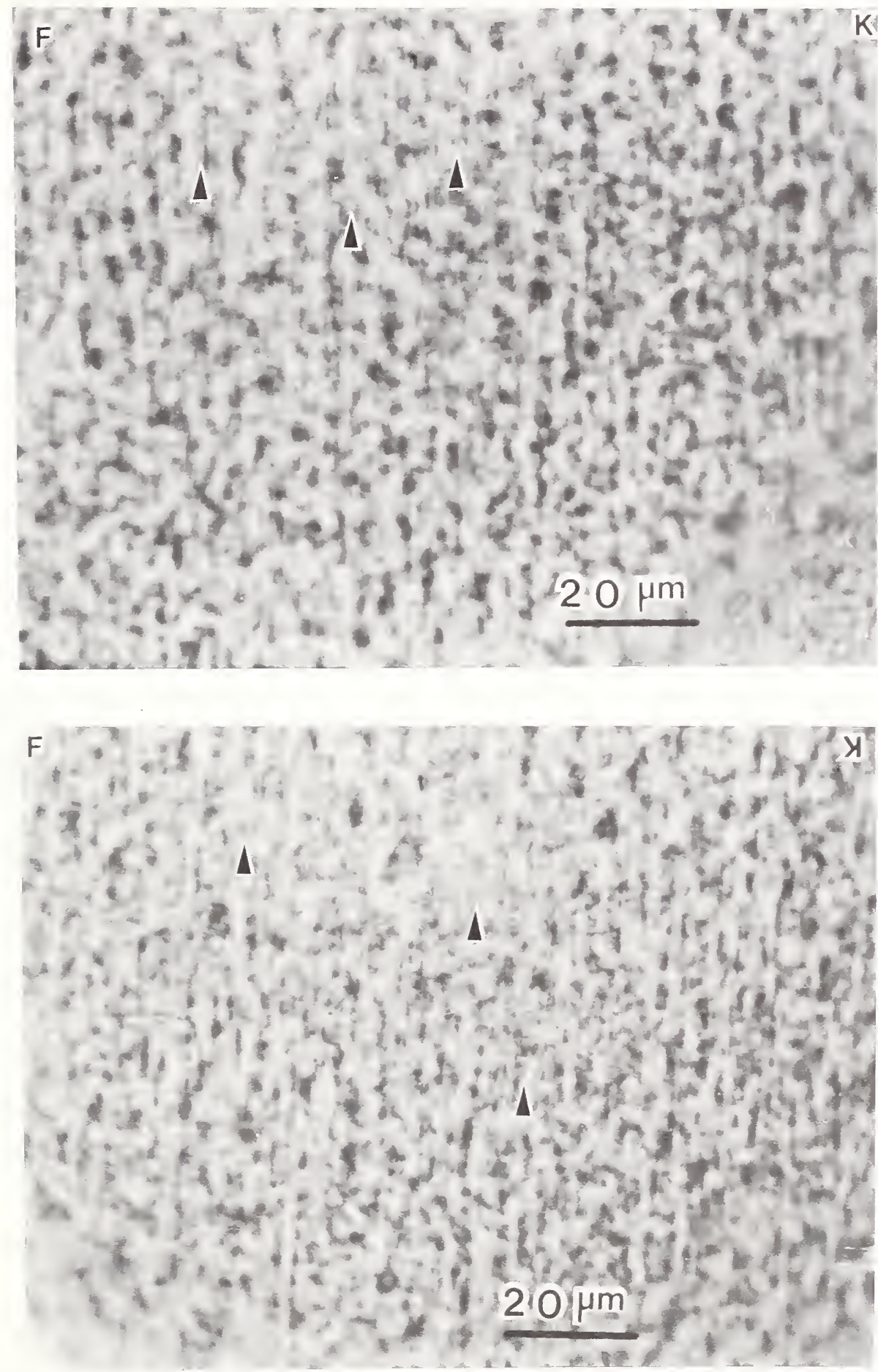

Fig. 34. Phase contrast light optical micrographs of replicas of cpposite surfaces of film Fl. Machine direction vertical. Arrows point to regions where finely separated striations running parallel to the machine direction can be seen. (Note magnification is higher than in Fig. 33). 



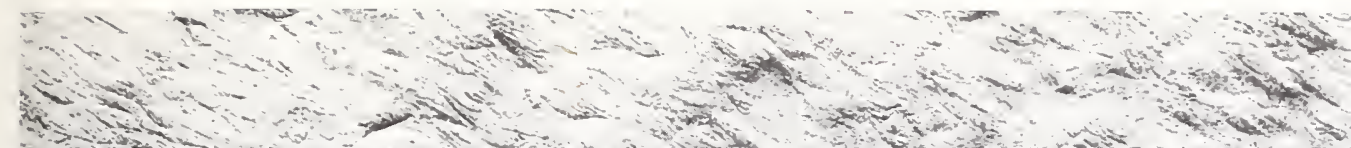

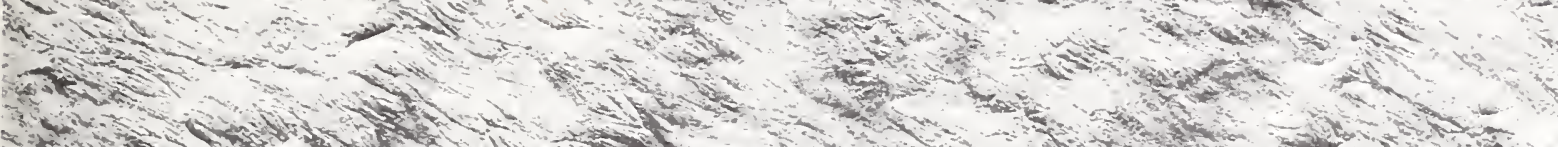

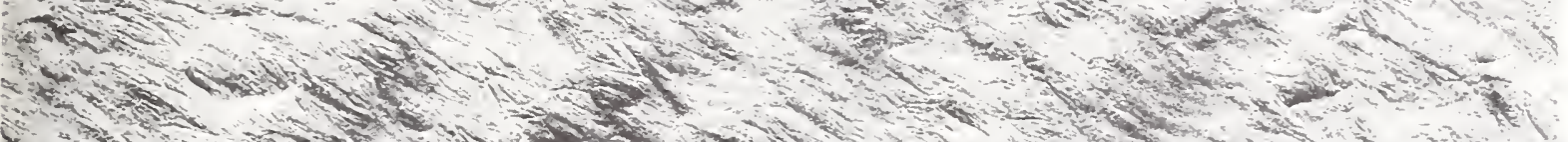

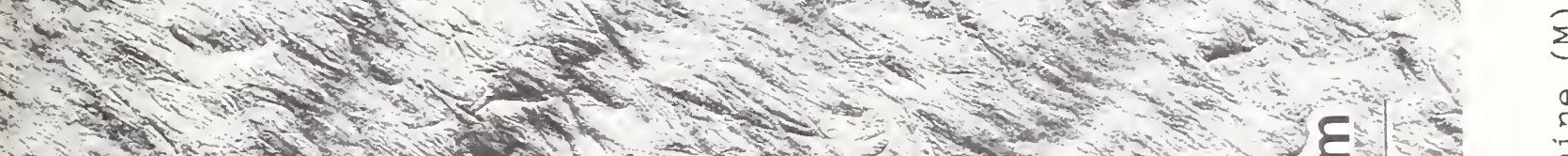

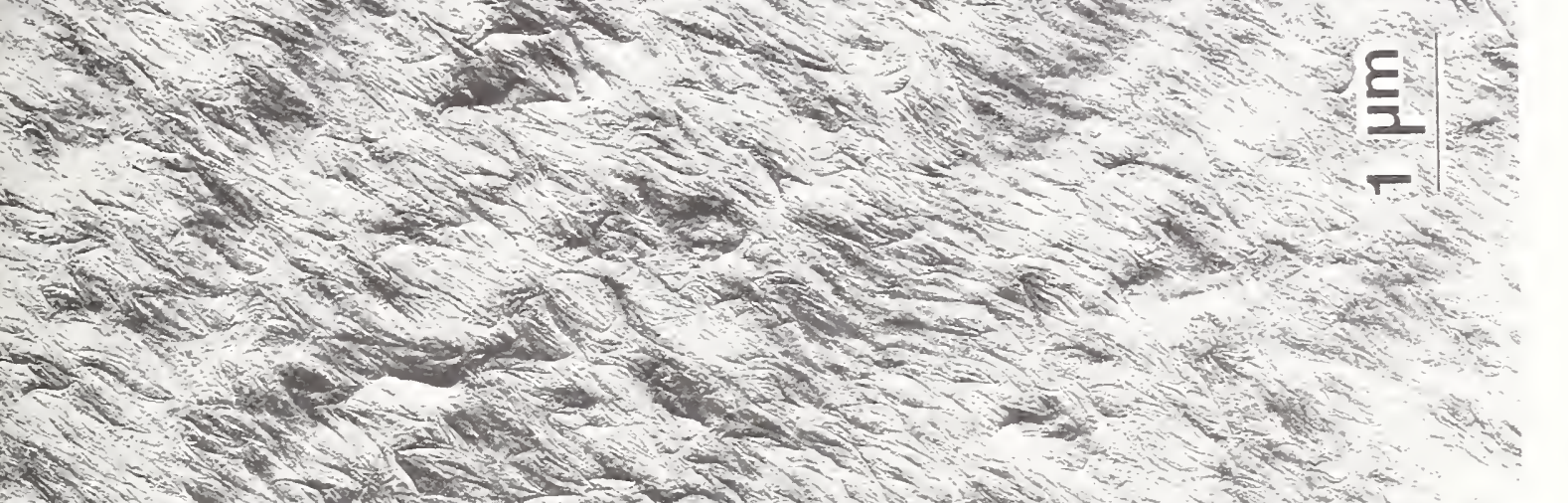

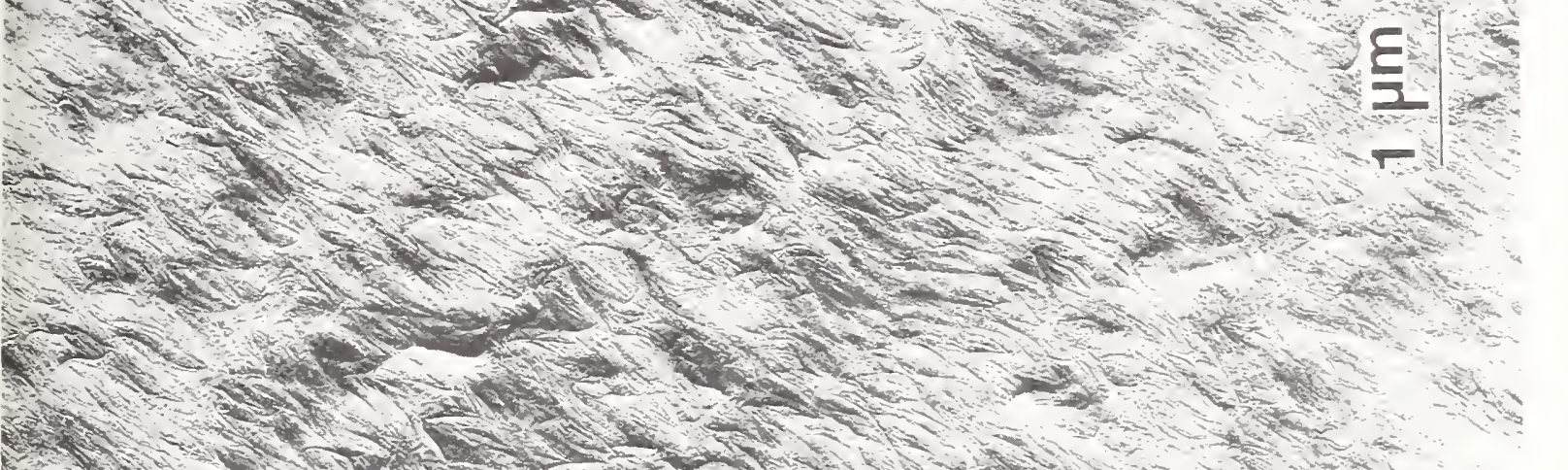

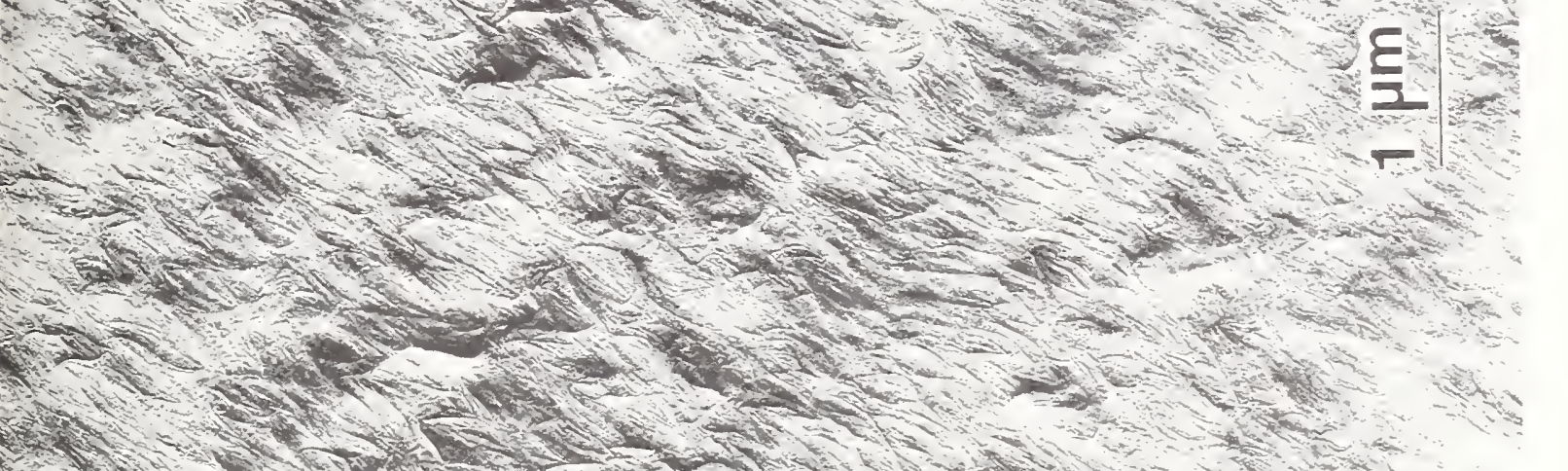

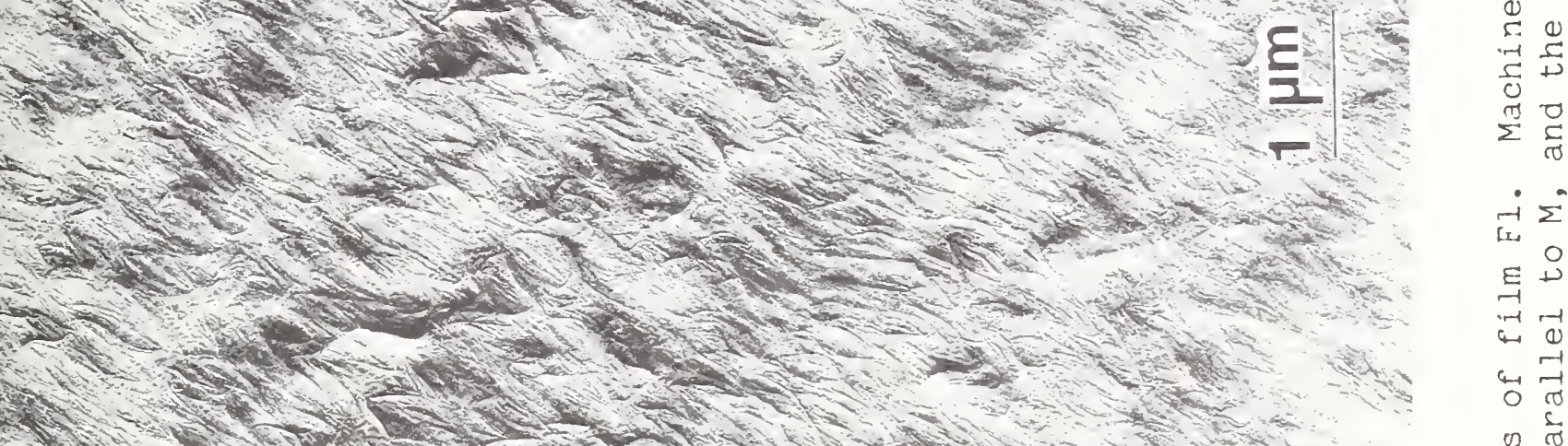

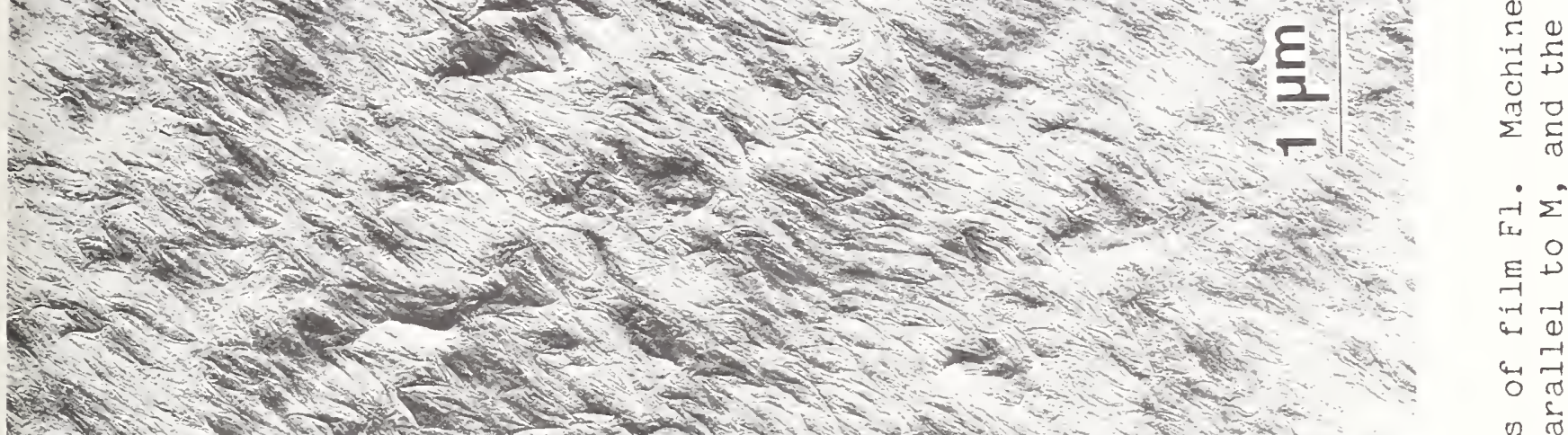

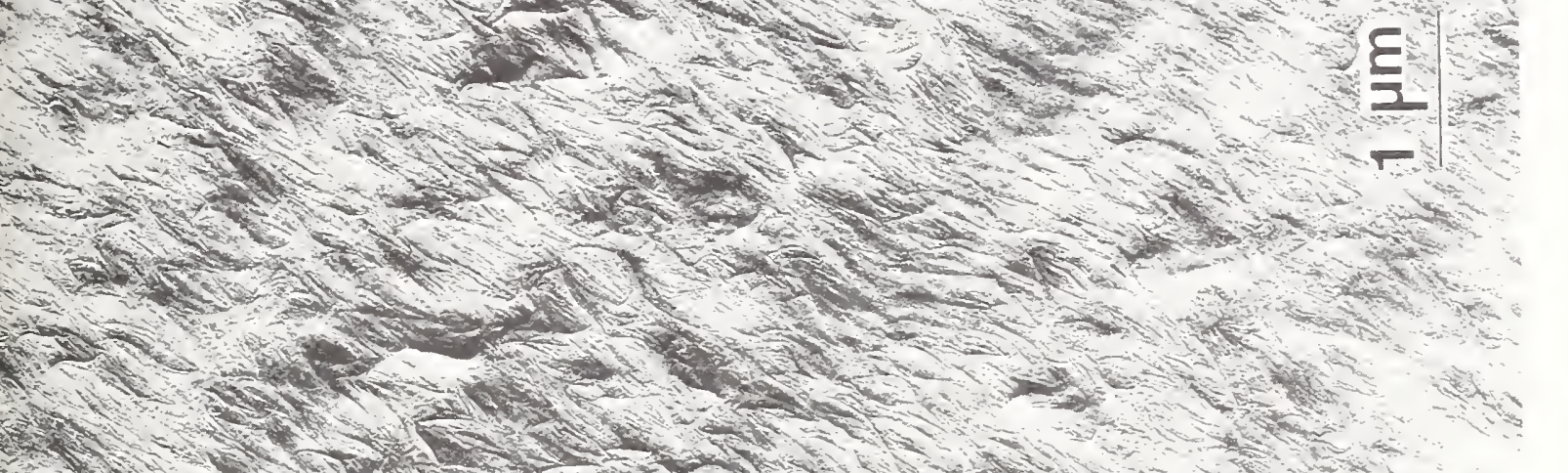

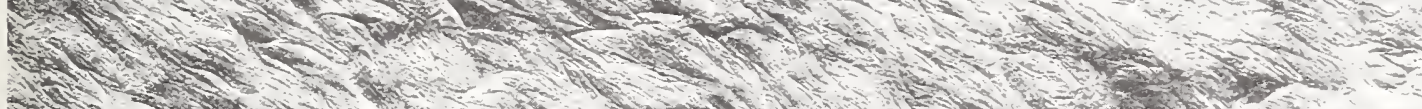

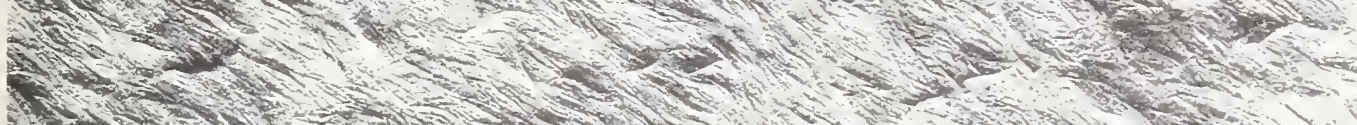

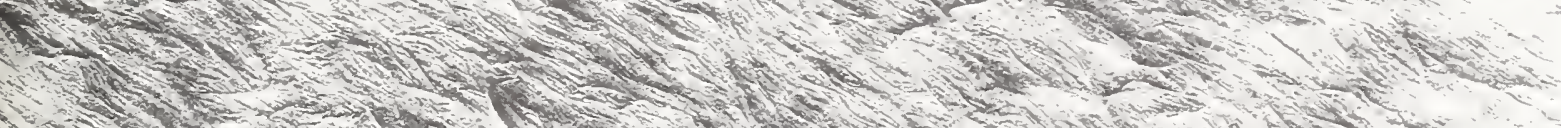

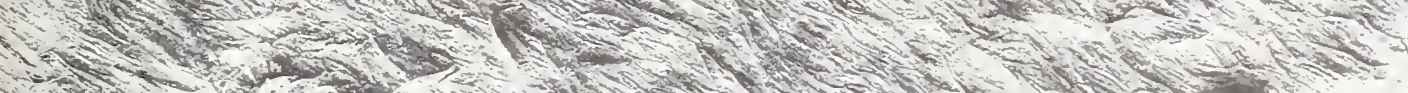

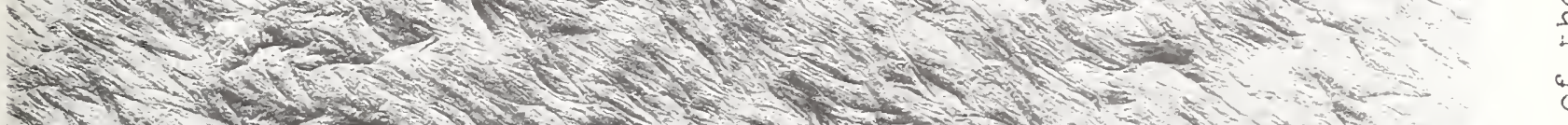

it

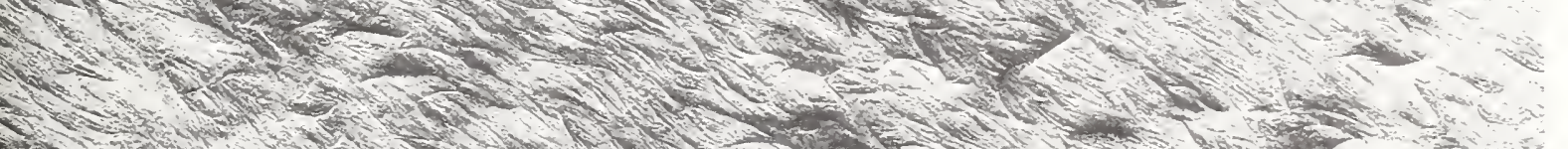

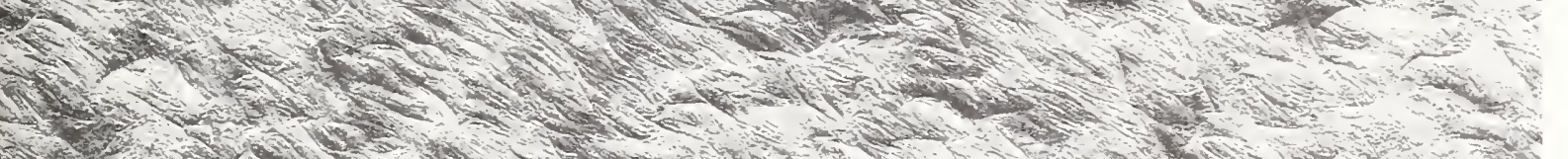

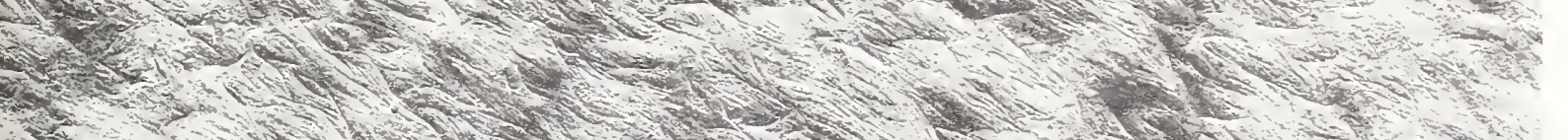

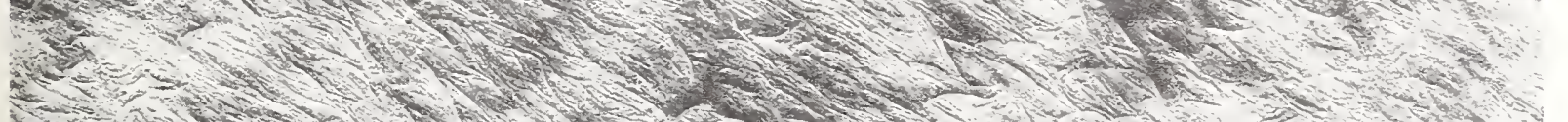

\section{(1)}

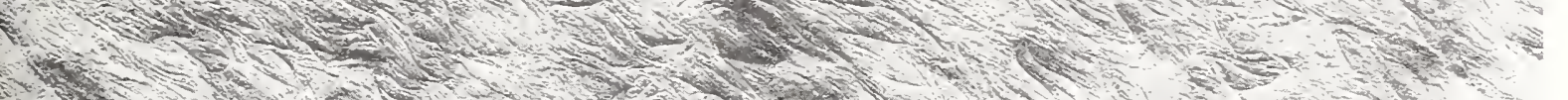

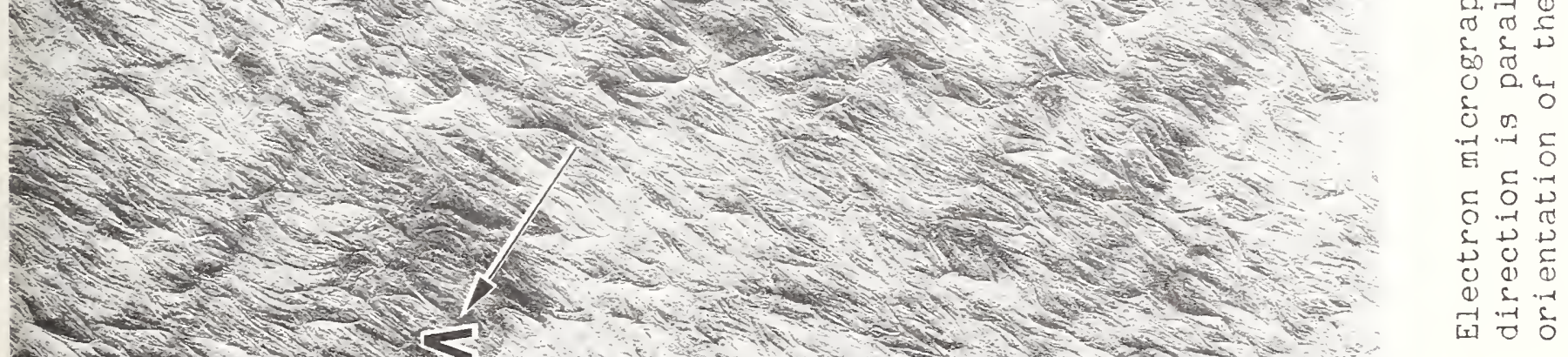

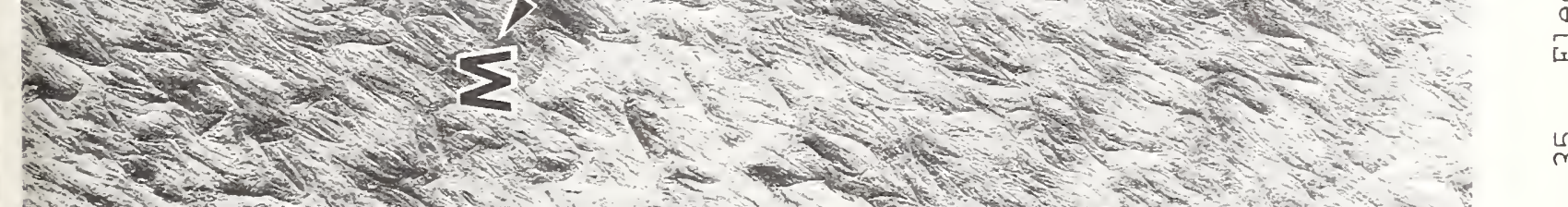

क

4.

舶

O

4. $E$

ज्ञ

() $\mathrm{s}$.

$\Rightarrow$ का

to 1

$0=-1$

(c) a

4

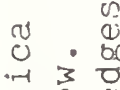

- 0

a)

त 0

岩一貝

ब)

क.

5 .

0 . 4

o 0

$c$

0

o

击

$\stackrel{\leftrightarrow}{m}$

$\underset{\substack{\infty \\-1}}{\infty}$

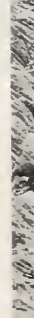
.

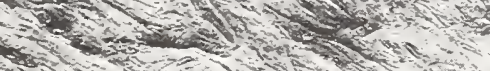

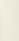

. 


The

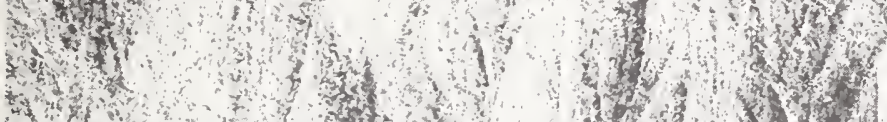

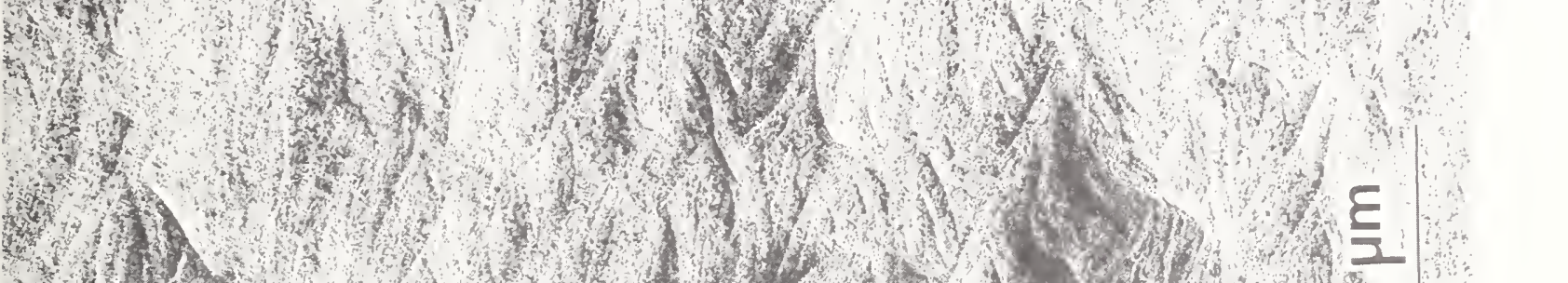
3.

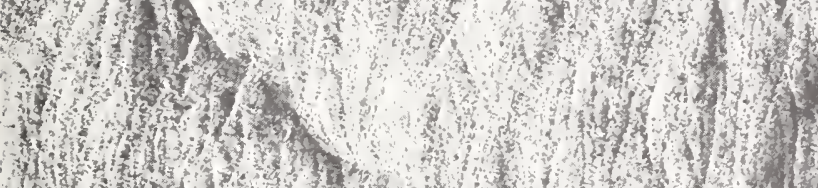

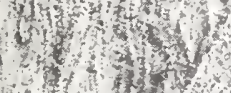

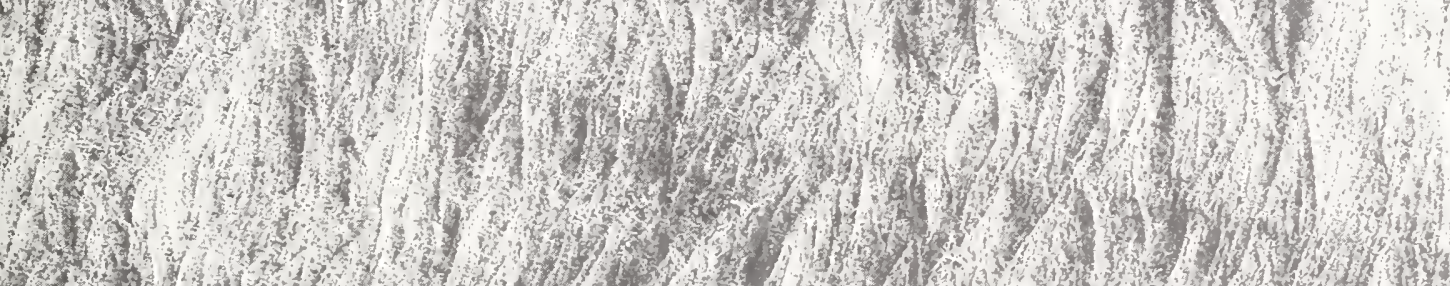

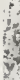

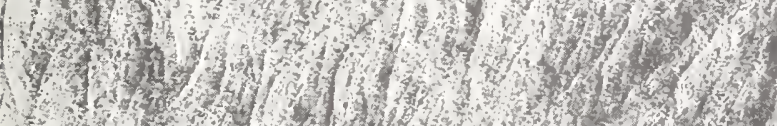

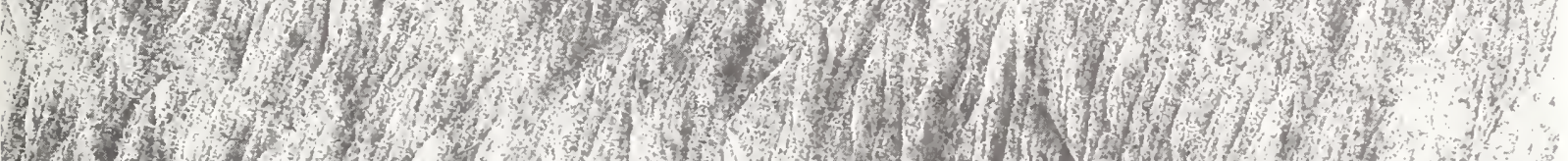

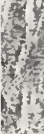

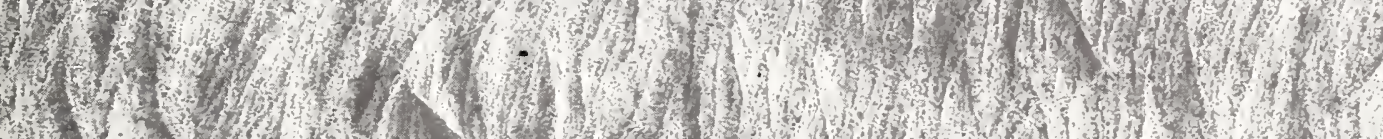

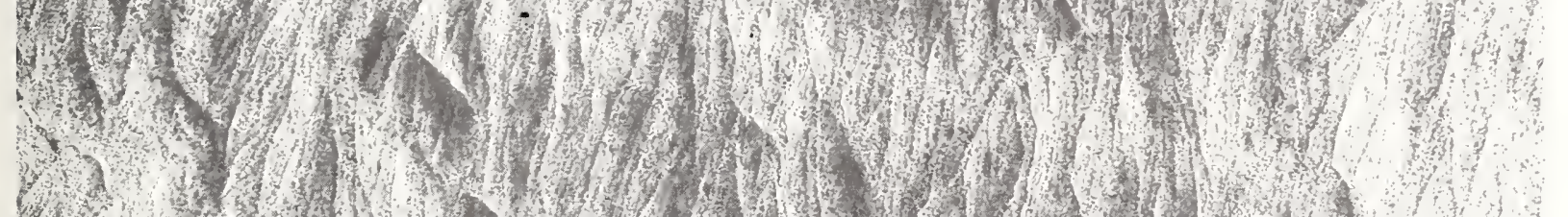
SW

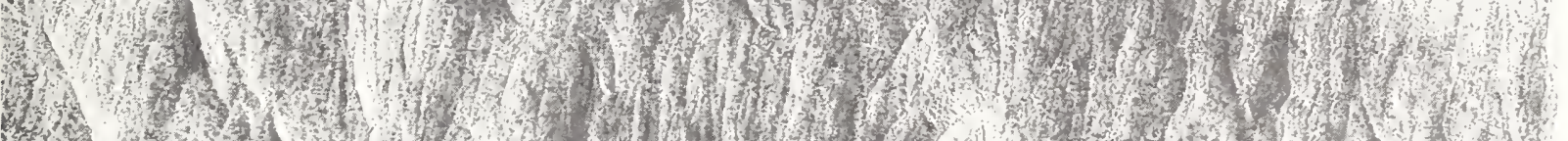

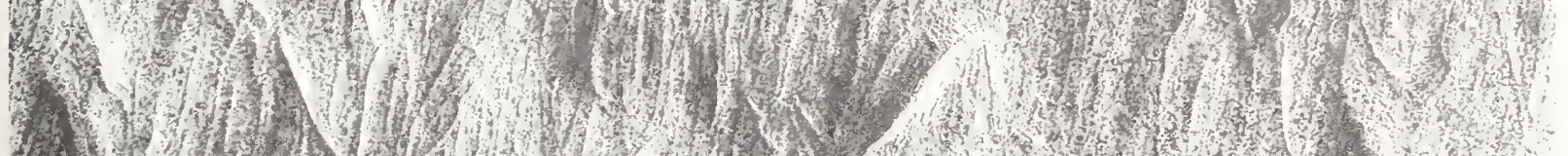

7.

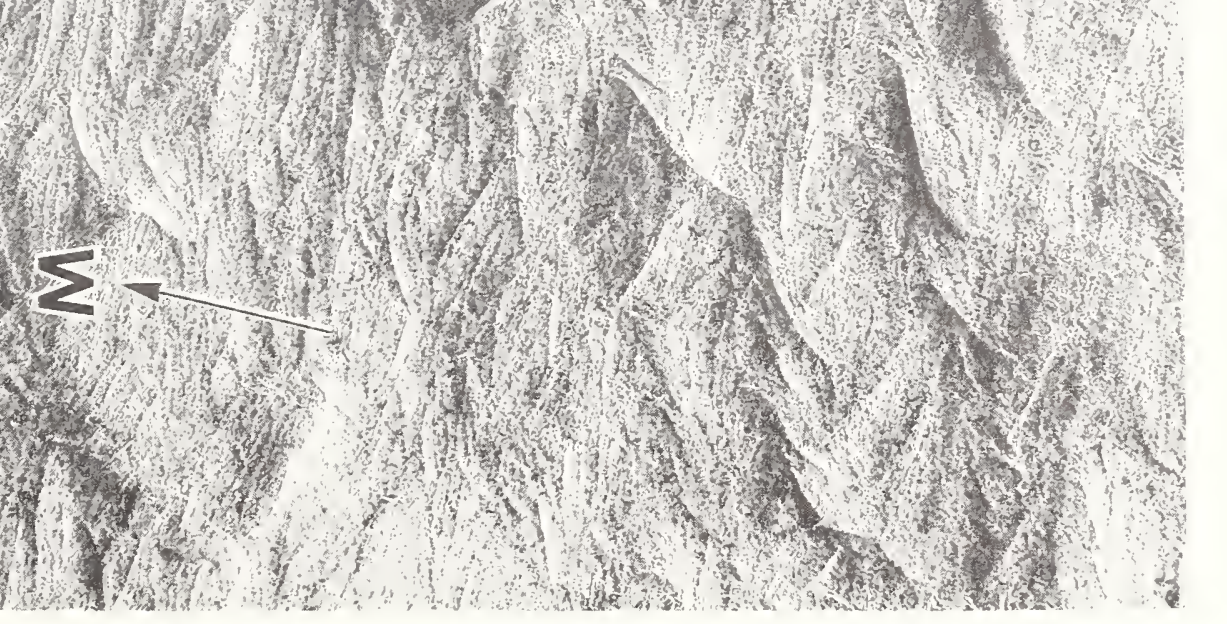

फ

())

(

40

on

(1)

(2)

\%

เ 2

it o

5

bo . 궁

0

c.

岂

잉

ธี

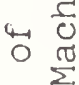

동

त.

$\varsigma_{00} \stackrel{\text { m }}{m}$

\&.

$-1$

ᄃ 5

에

प)

$\underset{-1}{0}$

(1) 0

동

is

0

范

弯

600

ह

호

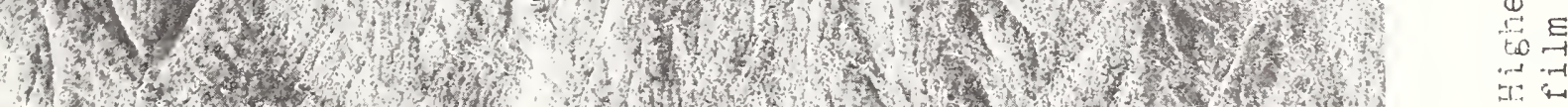

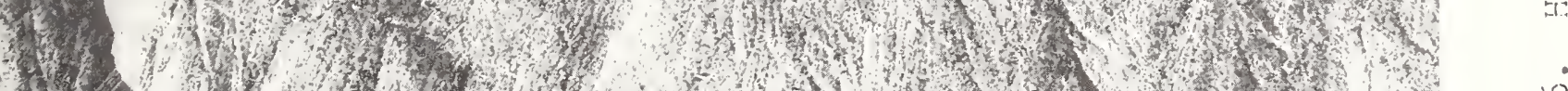

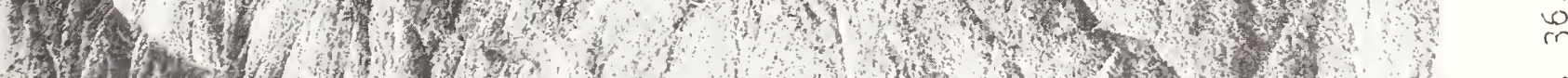

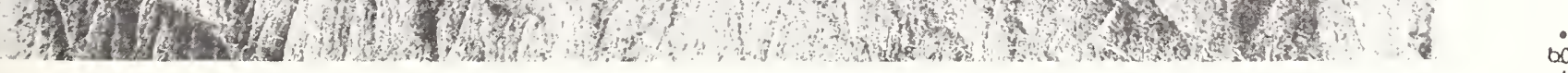





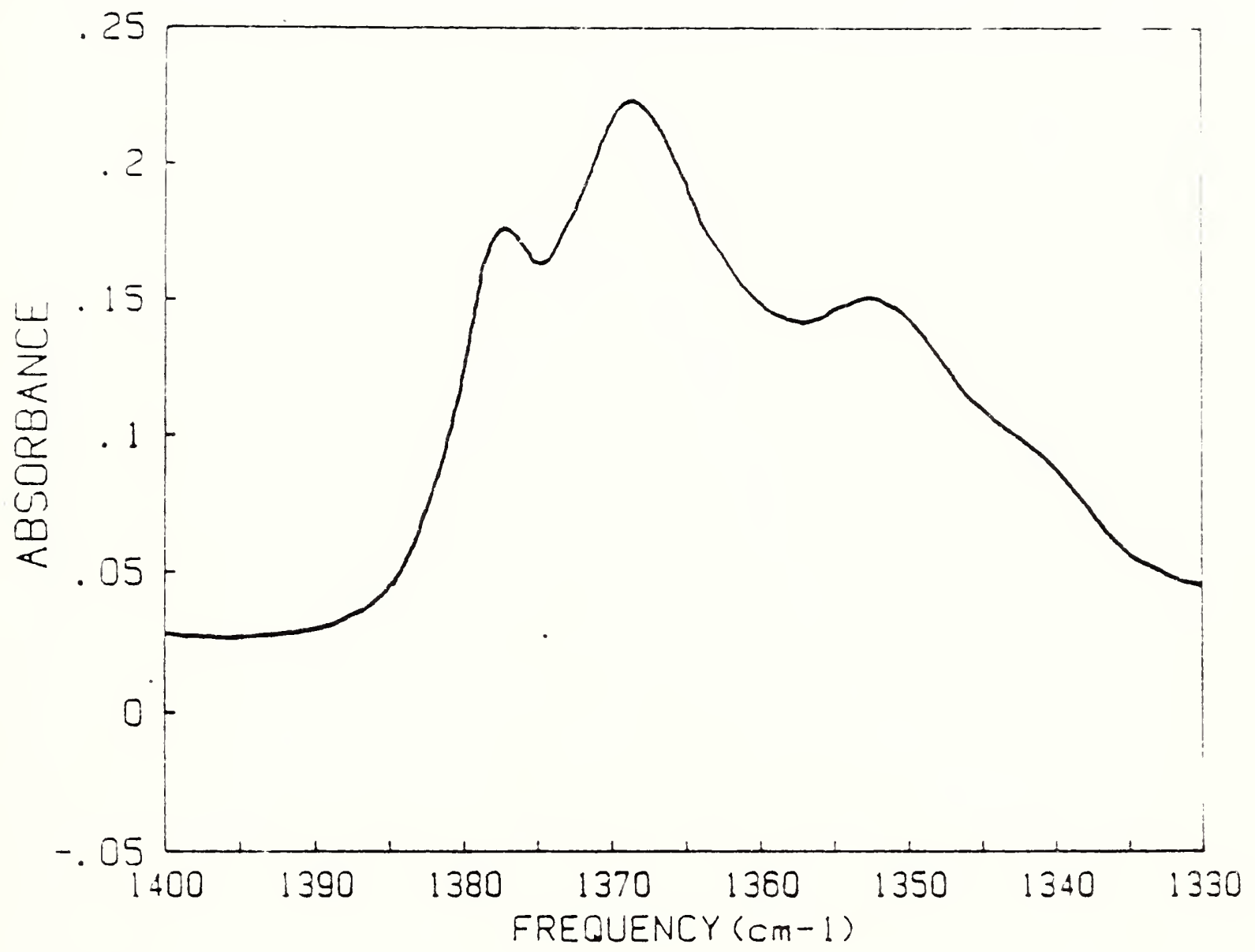

Eig. 37. Room temperature Infrared spectrum in the frequency range $1330 \mathrm{~cm}^{-1}$ to $1400 \mathrm{~cm}^{-1}$ obtained from the Fl film after it had been melted and cooled to room temperature. 

116

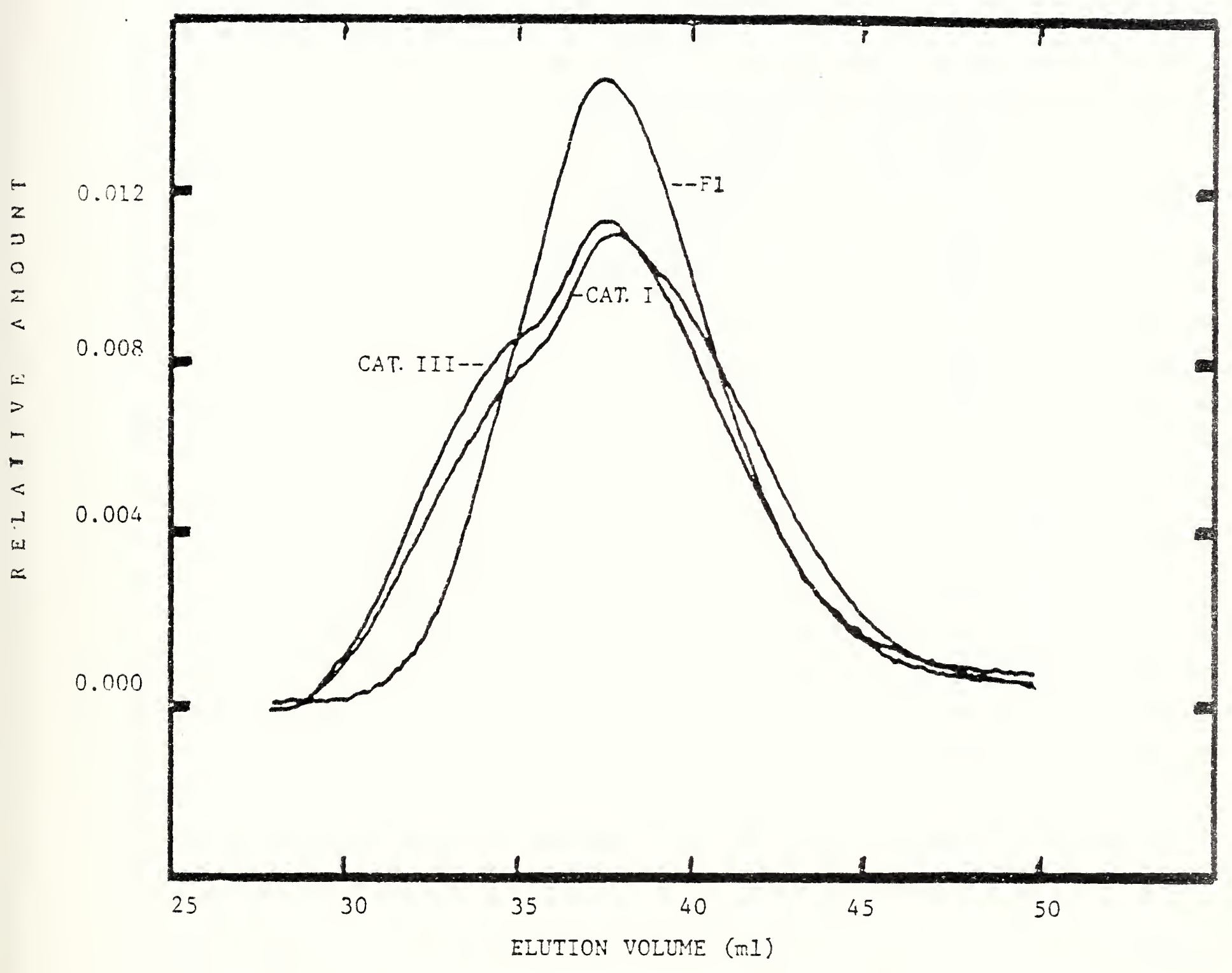

Fig. 38. Normalized Size Exclusion Chromatography of the Cat. I, Cat. III and Fl films (Series C measurements, Table 13). 

I

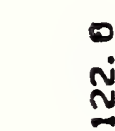

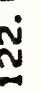

$\frac{x}{2}$

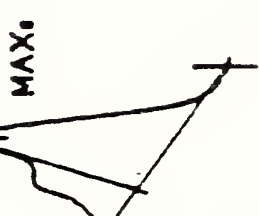

8

+ U

12

娚

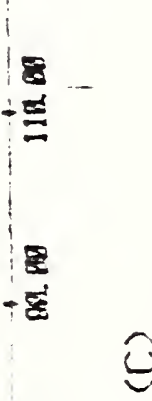

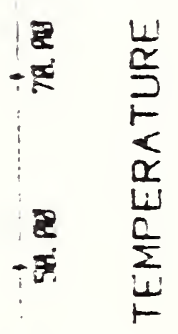

$-\frac{2}{8}$

$\hat{E}$

$\stackrel{0}{0}$

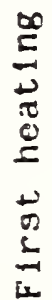

$\ddot{c}$

$E$

$\vec{E}$

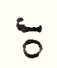

รี

范

宦

$\dot{\pi}$
$m$
$\dot{m}$

u $\sigma \stackrel{s}{\mathrm{~s}}$

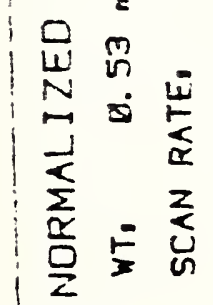

m

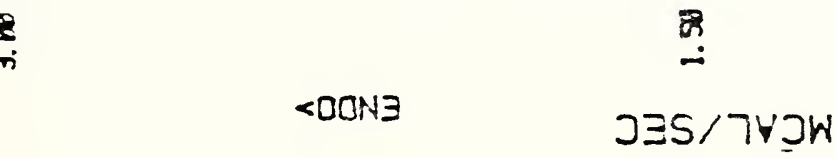





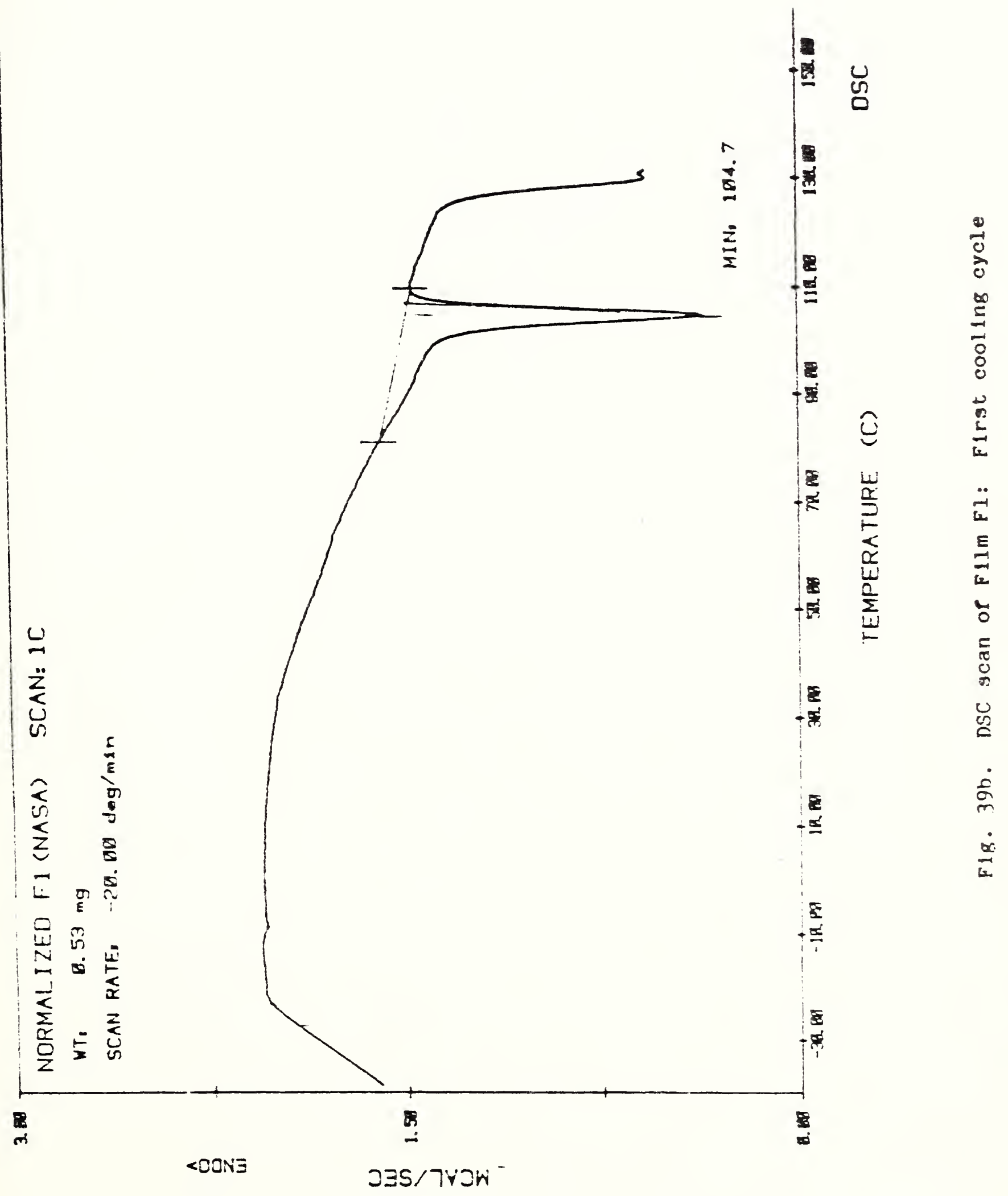




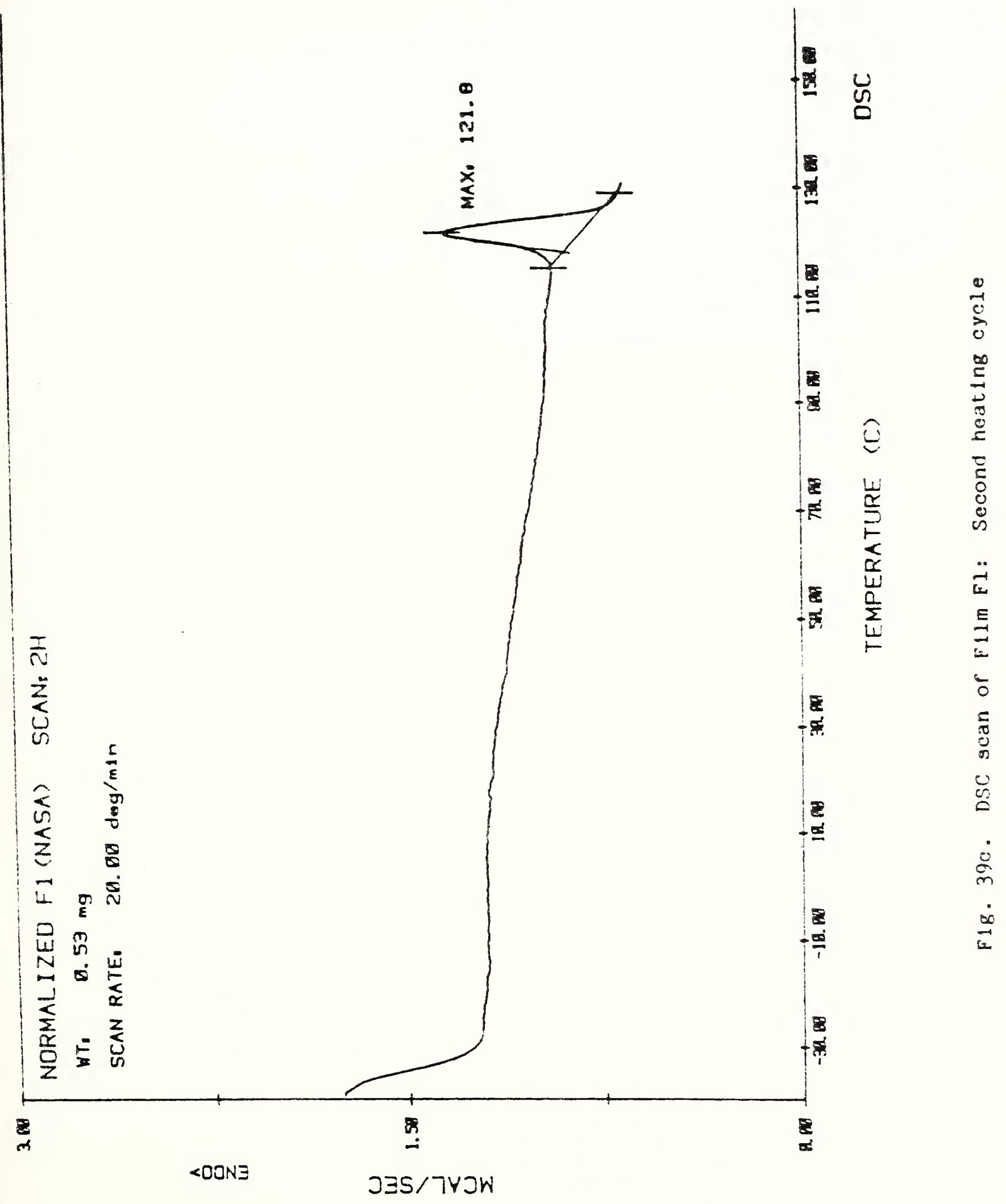





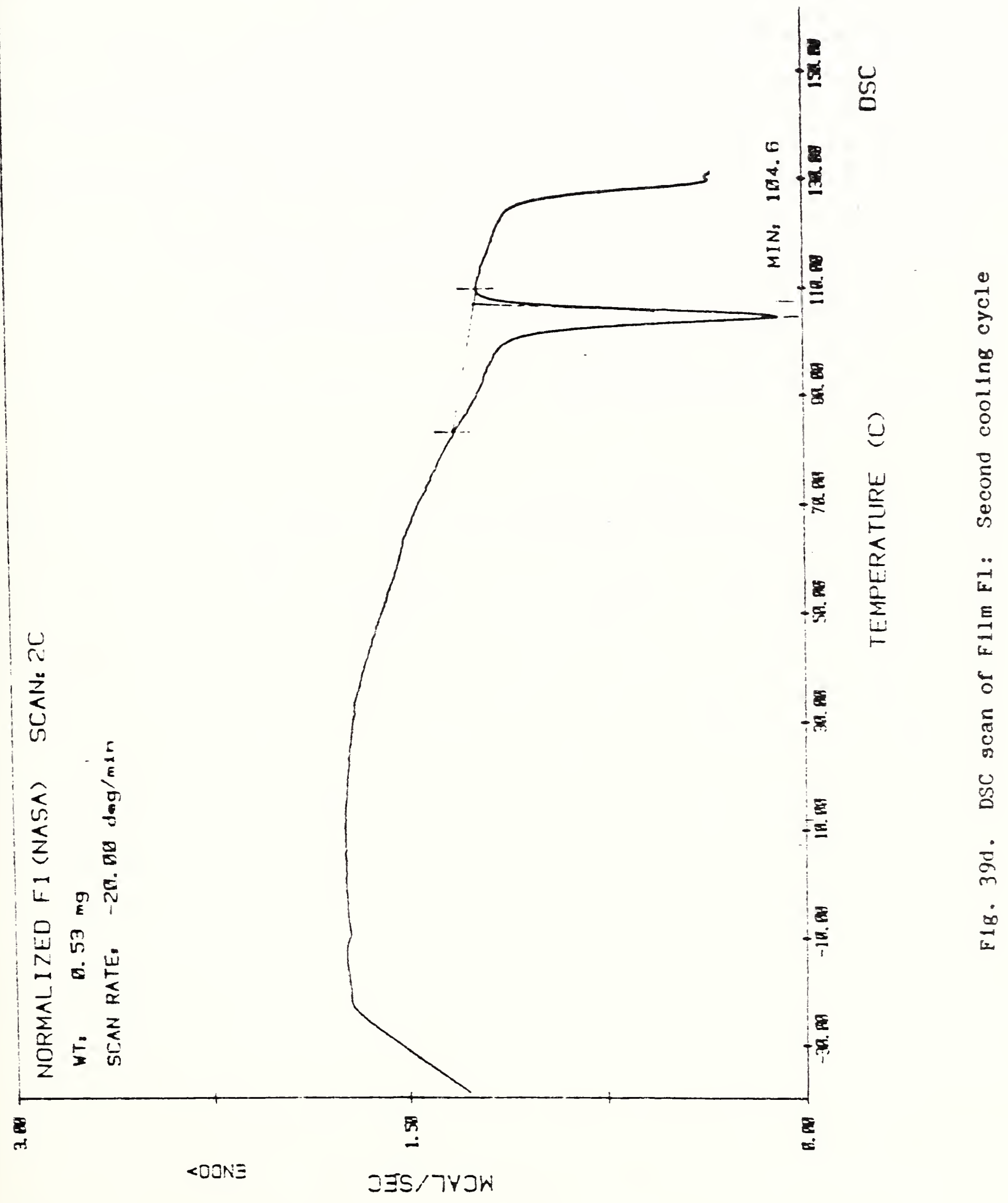





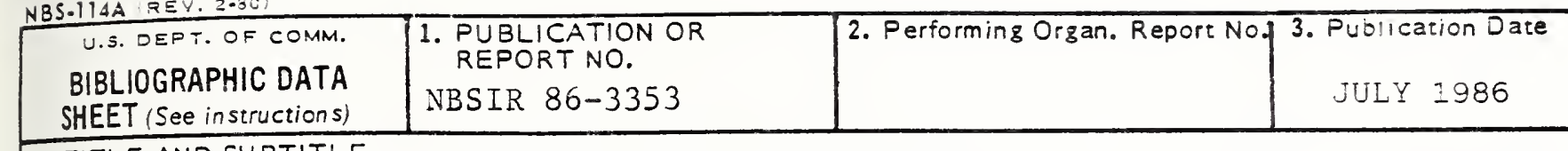

4. TITLE AND SUBTITLE

A Comparative Study of the Structure and Mechanical Properties of Polyethylene Films Used in Heavy Lift Balloons

5. AUTHOR(S) F. Khoury, J. M. Crissman, J. D. Barnes, B. M. Fanconi, H. L. Wagner, C. M. Guttman, J. R. Maurey, C. A. Harding, L. H. Bolz

6. PERFORMING ORGANIZATION (If joint or other than NBS, see instructions)

NATIONAL BUREAU OF STANDARDS

DEPARTMENT OF COMMERCE

WASHINGTON, D.C. 20234

9. SPONSORING ORGANIZATION NAME AND COMPLETE ADDRESS (Street, City, State, ZIP)

7. Contract/Grant No.

NASA Order S21607D

NASA Goddard Space Flight Center, Wallops Flight Center, Wallops Flight

Facility, Balloon Projects Branch, Wallops Island, VA 23337

8. Type of Report \& Period Covered

NBSIR - NOV. 1984 July 1985

10. SUPPLEMENTARY NOTES

Document describes a computer program; SF-185, FIPS Software Summary, is attached.

11. ABSTRACT (A 200-word or less factual summary of most significant information. If document includes a significant bibliography or literature survey, mention it here)

Aspects of the mechanical properties and structure of three types of

polyethylene film (I, III and BI) used by NASA in helium filled heavy ift balloons have been investigated and compared. An additional film (FI) which has as yet not been used in heavy lift balloons was also studied. The following are among the features which have been investigated:- Biaxial deformation behavior under inflation at $23^{\circ} \mathrm{C}$ and $-73^{\circ} \mathrm{C}$, biaxial creep under inflation at $23^{\circ} \mathrm{C}$ and $-73^{\circ} \mathrm{C}$, tensile properties at $23^{\circ} \mathrm{C}$ of unoriented specimens prepared by compression molding multilayers of the films, film shrinkage upon melting. The preferred orientation characteristics of the crystalline regions in the films were determined from pole figure coupled with small angle x-ray diffraction data. The possible morphological origins of the various orientation characteristics exhibited by the films are discussed with reference to three 'model' orientations and combinations thereof. Numerical simulations of the experimental pole figures of the films were attempted in an effort to compare differences in orientation among the films quantitatively. Finally, the following features which had been determined for films I, III and BI in a previous study have been determined for the 'newer' film Fl: Chain branching, molecular weight and molecular weight distribution, intrinsic viscosity, melting/crystallization, density/crystallinity, birefringence, and tensile properties at $23^{\circ} \mathrm{C}$ (uniaxial extension in the machine and transverse directions).

12. KEY WORDS (Six to twelve entries; alphabetical order; capitalize only proper names; and separate key words by semicolons) Balloon film; chain branching; density; intrinsic viscosity; molecular weight; orientation; polyethylene; tensile properties

13. AVAILABILITY

XX Unlimited

$\square$ For Official Distribution. Do Not Release to NTIS

$\square$ Order From Superintendent of Documents, U.S. Government Printing Office, Washington, D.C. 20402.

14. NO. OF PRINTED PAGES

\section{5}

15. Price

$\$ 16.95$

XX Order From National Technical Information Service (NTIS), Springfield, VA. 22161 



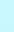


